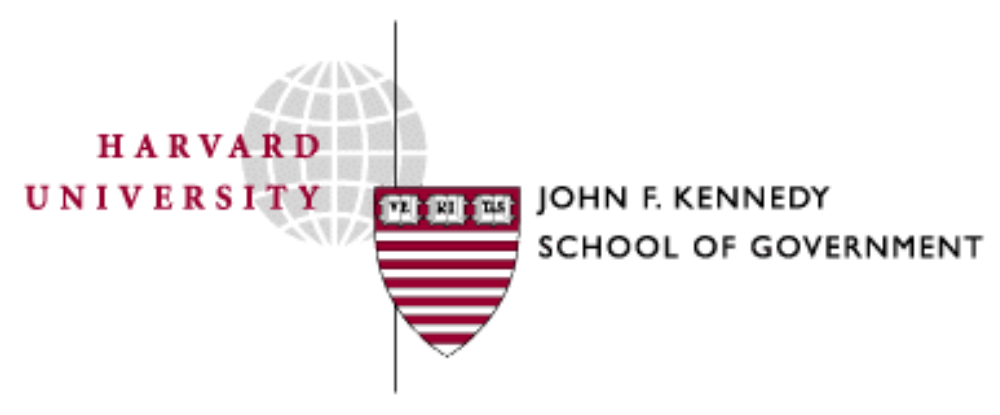

Faculty Research Working Papers Series

\author{
Listening to Parents: \\ Overcoming Barriers to the Adoption of Children from Foster Care \\ Julie Boatright Wilson, Jeff Katz, Robert Geen
}

February 2005

RWP05-005

This paper can be downloaded free of charge from the Social Science Research Network at: http://ssrn.com/abstract=663944

The views expressed in the KSG Faculty Research Working Paper Series are those of the author(s) and do not necessarily reflect those of the John F. Kennedy School of Government or Harvard University. Copyright belongs to the author(s). Papers may be downloaded for personal use only. 


\title{
Listening to Parents: \\ Overcoming Barriers to the Adoption of Children from Foster Care
}

By

\author{
Principal Investigator \\ Julie Boatright Wilson, Harry Kahn Lecturer in Social Policy \\ Director, Malcolm Weiner Center for Social Policy \\ Research Director and Principal Contact \\ Jeff Katz, Senior Fellow, Evan B. Donaldson Adoption Institute \\ Co-Research Director \\ Robert Geen, Senior Research Associate \\ The Urban Institute
}

January, 2005 


\section{Acknowledgements}

We gratefully acknowledge the generous support of the David and Lucile Packard Foundation. The not only provided the financial resources without which this study could not have been undertaken but also arranged to have Margie Shields provide comments on the initial report. These comments were very helpful.

In addition, we want to thank our advisory panel - Kathy Barbell, Richard Barth, Jill DuerrBerrick, Madelyn Freundlich, and Kathy Ledesma - for their guidance in the early stages of this study. We incorporated many of their suggestions in the final study design. We are grateful to the staff in child welfare offices and adoption agencies in Boston, Miami, and San Jose. Despite limited resources and enormous demands on their time, they generously provided descriptions and insights into the adoption process, the children and the adoptive parents. We thank Karin Malm and other staff at the Urban Institute as well as Alison Poppe and Shelly Coulter at the Kennedy School of Government for their work on this project.

Finally, we thank those individuals in the process of adopting a foster child for the time they took to tell us about themselves and their experiences with the adoption process. We hope all of them have been successful in adopting a child. Without them, and many others like them, thousands of children would never know the joys of a permanent, loving family.

The views expressed in this paper are those of the authors and do not necessarily reflect those of the John F. Kennedy School of Government, the Urban Institute, the Evan B. Donaldson Adoption Institute, or the David and Lucille Packard Foundation. Copyright belongs to the authors. This paper may be downloaded for personal use only. 


\section{Listening to Parents: \\ Overcoming Barriers to the Adoption of Children in Foster Care \\ Table of Contents}

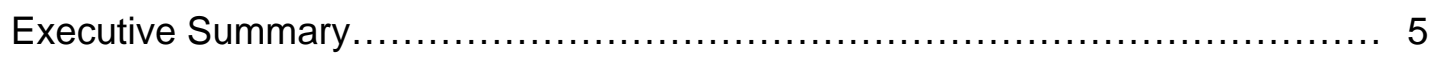

Section 1: Previous Research and Design of this Study ........................... 11

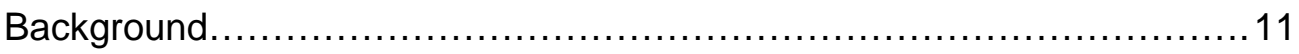

Demand for adopting children in foster care........................... 12

Characteristics of foster children adopted and the parents who adopt them ........................................................... 13

Consumer views of the adoption process............................. 14

Purpose and Rationale of this Study .................................... 15

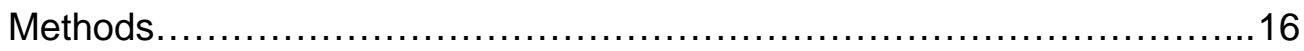

Section 2: Interest in Adoption and Likelihood of Completing the Process:

A View from the States................................................... 20

Flow of potential parents through the adoption process................ 20

Characteristics of adoptive parents and children adopted

from foster care ....................................................... 21

Section 3: Listening to Parents...................................................... 25

Recruitment: How do prospective adoptive parents first hear about

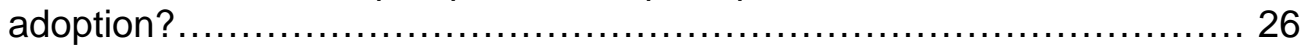

Screening or Recruitment? The function of the initial call.................. 27

Getting an answer: Multiple calls to agency to reach "right" staff........ 28

Strong personal connection is helpful.................................... 29

Conflict between what the parent wants to

hear and what an agency must say .................................... 30

Confusion about the process............................................ 30

Application and Orientation................................................... 31

Encouraging prospective parents vs. screening out inappropriate individuals................................................ 33

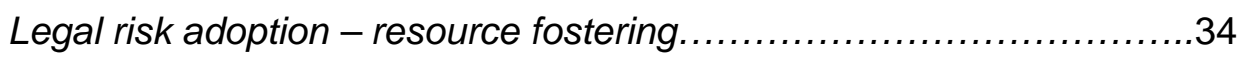

Training prospective adoptive parents........................................... 35

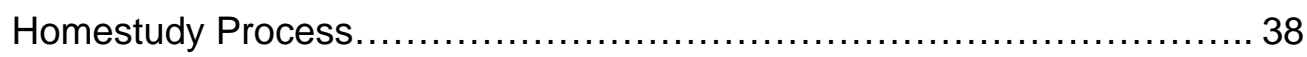

Matching and Placement................................................. 40

Public adoption agencies are designed to find "families for kids" and not "kids for families".... 
Agencies use different methods for allowing applicants to learn about adoptable children.

Applicants are often frustrated by what they perceive as the secrecy of the matching process................................. 43

Adoption applicants and agency respondents both noted that the matching process was very subjective....

Applicants often change their minds about the type of child/ren they want to adopt.

Section 4: Adoption applicant placement patterns and timing in the three states...48

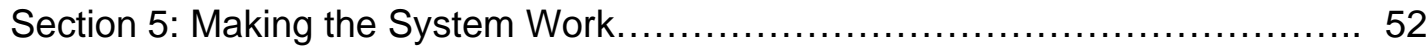

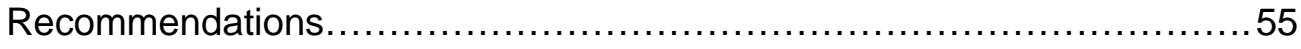

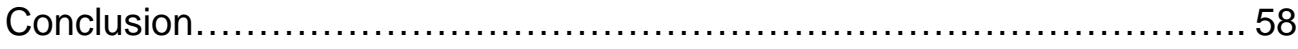

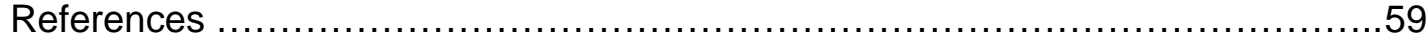

\section{Appendices}

Appendix A: National Survey of State Adoption Agencies...................... 60

Appendix B: Results of: National Survey of State Adoption Agencies: Understanding the Attrition of Adoption Applicants.................. 67

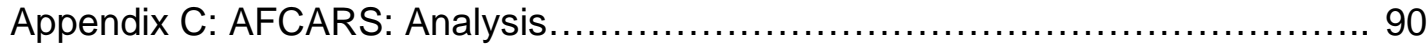




\section{EXECUTIVE SUMMARY}

The Adoption and Safe Families Act of 1997 (ASFA) codified the right of children in foster care to achieve a safe and permanent home. Since its passage, there has been a sharp increase in the number of children adopted from foster care -- from an average of 28,000 children adopted each year during the three-year period before the Act's passage to 50,000 adopted in FY 2001 (AFCARS, 2003). While this 79 percent increase reduced the number of children for whom child welfare agencies are seeking permanent homes, the 50,000 children adopted in 2001 still represent only 38 percent of the 131,000 waiting children (AFCARS 2003). Further, the vast majority of the post-ASFA adoptions were by foster parents or relatives of the children in care.

This study was designed to explore the question of why, despite an increasing demand for children to adopt and active adoptive family recruitment efforts, few "general applicants" (those who were not the children's relatives or foster parents) adopt children from foster care. We employed four data collection and analysis efforts:

1) An analysis of data from the 1997, 1998, and 1999 federal Adoption and Foster Care Analysis and Reporting System (AFCARS);

2) A national survey of state adoption directors, which yielded responses from 43 states;

3) Case studies of adoption practices in three locations - Boston, Miami, and San Jose that involved focus group and individual interviews with parents at various stages in the process of adoption as well as with state and private adoption workers; and,

4) An analysis of adoption applicant case record abstraction in our case study locations.

\section{Major Findings: The adoption process}

The actual adoption process consists of many components. First, an individual or couple seeking to adopt a child must hear about the children available through the public agency. We refer to this as recruitment. The next step in the process consists of the initial contact with the adoption agency. Once contact has been made there are several steps that agencies require, including meeting certain standards (e.g., criminal clearance, housing), completing an application and training sessions, and participating in multiple in-person interviews (i.e., homestudy). There is also paperwork that must be completed during each of these phases of the process. The final step is matching a child with a family.

- There is a steep attrition rate as prospective families go from initial call to adoption. Based on data from 40 states, we estimate that states annually receive about 240,000 foster care adoption inquiries. Since general applicants adopted 8,700 children in 2001 , it appears that only one in 28 people who contact a child welfare agency adopts a child from foster care.

- Word-of-mouth is more important than media for finding potential adoptive parents. Waiting child features like "Wednesday's Child" create general awareness. Most prospective adopters we spoke to, however, were drawn to adoption by a personal connection. Many mentioned a relative, friend, or co-worker who had adopted a child from foster care. Many also noted that they were adopted, had been in foster care, or had grown up with foster children. Their input reinforced workers' statements that wordof-mouth is the most common way people hear about the need for adoptive parents.

- The first information call can be an intensely emotional experience for the prospective adoptive parent. During focus groups, applicants described the emotional 
journey that precedes the initial call to inquire about adoption. The path that leads to adoption frequently involves frustration and loss - not finding the right partner, infertility, illness, miscarriage, failed infertility treatments. When making their first inquiry, applicants noted they wanted to obtain accurate information and also wanted to be treated well. Workers also mentioned the need for sensitivity.

- By and large, agencies do not handle the first call well. The parents we interviewed found their initial contact with an agency to be the most difficult aspect of the process for two key reasons. First, many simply found it hard to get a worker to answer their call. They got lost in voice mail, were transferred from one person to another, and left messages that were never returned. Many focus group participants had to make several calls before getting an information packet or application form. We did find, however, that adoption applicants in San Jose were more satisfied with their initial contact than were those in the two other sites.

Second, many who did speak with someone were frustrated by the tone and content of their initial contact. These callers, who had little or no knowledge of the steps in the adoption process, made their first call to seek general information and ran into a system bent on preemptively weeding out those who aren't interested in hard-to-place children.

- Agencies struggle to balance recruitment versus screening. Each state adoption agency has two contradictory responsibilities. On the one hand, it must recruit as many prospective adoptive parents as possible. On the other, it must screen out those who cannot, or should not, adopt for reasons ranging from felony convictions to unresolved fertility issues to serious emotional problems. One critical factor in balancing recruiting and screening is the timing and intensity of initial screening efforts.

We identified two very different patterns in our sites. In San Jose, the strategy is to invite as many people as are interested to an orientation session, which focuses on waiting children, their needs, how the system works, and parents' motivation for adopting. Because the orientation is the first meeting of the training class, those who choose to go forward may move directly into training. Prospective parents don't complete the detailed application until later in training. In Miami, the process begins with the completion of an inquiry form that gathers information on the number of people in the home, their ages, income, work schedules, household expenses, and characteristics of the type of child they hope to adopt. The orientation meeting begins with all applicants being fingerprinted. The rest of the meeting is devoted to helping attendees complete an application forms.

- A strong personal connection can make all the difference. Under the best of circumstances, adopting a child is complicated, scary, and challenging. One thing that can make or break the experience for adopters is having a strong personal relationship with someone at the agency. Case study respondents reported that this personal connection was important at the time of the first inquiry call as well as during the home study.

- By and large, people adopting from foster care find the training they received to be helpful. Though the training is not easy, focus group participants (especially those who had completed training) generally had positive feelings about it. The most common complaints about training were that it focused too much on waiting children's difficulties, and information about supports to address special needs came too late in the sessions. 
- Potential adoptive parents struggle with how open to be during the training and home study process. Many participants were concerned about how workers would use what would-be adopters said during training to assess their fitness as parents. The training, they said, was like "being in a fishbowl" with workers looking to see how they would react to incredibly difficult things.

\section{Recommendations}

We believe implementing the following recommendations would make a considerable difference in increasing the number of families who adopt from foster care:

\section{Screening vs. Recruitment}

Throughout the adoption process, public child welfare agencies must strike a balance between recruitment of new adoptive parents and screening prospective parents who may be inappropriate.

- We recommend that in the beginning stages of the adoption process (initial contact, information meetings and orientation) the emphasis be placed on recruitment. Early in the process, the risk of alienating a potentially suitable adoptive parent outweighs the risk of allowing an inappropriate parent to begin the training process. During this time, prospective parents should have clear, written guidelines about the qualifications to adopt and grounds for being screened out.

- Wherever possible, agencies should separate the screening and training functions. There is an inherent conflict for parents in their dealings with adoption workers. On the one hand parents are asked, and generally want, to be open with their feelings as a necessary part of preparation for adopting a child. On the other hand, the adoption worker is their judge and has the power to grant or deny placement of a child. Applicants have stressed the importance of having a strong personal connection with one agency worker. Agencies should look to other means of screening out, including clear written guidelines that allow families to self-screen.

\section{First Contact}

- For most prospective adoptive parents, the first contact with a public child welfare agency to learn about adoption is very emotionally charged, frequently the culmination of losses such as broken relationships, infertility and medical problems. The first contact with an agency must be treated in this context. The first person to speak with prospective parents should be professional staff with a background in counseling and specialized training in adoption.

- Many prospective parents expressed frustration with the difficulty in reaching the right person with their first phone call. Agencies should have a specialized adoption hotline where a well-trained and friendly individual assures callers of a direct and immediate response. 
- In addition to the inherent uncertainties, the adoption process is very confusing to many prospective parents. Parents expressed confusion about the roles played by different workers and the order of different steps in the adoption process. Agencies should provide families with a clear, written road map of the adoption process at the outset.

\section{Matching}

In terms of parental involvement, the process of matching children and families is handled very differently in the sites we studied. While there are good reasons to make matching a primarily worker-driven process, there are also reasons to involve parents in the process. Some parents expressed concern that their worker did not know them well enough to make a decision about a best placement or were not sufficiently aware of the parent's ability to expand beyond the initial profile of a child they would find to be an acceptable match. We recommend that all applicants receive clear information about the matching process and expectations of prospective parents.

\section{Training}

While recognizing the need to present prospective parents with a realistic view of the challenges they will face, applicants expressed a strong need for a more balanced perspective in the training sessions. Bringing adoptive parents into the training curriculum earlier would accomplish this goal.

\section{Buddy System}

Adopting a child from foster care is an inherently difficult process. For the prospective adoptive parent, adoption may be the most emotionally intense experience of their lives. But for an overworked and beleaguered child welfare agency, whose focus is the child, not the parent, the resources may not be available to provide the "hand-holding" that parents require. As one prospective parent put it, "this a very impersonal process for a very personal thing."

Ideally, the adoption process should be far more personal and intimate. Given the financial strains under which public child welfare agencies now operate, it is unrealistic to expect agencies to provide smaller classes and more personal service to prospective parents. One way to bridge this gap may be to make more use of families that have previously adopted. Many applicants found the input of adoptive parents to be of enormous help during training. By pairing new adopting parents with established ones, many of the issues new adopting parents raise can be addressed. Using parents who have previously adopted can make the process more personal, give families the realistic view of adoptive families they seek in training, and take some of the burden off overburdened agency staff.

\section{Listen to Prospective Parents}

It is absolutely critical that child welfare agencies develop ways of listening to prospective parents throughout the adoption process, then respond to their needs and concerns. We strongly recommend that every child welfare system establish a process for soliciting, and incorporating such feedback. This can be done in many forms, including surveys, focus groups, or parent advisory boards. 


\section{Further Study}

This study was designed to better understand how many people express interest in adopting children with whom they have no prior relationship and to begin to assess how and why many who begin the adoption process do not complete it. This study was largely exploratory in nature, raising more questions than it answers. There are important limitations to each data collection component that readers should be aware of while interpreting the findings.

- The main limitation of the AFCARS data analysis is that the data provided by the state child welfare agencies are of uncertain quality. In particular, it is not clear how often a child is adopted by a parent we would label as "general applicant" that may in fact be a relative or a former foster parent. Similarly, states may label persons as foster parents who may in fact be general applicants. This labeling of adoptive applicants is made even more problematic by the fact that in some states, adoption seekers are encouraged to become foster parents to increase their chances of adopting, or become foster parents between the time of placement and finalization in order to receive subsidy payments.

- Our national survey of adoption managers provided useful information on the number of adoption inquirers and the number of potential adoptive parents who continue through the process. However, these data are, by states' own admission, of questionable accuracy. Moreover, estimates of the percent of persons who drop out between points in the process were sometimes based on the individual adoption managers' impressions rather than hard data.

- The case studies of adoption practices provide rich qualitative information that provides an excellent context within which to understand the data collected from other methods. However, the persons interviewed and the focus group participants were by no means selected to be representative of adoption workers or persons who have inquired about adoption.

- The case record abstractions were limited by the accuracy and completeness of the data available in the case records. Moreover, while the records were selected randomly, they were not selected randomly from the pool of all available case records of persons who completed a home study.

- Finally, a major limitation is that we only studied people who had at least attended an orientation meeting; we were unable to study the vast majority of individuals who call for information but do not take the next step. We have documented both a steep drop-off between initial call and attendance at an orientation meeting and frequent difficulties callers have during their initial contact. The question of the number of people who are lost as potential adoptive parents because of a bad experience during their initial contact is worth further study.

\section{Conclusion}

The above limitations not withstanding, our findings support the contention that any effort to increase the number of waiting children who are adopted must focus not only on improving recruitment efforts but also on improving elements of the adoption process. Results of this study provide detailed information about different aspects of the adoption process from a variety 
of data sources. Overall, most of the prospective adoptive parents we spoke with in our focus groups had had a positive experience with their public agency. Frustrations occurred most often at the beginning and end of the process--when applicants were first trying to contact the agency for information and after completing the home study and waiting for a match. To some extent, agency resources play a role here. Licensed social workers are needed to conduct the trainings and home studies. Answering the many calls received may seem like a task that less trained or skilled professionals can handle. However, as we learned during our focus groups, miscommunication or mishandling these calls at the outset seriously affects how applicants view the agency. Since word-of-mouth is such a large recruitment tool, customer relations are extremely important. 


\section{Section 1}

\section{Previous Research and Design of this Study}

The Adoption and Safe Families Act of 1997 (ASFA) codified the right of children in foster care to achieve a safe and permanent home. Since its passage, there has been a sharp increase in the number of children adopted from foster care -- from an average of 28,000 children adopted each year during the three-year period before the Act's passage to 50,000 adopted in FY 2001 (AFCARS, 2003). While this 79 percent increase reduced the number of children for whom child welfare agencies are seeking permanent homes, the 50,000 children adopted in 2001 still represent only 38 percent of the 131,000 waiting children (AFCARS 2003). Further, as was the case with pre-AFSA adoptions, most post-ASFA adoptions were by foster parents or relatives of the children in care.

One might have expected the number of general applicants adopting children in foster care to have increased more rapidly over this period. First, demand for children to adopt is increasing due to delayed childbearing, increased infertility, and an increasing acceptance of adoption as a way to build a family. Second, children in foster care are an increasing share of children in the United States available for adoption. The supply of adoptable, healthy infants is declining as the number of young, single, pregnant women choosing to raise their children rather than place them for adoption increases. Third, over this time period, states were working hard to increase the number of adoptions of eligible children in foster care. Given these trends and active recruitment efforts, are there actions states can undertake to increase the number of general applicants adopting these children each year?

This study uses data from multiple sources to document the national interest in foster care adoption among general applicants, the characteristics of general applicant adoptive parents and the children they adopt, the experiences general applicants have with the adoption process, and factors that influence the success of general applicants having a child placed with them. Together, these data highlight the difficult task child welfare agencies face in finding permanent homes for waiting foster children and suggest new strategies that agencies might pursue to recruit and retain adoptive parents.

\section{Background}

Despite widespread interest in adoption, only limited data are available on the propensity of people to adopt or the characteristics of adopted children and adoptive parents. The National Survey of Family Growth (NSFG), conducted by the National Center for Health Statistics, U.S. Department of Health and Human Services (HHS), is a nationally representative survey of women 15-44 years of age on topics related to fertility, family planning, and reproductive health. The survey includes questions about interest in adoption and steps taken to seek adoption. The NSFG was conducted in 1973, 1982, 1988, 1995, and 2003. Though not focused solely on foster care adoption, the NSFG does provide information on the characteristics of children that women seeking to adopt would prefer or would consider adopting.

Data on children adopted and waiting to be adopted from the foster care system are available from the Adoption and Foster Care Reporting and Analysis System (AFCARS). AFCARS collects case level information on all children in foster care for whom state child welfare agencies have placement, care or supervision responsibilities, as well as children who are adopted under the auspices of the state's public child welfare agency. States are required to 
submit AFCARS data semi-annually to HHS. While AFCARS data collection began in 1995, most experts consider pre-1998 state adoption data unreliable.

There is limited information on child welfare agency practices related to adoption. In the 1980s, HHS funded studies of adoption exchanges and agencies' efforts to recruit families for minority children. Since that time, HHS has provided adoption opportunity grants to state agencies to improve various aspects of their adoption process, but has not undertaken any large national evaluations.

\section{Demand for adopting children in foster care}

The exact number of persons interested in adoption is unknown, but there is reason to believe the number is substantial. One survey found that a third of all American families have considered at least somewhat seriously adopting a child (Princeton Survey Research Associates 1998). Data from the NSFG survey indicate that in 1995, 232,000 women were seeking to adopt and had taken steps to do so. An additional 240,000 women reported that they were planning to adopt but had yet to take steps to do so. Generalizing this sample to the full population suggests that in 1995 almost 10 million ever-married women ages 18 to 44 had considered adoption and more than 1 million had taken steps to adopt a child but had yet to complete the process (Chandra, Abma, Maza, and Bachrach 1999).

Data from the NSFG describe the women who reported they were currently seeking to adopt as disproportionately married (82 percent) and either sterile or with impaired fecundity (73 percent sterile). Two-thirds (67 percent) of these women were 35 or older and roughly the same number (67 percent) had had a prior birth. Less than a quarter of them (22 percent) had a college degree. The majority of women seeking to adopt were white (51 percent); 21 percent were Hispanic and 19 percent were black.

There are more recent and direct indicators of significant interest in foster care adoption. "Adoption exchanges," a large network of organizations that recruit adoptive families for children in foster care, report receiving hundreds of thousands of inquiries every year from people interested in adopting a child from foster care. The National Adoption Center, which actively recruits families across the United States, receives over 40,000 telephone calls each year. Of these, the Center defines almost 15,000 calls as "usable"- that is, calls from people who are specifically interested in adopting a child from foster care. ${ }^{1}$

Not everyone interested in adopting would adopt a child from foster care. Indeed, the number of persons in the United States adopting children from other countries has increased significantly over the past decade. In FY 2002, Americans adopted more than 20,000 children from other countries, more than three times as many as were adopted in FY 1992. ${ }^{2}$ Most respondents to the NSFG who were currently seeking to adopt reported that they would prefer to adopt a single child who is young and has no physical or mental disability (Chandra et al. 1999). However, a substantial share of respondents reported that they would "accept" a child who looks similar to children available from the foster care system. For example, 56 percent of persons seeking to adopt said they would accept a child aged 6 to 12 and 37 percent a child 13 years old or older. Of those seeking to adopt, 83 percent reported they would accept a child with a mild physical or mental disability and 33 percent a child with a severe disability. Two-thirds (66 percent) of adoption seekers reported they would accept a sibling group. Moreover, the vast majority of

\footnotetext{
${ }_{2}^{1}$ Based on personal communication with NAC officials.

${ }^{2}$ State Department, 2004.
} 
adoption seekers reported they would consider adopting minority children. Of all women seeking to adopt, 79 percent reported they would accept a black child and 90 percent other non-white children.

\section{Characteristics of foster children adopted and the parents who adopt them}

At the start of FY 2001, there were approximately 131,000 children under the care of public agencies waiting to be adopted (AFCARS 2003). ${ }^{3}$ The mean age of the children waiting to be adopted was 8.1 years; 64 percent of them were older than five. These children had been in care an average of 3.75 years. More than half of the waiting children were minorities: 43 percent were black and 13 percent were Hispanic. And slightly more than half were male (52 percent). While exact data are not available, it is likely that the vast majority of waiting children have special needs.

In that same year, 50,000 foster children were adopted. Of these, 38 percent were non-Hispanic white, 35 percent were non-Hispanic black, and 16 percent were Hispanic. The mean age of adopted children was 6.9 years, while the median age was 6.3 years. An equal number of boys and girls were adopted.

The majority of foster children adopted in 2001 were adopted by their foster parents (59 percent) or a relative (23 percent). Federal data indicate that only 17 percent of foster children who were adopted were adopted by persons with whom they did not have a prior relationship. The high share of children adopted by relatives and foster parents represents a radical shift in child welfare practice. Originally conceived of as temporary caretakers, as late as the 1970s many foster parents were required to sign a statement that they would not seek to adopt children placed in their care. Similarly, relatives were typically not considered as adoptive resources. Less than three percent of children adopted in 1982 were adopted by their relatives (Family Impact Seminar 1997).

It is highly likely that these 2001 data underestimate the share of foster children adopted by general applicants. An increasing number of states encourage or require general adoption families to become foster families prior to finalizing the adoption. Since we do not know how many of the adopting foster parents became foster parents only for purposes of adoption, we do not know how many adopters recorded as foster parents are really general applicants.

Nevertheless, we have reason to believe that most of the reported foster parent adoptions were by longer-term foster parents.

Very little information has been published on the characteristics of persons adopting foster care children. AFCARS data indicate that two-thirds ( 67 percent) of the foster children who are adopted, are adopted by married couples. Data from a small-scale study of persons adopting special needs children found that the majority were white (69 percent), married (84 percent), had not graduated from college (72 percent), and were either the child's foster parent (43 percent) or relative (10 percent) (Rosenthal, Groze, and Curiel 1990). Children adopted by minority adoptive parents were more likely to be adopted by relatives, foster parents, single parents, or mothers who did not graduate college (Rosenthal et al. 1990).

A pre-AFSA study comparing adoptive parents of foster children to parents adopting independently in California found that while the majority of both groups of adoptive parents were between the ages of 31 and 40, a significant number of public agency adopters were less than

\footnotetext{
${ }^{3}$ Unless otherwise stated, data in this section are based on AFCARS.
} 
30 years old (Barth, Brooks, and lyer 1995). Moreover, parents adopting foster children had lower levels of education and income than parents adopting independently (Barth et al. 1995).

\section{Consumer views of the adoption process}

Several small-scale studies have been completed that document prospective adoptive parents' experiences with the adoption process. A few studies have sought to explain why so many persons who begin the adoption process drop out and why others who may be interested do not begin the process. Because of the disproportionate number of minority children waiting to be adopted, most of the research focusing on adoption practices has focused on the experiences of minority families, though the lessons learned from these studies may be true for all adoption applicants.

A recent study examined retention of callers to a New York City adoption hotline for two months (November/December) in 2000 and 2001 (Festinger and Pratt 2003). Of the 146 callers interviewed for the study, 35 callers (24\%) attended an orientation. Only $15(10.3 \%)$ completed the home study process. However, $80 \%$ of those who did not attend an orientation responded that they might consider going to an orientation in the future. Of those not attending an orientation, the reasons cited most often dealt with time commitments of prospective parents (26.9\%) and changes in circumstances (e.g., pregnancies, job changes, relocation, financial problems) (20.2\%). Fewer respondents (11.5\%) reported agency unresponsiveness or insufficient information as the reason. When asked about general barriers to the adoption of children from foster care, the primary concerns were the children's problems (21\%), the length of the process (18\%), and the role of birth families (15\%). Financial concerns, time commitment of parenting, and receiving inaccurate or insufficient information about the process were secondary concerns.

Hollingsworth (2002) studied African-American adoption seekers regarding their decision not to adopt and compared their experiences with those who had a child placed with them. In this small-scale study $(n=92)$, non-adopters differed significantly from adopters in two respects they were more likely to be never married, divorced, or separated, and had lower household incomes. Most respondents (71 percent) who did not complete the process attributed their failure to adopt to circumstances having to do with their own situation. However, 26 percent cited circumstances related to the adoption process. Moreover, the author notes that many reasons for not adopting that were categorized as personal reflect agency processes. For example, several respondents mentioned cost as a barrier to adoption and may have benefited from having the fee waived, having subsidies made available, or receiving information about tax credits.

Several other researchers have identified barriers faced by child welfare agencies in recruiting and retaining minority adoption applicants. These barriers are related to unresponsive worker practices, culturally insensitive policies and procedures, and the poor reputation of child welfare agencies.

In 1987, the U.S. Department of Health and Human Services Inspector General's Office assessed agency practices aimed at increasing adoption by minority families and removing obstacles to such efforts. Despite overall satisfaction with the adoption process, even among those who said they were satisfied, three-quarters of minority families had complaints about workers and agencies (Rodriguez and Meyer 1990). Complaints centered primarily on poor communication by workers, including not keeping in contact, withholding information, and not making the applicant feel comfortable. Other researchers have noted that responding to initial 
inquiries is a critical point in the adoption process (Hamm 1997). Yet, this is an area where child welfare agencies have had difficulties as adoption seekers who respond to ads for adoption and phone a child welfare agency on the spur of the moment may reach a telephone that is never answered (Harvard University 1988).

Some parts of the adoption process are particularly vulnerable to worker unresponsiveness. For example, early studies documented the failure of adoption agencies to implement culturally sensitive recruitment strategies and eligibility standards for potential minority adopters. In the past, African American adoption seekers frequently did not meet income, housing, marital status, or other standards that qualified people for adoption (Day 1979; Herzog et al. 1971). Even when adoption standards were not culturally insensitive, researchers noted that most social workers dealing with adoption were white and that these workers frequently used white, middle class norms (i.e., size of home, family structure, education, and income needed to be "good" parents) to evaluate prospective parents. While many agencies addressed these issues and made significant improvements to their practices with minority adoption seekers, researchers continue to identify barriers to the recruitment of minority parents (Gilles and Kroll 1991; Rodriguez and Meyer 1990) and public agencies are increasingly contracting with minority-controlled agencies to improve their recruitment of minority applicants.

Likewise, the home study is an intensive process that can be overwhelming to adoption seekers if not handled appropriately. Several researchers have noted the importance of explaining why questions are being asked. Gilles and Kroll found that potential minority adopters were willing to participate in the home study process when they received thorough explanations of the reason for it. Similarly, Lakin and Whitfield (1997) suggest that "An agency that views families as resources who are empowered throughout the process [and] that prepares and supports families to parent children with special needs, will get a different result from one that begins screening families out from the time of initial contact and takes an investigatory approach to assessment and preparation."

Another barrier to successful recruitment and retention of adoption applicants is poor reputation and media portrayal of the child welfare agency. The child welfare agency's identity in many neighborhoods is its function for child protection. Thus, many potential adopters do not see the child welfare agency as an agency trying to find good homes for children, but rather as an institution that removes children from their mothers and communities. Moreover, the abundance of stories in the news of worker incompetence or bureaucratic processes that have led to the abuse of children may leave potential adopters with little confidence that the agency will manage the adoption process well.

\section{Purpose and Rationale of this Study}

Although offering financial incentives to states for increasing the number of children adopted, the Adoption and Safe Families Act includes no special provisions to increase the number of persons willing to adopt foster children. As the data above illustrate, states have encouraged and removed many of the barriers for foster parents and relatives to adopt. It appears unlikely, though, that states will be able to count on foster parents and relatives to adopt at a rate that would enable all waiting children to find permanent homes. Thus, if child welfare agencies are going to be successful in significantly reducing the number of children who are waiting to be adopted, they will need to recruit additional general applicants and ensure that their current policies or practices do not inadvertently discourage general applicants from completing the adoption process. 
This study was designed to learn more about general applicant adoptions in order to inform child welfare agencies' recruitment efforts and adoption practices. The study sought to estimate the number of general applicants who seek to adopt foster children, understand the factors that influence whether they succeed in having a child placed with them, and document how general applicant adoptions are different from adoptions by foster parents and relatives. The study also sought to document the experiences of general applicants, including aspects of the adoption process that they find most difficult and suggestions they have for improving the adoption process.

\section{Methods}

This study involved four different data collection and analysis efforts: 1) an analysis of data from the federal Adoption and Foster Care Analysis and Reporting System (AFCARS), 2) a national survey of state adoption directors, 3) case studies of adoption practices, and 4) an analysis of adoption applicant case record abstraction.

\section{$\underline{A F C A R S}$}

As part of AFCARS, each state provides data to the federal government on all children adopted from foster care and on the parents who adopt them. Fiscal year 1999 data were the most recent data available at the start of this study.

Each adoption file in AFCARS contains 45 elements. Three of these indicate the pre-adoptive relationship between the child adopted and the adoptive parents: whether the adoptive parent was the child's foster parent, was related to the child, or was unrelated to the child. We categorized children by their pre-adoptive relationship to their adoptive parents. All children with records indicating the adoptive parents were foster parents of that child are considered foster parent adoptions; those indicating the adoptive parents were not foster parents but were related are considered relative adoptions; and, those indicating that the adoptive parents were not foster parents or relatives are considered general applicant adoptions. ${ }^{4}$

Less than one percent of the records had missing information for the three pre-adoptive relationship variables. However, several states reported that they either had no general applicant adoptions or that they had no foster parent adoptions. Because neither of these situations is likely to be the case, data from these states (Alabama, Alaska, Illinois, Kentucky, Massachusetts, Nebraska, Maine, and New York) were not included in the analysis. In addition, we excluded a few case records in which the time since termination of parental rights (for either the mother or father) was greater than or equal to the age of the child. In total, our analysis is based on 30,452 of the 46,000 children adopted in FY 1999.

\section{National survey}

In 2002, the Urban Institute mailed a survey to each state adoption director. ${ }^{5}$ The survey was designed to begin to understand the attrition of adoption applicants by documenting the number of persons who successfully pass through different points of the adoption process. The survey was developed in consultation with the National Association of Adoption Managers to ensure that there were no existing data that could address the questions posed. While not all states that

\footnotetext{
${ }^{4}$ Based on our earlier discussion, we know this categorization underreports general applicant adoptions and over-reports foster parent adoptions.

${ }^{5}$ For a copy of the survey, see Appendix A. For data on responses, see Appendix B.
} 
responded could provide complete data, 40 states provided at least partial information. Followup phone calls were made to clarify some responses.

The survey asked for state-level data ${ }^{6}$ on 1 ) the number of persons who requested information from state foster care adoption hotlines as well as from other sources the state adoption agencies track; 2) the percentage of individuals requesting information who go forward with the adoption process, either by attending an orientation session or completing an application, 3) the number of home studies the state agency and private agencies under contract with the state completed in the prior year, 4) the percent of individuals completing an initial adoption application who complete the home study process, and 5) the number of adoption applicants with approved home studies who are waiting to be matched with a child in foster care. In addition, the survey collected background information on state adoption practices including the extent to which different parts of the process are contracted out, the types of recruitment activities the state conducts, and the training provided to adoption applicants.

\section{Case studies}

Three sites (San Jose, California; Miami, Florida; and, Boston, Massachusetts) were selected for in-depth qualitative research on the adoption process. ${ }^{7}$ Data collection included interviews with state and local adoption directors and private agency adoption directors as well as 15 focus groups with adoption workers and individuals currently in the midst of the adoption process (4 in Miami, 5 in San Jose, and 6 in Boston). ${ }^{8}$ In total, we talked with 92 participants. Participating applicants were at varying stages of the adoption process. Some participants had only attended an orientation session and had not yet completed training sessions, others were in the middle of their adoption training, and others had completed their adoption training and were waiting to have a child placed in their home. Due to resource limitations, only English-speakers were interviewed. ${ }^{9}$ Focus group participants were recruited by the local adoption agencies as well as by the research team. A team of two researchers conducted all interviews and focus groups using semi-structured data collection protocols. All focus groups were audio taped and transcribed. The transcribed focus groups and the notes from the individual interviews were coded using Nud*ist content analysis software.

Focus group participants were also asked to complete a short questionnaire that captured information on applicant demographics, the types of children applicants were willing to adopt, and applicants' opinions of the adoption process. Focus group participants represented a variety of racial and ethnic backgrounds as well as ages and marital status. Sixty-six percent of participants were white, 15 percent Hispanic, and 10 percent African-American. Had there been groups conducted in Spanish, the percentage of Hispanic participants would no doubt have been greater given the location of the three sites. The ages of the participants ranged from 27 to 57 years old with an average age of 41 . Seventy-seven percent of the participants were

\footnotetext{
${ }^{6}$ We asked states to provide either yearly, monthly, or other time-specific data. All data not based on one year were extrapolated to estimate yearly totals.

${ }^{7}$ We had planned to conduct interviews in Chicago as well, but due to the transitions of key individuals in state government, we were unable to get an approval from their Institutional Review Board.

${ }^{8}$ We intentionally sought the input of persons still in the process of adopting as we felt that persons who completed the process (either successfully or unsuccessfully) may be biased in their memory as a result of their success or lack thereof.

${ }^{9}$ We are seeking information on the share of adoptive parents who speak no English to estimate the implication of this constraint.
} 
married, 16 percent were single (including divorced and separated), and 7 percent were same sex partner relationships.

Many of the participants were already parents. Thirty-six percent of the participants had biological children and 15 percent had adopted children. In two-thirds of the applicant families with biological children, one or more of these children were living in the home. All of the adopted children were living with the applicants.

Focus group participants were asked about the types of children they were willing to adopt:

- Age: Eighty-two percent said they are willing to adopt a child over the age of 3, while 35 percent said they would adopt a child over the age of 7.

- Siblings. Sixty-five percent said they are willing to adopt a sibling group of two to three children, but very few participants (7 percent) said they are willing to adopt a sibling group of more than three children.

- Special Needs: Fifty-nine percent of the participants noted that they are willing to adopt a child with behavioral problems, and 25 percent said they are willing to adopt a child with medical needs.

Focus group participants were also asked their opinions of the adoption process, specifically whether they strongly agreed, agreed, disagreed, or strongly disagreed with a number of statements. For the most part, participants viewed the process favorably. ${ }^{10}$ Almost all focus group participants (99 percent) agreed (or strongly agreed) that training sessions were helpful in preparing them to adopt a child. Nine out of ten participants said they would recommend the agency with which they worked to friends or relatives interested in adopting. However, approximately one-in-four participants did not feel the adoption worker provided an accurate estimate of the length of time it may take to have a child placed ( 25 percent) or advocated for them or encouraged them (23 percent). Moreover, more than a third of participants (35 percent) disagreed that the agency was actively trying to place a child with them.

\section{Case record abstraction}

At each case study site, researchers examined a sample of adoption applicant case records, applying a case abstraction protocol based on the data available from local sites' adoption applications and home-study protocols. We requested files of general adoption applicants who had begun the process at least one year ago so that each had a realistic chance of having a child placed with them. We requested that adoption files be selected randomly so as to insure the inclusion of applicants who had had a child placed with them and those who had not. In Miami and San Jose, we were limited to adoption files that were still open (adoptions not yet finalized). In Boston, a few of the files we reviewed were closed (either due to a finalized adoption or applicant withdrawal from the process). Researchers abstracted a total of 143 case records. Upon review, we determined that a few of these records were not general applicants. In addition, while we sought files from all adoption applicants, whether or not they made it far into the adoption process, we found that the vast majority of case records made available to us

\footnotetext{
${ }^{10}$ It is possible that focus group participants, because they agreed to participate, were more positive about their experience than persons who did not agree to attend.
} 
were of applicants that completed a home study. ${ }^{11}$ Thus, we limited our analysis to 132 case records of general applicants who had an approved home study, including 69 applicants who had a child placed with them and 63 who did not.

${ }^{11}$ The agencies do not appear to maintain much information about adoption applicants that do not at least complete the home study process. 


\section{Section2}

\section{Interest in Adoption and Likelihood of Completing the Process: A View from the States}

Based on the data received from 40 states, we estimate that states receive approximately 240,000 requests a year for information about foster care adoption. ${ }^{12}{ }^{13}$ We estimate that states complete approximately 36,000 home studies a year and that there are currently 19,000 applicants with approved home studies waiting to be matched with a foster child. Twenty-two states were able to provide data on individuals at multiple points in the adoption process. These 22 states had received 96,000 requests for information in the prior year, completed 7,000 home studies, and placed 4,000 children with general applicants. ${ }^{14}$ In the vast majority of states (33 of 38), officials believe that there are enough persons interested in adoption, but not enough interested in adopting foster children, to provide homes for every child in their care.

\section{Flow of potential parents through the adoption process}

Knowing the numbers of people involved at each stage of the process is not the same as knowing what share of people who initiate a call to express interest in adopting complete the process and have a child placed with them. Most states (32 of 34 responding) believe that less than half of the persons requesting information about adopting ever attend an orientation session or complete an application. As will be seen in the next section, this percentage is, in part, driven by state responses to initial calls. But it is also true that adoption is a very emotional process and individuals who make an initial call may wait a considerable period of time before going forward. We currently have no longitudinal data on the process following the initial call.

This may change. A few states noted innovative strategies to assist and/or track the progress made by adoption applicants. For example, one state has contracted out to a private vendor who tracks initial calls to the agency and determines whether the agency followed through properly. A few states have created recruitment or retention counselors who are responsible for assisting interested parties in making it through the adoption process. One state's Automated Child Welfare Information System includes fields designed to identify all requestors at the time of initial call. However, several states noted that tracking adoption applicants is an area of weakness for them, and others indicated significant variations in tracking across the state.

Based on the data reported, attrition between application and completion of the home study process appears to vary by state. Officials in half the responding states (17) estimate that less than half of adoption applicants complete the home study. These estimates did not vary by the extent to which the states contract out the application or home study process. Based on the findings discussed below, we believe most of this attrition occurs between the time of application and commencement of the home study.

In most states, officials estimate that a smaller number of persons who begin the home study process fail to complete it; in 23 states, fewer than 25 percent drop out at this point and in 8 states, between 25 and 50 percent drop out. States offered many reasons why applicants fail to

\footnotetext{
${ }^{12}$ Data from the 40 states were extrapolated to the nation, based on the proportion of the total population included in the 40 states.

${ }^{13}$ These data may include multiple requests from the same persons/couple.

${ }^{14}$ Note that states may have completed home studies for persons requesting information in a prior year. Similarly, applicants who had a child placed with them may have had a home study completed in a prior year.
} 
complete the home study process. These reasons tend to fit into four categories: 1) Applicants do not want the children available for adoption or decide they cannot handle special needs children (22 states); 2) Applicants experience a change in their lives such as the birth of a child or a divorce, or the spouses cannot agree on the decision to adopt (14 states); 3) Applicants were eliminated due to agency concerns (11 states); and 4) Applicants found the process to be too burdensome (11 states). Of interest, states estimating that a low proportion fail to complete the home study process are more likely to contract out home studies (13 of the 23 compared to 3 of the other 13). It may be that financial incentives encourage private agencies to find ways to increase the completion rate or to select parents who are most likely to complete the process.

Home studies are not the only part of the adoption process that is contracted out. Every state in our survey contracts for at least one service and 15 of the 38 states contract for most or all of three or more functions. The most common services that states contract out are home studies (16 states contract out most or all), post-adoptive services (14), and orientation meetings (12). In addition, 11 states contract for most or all adoption training and application processes, and 9 states contract for adoption recruitment. The services states are least likely to contract out are placement (4) and matching (6).

States were also questioned about application fees. While several states identified fees associated with the adoption process, almost all of these noted that these fees are typically waived or applicants are reimbursed for expenses following adoption finalization.

\section{Characteristics of adoptive parents and children adopted from foster care}

States' reliance on foster parents, relatives, and general applicants as adoptive resources varies greatly. As reported in the 1999 AFCARs data:

- In 11 of the 43 states (including the District of Columbia as a state) that provided data, foster parents accounted for more than 75 percent of foster care adoptions in FY 1999. In another 11 states, foster parents accounted for fewer than half of foster care adoptions.

- In 12 states, relatives accounted for less than 5 percent of children adopted but more than one-quarter of all adoptions in 10 states.

- In 9 states, general applicants accounted for less than 10 percent of all children adopted, but in 9 other states, they accounted for more than 40 percent.

The true extent of this variation is difficult to assess because of the practice in some states of converting general applicants to foster parents to enable the adopting parents to take advantage of adoption subsidies and the likelihood that general applicants will become foster parents because they believe it will improve their chances to adopt. In response to our survey of states, adoption officials estimate that:

- In 11 states less than 25 percent of general applicants become foster parents to adopt.

- In 11 states, officials estimated this percentage to be between 25 and 50 .

- In 10 states, officials estimated that more than half of general applicants become foster parents in order to improve their chances to adopt.

Differences in who adopts children from foster care are important because the differences seem to influence which children are adopted (Table 1). Overall, foster children who are adopted are younger and more likely to be female, Caucasian, or Hispanic than those children waiting to be 
adopted. With one exception, the characteristics of children adopted by foster parents and general applicants look quite similar. The exception is that general applicants are significantly less likely than foster parents to adopt a special needs child. We believe this difference is real, though if we were able to accurately distinguish general applicant adoptive parents who became foster parents in order to obtain the subsidies available for adopting special needs children, the difference between foster parents and general applicants would be smaller. The children adopted by relatives are more likely than those adopted by general applicants or foster parents to be older, minority, and male.

Table 1

Children Adopted by Different Types of Parents

\begin{tabular}{|c|c|c|c|c|c|}
\hline \multirow[b]{2}{*}{ Child Characteristics } & \multirow[b]{2}{*}{$\begin{array}{l}\text { Waiting } \\
\text { Children }\end{array}$} & \multicolumn{4}{|c|}{ Adopted Children by type of Adoptive Parent: } \\
\hline & & All & Foster Parents & Relatives & $\begin{array}{l}\text { General } \\
\text { Applicants }\end{array}$ \\
\hline \multicolumn{6}{|l|}{ Age } \\
\hline Mean (yrs) & 8.1 & 6.01 & 5.82 & 6.59 & 5.96 \\
\hline Over age 5 & $64 \%$ & $48 \%$ & $46 \%$ & $55 \%$ & $49 \%$ \\
\hline Sex (Male) & $52 \%$ & $50 \%$ & $50 \%$ & $53 \%$ & $49 \%$ \\
\hline \multicolumn{6}{|l|}{ Minority } \\
\hline Black (non-Hispanic) & $43 \%$ & $34 \%$ & $34 \%$ & $36 \%$ & $35 \%$ \\
\hline Hispanic & $13 \%$ & $16 \%$ & $14 \%$ & $21 \%$ & $18 \%$ \\
\hline \multicolumn{6}{|l|}{ Older Minority (10+ years) } \\
\hline All & NA & $20 \%$ & $20 \%$ & $26 \%$ & $19 \%$ \\
\hline Males & NA & $10 \%$ & $10 \%$ & $12 \%$ & $9 \%$ \\
\hline Special Needs & NA & $80 \%$ & $83 \%$ & $87 \%$ & $68 \%$ \\
\hline
\end{tabular}

In addition to adopting different types of children, the characteristics of adoptive parents vary depending upon the parents' prior relationship to the children they adopt (Table 2). While there are few differences between foster parent and general applicant adoptive parents, relatives who adopt are markedly different. All types of adoptive parents tend to be older than new biological parents, but relative adoptive parents are significantly older than either foster parents or general applicants. In addition, relatives are much less likely to be married and much more likely to be adopting Hispanic children.

An issue of unsettled debate that influences the placement of children in adoptive homes is the extent to which child welfare agencies should consider the race of a prospective adoptive parent in the decision to place a child. Many minority leaders, including the National Association of Black Social Workers, oppose transracial adoptions. The Multiethnic Placement Act of 1994 (MEPA) prohibited agencies or entities engaged in adoption or foster care placements that receive federal money from "categorically deny[ing] to any person the opportunity to become an adoptive or foster parent, solely on the basis of race, color, or national origin of the adoptive or foster parent" and "from delay[ing] or deny[ing] the placement of a child solely on the basis of race, color, or national origin of the adoptive or foster parent or parents involved" emphasis added\} (p. 4056). This law specifically allowed an agency to consider race "as one of a number of factors used to determine the best interests of a child" (p.4056). However, in 1996 Congress modified MEPA and removed this qualification. 
Relative adoptive parents, not surprisingly, are more similar in race and ethnicity to the children they adopt than are foster parents and general applicants. Some experts have asserted that the rise in foster parent adoptions is increasing the number of transracial adoptions, since there are insufficient numbers of minority foster parents (Hollingsworth 1998). However, it appears that adoptions by general applicants are more likely to be transracial than are adoptions by foster parents. We have no reason to believe that this difference would "disappear" if we were able to more accurately distinguish "true" foster parents from those general applicants that became foster parents in order to adopt.

Table 2

Who Are the Adoptive Parents?

\begin{tabular}{|c|c|c|c|c|}
\hline & \multicolumn{4}{|c|}{ Adoptive Parents } \\
\hline Married & $\begin{array}{l}\text { All } \\
72 \%\end{array}$ & $\begin{array}{c}\text { Foster Parents } \\
75 \%\end{array}$ & $\begin{array}{l}\text { Relatives } \\
55 \%\end{array}$ & $\begin{array}{c}\text { General Applicants } \\
77 \%\end{array}$ \\
\hline Mean Age (yrs) & & & & \\
\hline Mother & 43 & 43 & 46 & 41 \\
\hline Father & 44 & 44 & 47 & 42 \\
\hline Minorities & & & & \\
\hline $\begin{array}{l}\text { Black (non- } \\
\text { Hispanic) }\end{array}$ & $26 \%$ & $25 \%$ & $29 \%$ & $27 \%$ \\
\hline Hispanic & $6 \%$ & $4 \%$ & $14 \%$ & $4 \%$ \\
\hline Transracial Adoption ${ }^{a}$ & $21 \%$ & $22 \%$ & $12 \%$ & $28 \%$ \\
\hline
\end{tabular}

${ }^{a}$ Child is of a different race or ethnicity than adoptive parents (different from both parents if married adoptive parents).

There also appear to be differences in the characteristics of general applicant adoptions depending on the extent to which a state relies on general applicants for foster care adoption (Table 3). In states that rely more heavily on general applicants to adopt foster children, the children they adopt are older, more likely to be female, more likely to be minorities, and less likely to have special needs. If states with fewer general applicant adoptions were converting general applicants to foster parents in order to provide subsidies to adoptive parents, we would expect the findings on special needs adoptions to be quite different.

In states in which general applicants adopt a greater percentage of foster children, these adoptive parents are more likely to be the less traditional adoptive parents; they are more likely to be single and black. 
Table 3

General Applicant Adoption by States' Reliance on General Applicants

\begin{tabular}{|c|c|c|c|}
\hline & \multicolumn{3}{|c|}{ General Applicants(as a percent of state's adoptive parents) } \\
\hline & $\leq 15 \%$ & $16 \%-29 \%$ & $\geq 30 \%$ \\
\hline \multicolumn{4}{|l|}{ Age of child at time of adoption } \\
\hline Under 6 & $60.0 \%$ & $50.0 \%$ & $47.0 \%$ \\
\hline Mean Age (yrs) & 5.2 & 6.1 & 6.3 \\
\hline \multicolumn{4}{|l|}{ Race of child } \\
\hline White non-Hispanic & $50 \%$ & $42 \%$ & $40 \%$ \\
\hline Black non-Hispanic & 30 & 41 & 33 \\
\hline Hispanic & 19 & 14 & 24 \\
\hline Special Needs & $82 \%$ & $85 \%$ & $50 \%$ \\
\hline Adoptive Family Married Couple & $79 \%$ & $81 \%$ & $75 \%$ \\
\hline Age of Adoptive Mother (yrs) & 41.2 & 40.2 & 42.2 \\
\hline \multicolumn{4}{|l|}{ Race of Adoptive Parents* } \\
\hline White non-Hispanic & $65 \%$ & $58 \%$ & $52 \%$ \\
\hline Black Non-Hispanic & 23 & 31 & 31 \\
\hline Hispanic & 5 & 5 & 4 \\
\hline
\end{tabular}

*In states where general applicants account for 30 percent or more of the adoptions, 6 percent of adoptive parents are Asian; in other states less than 1 percent of adoptive parents are Asian. 


\section{Section 3}

\section{Listening to Parents}

The question this research set out to address is why do general applicants drop out of the adoption process along the way and what, if anything, can be done to retain them. Aggregate data provided by states, either to us (state surveys) or to the federal government (AFCARS), provide rough estimates of the magnitude of attrition but do not provide insights into the reasons for dropping out of the process. To address this questions, we conducted case studies in San Jose, Miami, and Boston. Our goal was to generate in-depth qualitative information about whether, and to what degree, attrition of prospective parents is caused by agencies' adoption processes and procedures as opposed to personal reasons such as changes in life circumstances or recognition that parenting a foster child is not the right choice for them.

Our strategy was quite simple. We set out to learn about the adoption process in each agency and adoptive applicants' responses to it. We asked how prospective parents first heard about adopting a foster child, the response they received when they first contacted the agency, and their experiences with the application, training, and home study process as well as the "matching" process. During our discussions with prospective parents and adoption workers in the three sites, we were also able to examine a number of complexities inherent in the process that may lead to attrition of adoption applicants. These are presented at the end of this section.

Adopting a foster child from a public child welfare agency in the U.S. is by no means a simple process. Individuals who contact a public agency in hopes of adopting a child often have little or no information about what the process entails. The public agencies whose task it is to find adoptive families for foster children report budget limitations, staff turnover, and other bureaucratic hurdles. Prospective adoptive parents are a varied group of individuals-some are married couples who have struggled for years with infertility; some are same-sex couples wishing to parent children together; others have biological children and either wish to parent a less fortunate child, or have remarried and wish to parent a child with their new spouse; and some applicants are single and wish to parent a foster child. They also represent a range of racial/ethnic, socioeconomic, and religious backgrounds.

Seeking a "permanent" home for a foster child is one of the most important goals of the child welfare system. Administrators, supervisors, and workers in public child welfare agencies know their mandate and take their job seriously. Adoption is permanent. For foster children who are not able to return to their biological parents, adoption workers want the very best. They want an adoptive home that can best meet the needs of the child.

The adoption process has many steps. First, an individual or couple seeking to adopt a child must hear about the children available through the public agency. We refer to this as recruitment. Then the prospective parent contacts the adoption agency. Once contact has been made there are several steps that agencies require, including meeting certain standards (e.g., criminal clearance, housing), completing an application, attending training sessions, and participating in in-person interviews to assess their home environment and suitability as adoptive parents (i.e., home study). At each of these steps, paperwork must be completed. The final step in the process is matching a child with a family. In an ideal world, the adoption process would be smooth and have few or no delays. The sections that follow provide details about each of the steps in the adoption process and describe some of the complexities. 


\section{Recruitment: How do prospective adoptive parents first hear about adoption?}

While there are many sources from which they hear about the need for parents to adopt children from foster care, many, if not most, prospective adoptive parents appear to have some personal connection to adoption or the foster care system. It was remarkable how many persons who participated in our focus groups mentioned a relative, friend, or co-worker who had adopted a child from foster care. Additionally, many prospective adoptive parents noted that they were adopted or were in foster care, or had grown up with foster children in their homes. Thus, focus group participants frequently noted: "I just always knew about [foster care] adoption." Similarly, adoption workers noted that "word of mouth" is the most common way that people hear about the need for adoptive parents.

Those without a specific personal connection were introduced to foster care adoption through a number of sources, including a wide variety of electronic and print media. Many focus group participants said they first heard about the need for persons to adopt children from foster care from Wednesday's Child segments on television or similar segments on featured children in newspapers. Participants in Miami noted billboards that highlighted the need for foster and adoptive parents. Boston participants noted that a private retailer, Jordan's Furniture, held numerous adoption events and advertised the need for adoptive parents. Participants in San Jose also heard about foster care adoption through non-child specific public service announcements and from individuals staffing booths at community festivals.

In discussing their motivations for seeking to adopt foster children, participants identified reasons that can be classified as either "child-centered" or "parent-centered". Most adoption seekers we interviewed reported some type of fertility problem and were seeking to form a family by adopting young children (parent-centered adopters). Others were motivated to adopt to "save a child" (child-centered adopters) and tended to seek older children. The latter group were less common than the former.

Many prospective adoptive parents report that they had a number of misconceptions about the adoption process when they first considered adopting a foster child. Many adoption seekers thought there were many more children available then there actually are. Some noted that they feel the media provide misleading information about foster children "available." Other adoption seekers noted that they were surprised to find out that you do not need to be married or rich to adopt foster children, and that being handicapped or homosexual (except in Miami) did not disqualify you. Many adoption seekers also said they were surprised by the process of adopting from foster care; many thought the process would be quicker and easier, though a number also thought it would be longer and more difficult

Most people considering adopting a foster child have also looked into private and international adoption. While many are pursuing adoption through multiple agencies simultaneously, most prospective adoptive parents of foster children have decided not to adopt through a private agency for financial or moral reasons. Nearly everyone in our focus groups who pursued international adoption commented on how expensive it could be and reported that they decided to focus on foster care adoption because it is less expensive. Many people who considered international adoption said they were turned off by the expense, not only because they could not afford it, but also because they felt it was like "buying a child," which they found to be distasteful. Others said that once they found out how many children in their own community needed homes, they could not look elsewhere. Most of the people who were still considering private and international adoption were seeking infants and/or wanted more control over the adoption process. 
"There are two sides [to adoption] - the rich people side and the other side is the kids in need right here. It is frustrating because I can provide a cultured, wonderful home for a child, but I don't want to buy a child." Adoption applicant

"It does sort of feel morally reprehensible to spend a lot of money, which I don't have anyway, but a lot of money to go outside of the country to get a kid when there are so many kids that need homes here." Adoption trainee

"I always thought that it would be nice to adopt a Chinese baby because of what they do over there with the girls, but then it gets me so angry because of how the government is trading these girls. The money that they get from consumers to adopt these children goes to the government on top of it all. As much as my heart goes out to the kids, I couldn't feasibly participate in that knowing that the money is going to the government and it is wrong what they are doing." Adoption trainee

"Yes, it's the money but you feel like you're paying $\$ 30,000$ for a human life. I understand that the child has medical bills, whatever else, but $\$ 30,000$ for a child that's a few months old. How do you place a value on a child?" Adoption trainee

Agency workers and administrators report increased efforts to recruit adoptive parents, yet acknowledge that limited resources constrain efforts to implement innovative strategies. In all three sites visited, administrators noted recruitment activities that were global (to the entire population), targeted (to persons more likely to adopt), and child specific (focused on a specific foster child). Yet administrators and workers noted limitations to their current recruitment strategies, particularly identifying common recruitment strategies as often ineffective in identifying minorities that would consider foster care adoption. They noted a need to conduct community-based recruitment, because "you really need to go to them - you can't expect them to come to you." Some workers also noted the need (currently not met) for recruiters who are minorities and recruiters who are bilingual. In addition, in Boston, child welfare officials noted that recruitment strategies have focused too much on infertile couples and need to expand to include parents who already have biological children.

Potential adoptive parents commented on current recruitment efforts and offered suggestions for improving recruitment of adoptive parents. Several Miami focus group participants reported being influenced by the message on billboards that noted, "adoption has been made easier." Others noted that since adoption is such a personal topic, a more personalized approach would be more effective (e.g., small group presentations that allow participants to ask questions). Still others suggested that recruitment messages should stress the supports that are available to parents who adopt children from foster care.

\section{Screening or Recruitment? The function of the initial call}

The next step in the process for a potential adoptive parent is contacting the public agency to find out about adopting a foster child. While some individuals may respond impulsively to publicity about a specific child, most individuals who call have given the idea of adoption considerable thought. During focus groups, applicants described the emotional journey that precedes the initial call to inquire about adoption. The path that leads to adoption frequently involves frustration and loss - not finding the right partner, infertility, illness, miscarriage, failed 
infertility treatments. When making their first inquiry, applicants noted they wanted to obtain accurate information but also wanted to be treated well.

\section{Getting an answer: Multiple calls to agency to reach "right" staff}

Agency staff strive to respond quickly to initial telephone inquiries, with the caller either reaching a person directly or getting a quick call back. However, agencies recognize that this goal is not always met. Callers often reach either an operator or voice mail. In Boston and Miami, a number of applicants expressed frustration with their initial phone call. Complaints included getting no answer, leaving voice mail messages but getting no return call, and getting bounced from staff to staff before reaching the "right" person. In San Jose, some applicants found it hard to find the right phone number, but, when they were able to make their first call, were pleased with the response.

The focus groups we conducted included potential adoptive parents at several stages of the adoption process, with many having initiated the process more than a year earlier. Over that period of time, each of these agencies changed its process for answering inquiries, either proactively or in response to budget crises. In Boston, DSS endured serious budget cuts, forcing staff layoffs that undoubtedly influenced agency responsiveness to potential adoptive parents. Miami also experienced budget cutbacks over this period. Thus, the responses from those we interviewed provide important information about the process in general but may not reflect the current practice in these sites.

"My first experience was my sister calling me about a boy who had been on TV. . . I just wanted to know about this little boy and it just seems like it was a thousand phone calls and a thousand people and this one doesn't know what you are talking about and let me transfer you to somebody else...." Adoption applicant

"I think my initial call was in July and it took about six weeks for them to call back. And actually I think the only reason I did get a call back was because I made a second phone call..." Adoption applicant

"We had started by contacting DSS directly, the district office. And it was right at the time when they went through serious budget and staff cuts and we couldn't get a call back. We would call and they would say 'well this person handles that but they may not have a job tomorrow, we will call you back.' And then we would have to call again and then wait two weeks and finally they put us to somebody who finally pointed us to somebody at Catholic Charities." Adoption applicant

"Yes [we have an 800 number], but we don't have staff to handle the calls always. In an ideal world, we would. That's been a challenge for us." Adoption Administrator

"I didn't get the information until maybe the third call. Then I actually came down here to get the forms. There's a 1-800 number to call and you get some packet, general state of Florida information. I just feel like I've really had to push.... It's just getting to the right people." Adoption applicant

"I made a phone call and found out that classes started the next week. I got a person on the phone." Adoption applicant 


\section{Strong personal connection is helpful}

While many applicants expressed great frustration gaining access to "the system," making a strong personal connection with an individual once they obtained access made a tremendous difference in how applicants perceived the process and any systemic problems that arose.

"Finally I called and happened to get (worker) on the phone, who is a like-minded person and we kind of clicked.... That is what I needed, a person to talk to ...I just found a human being who would have a conversation with me and then found out the next steps. It was simple information. I just needed somebody to give me that information. So I would say warmth and actually being clear about what the process is [is what got her into the door]." Adoption applicant

". . . when I called here the social worker was so pleasant and informative and willing to answer any question that I had. We just clicked. I think, you could feel that connection, and that just right there just made my decision." Adoption applicant

"The first person I talked to was (worker). From that moment it's like she cradled us, she walked us through the process, it was so easy it was almost unbelievable.... it went exactly like she said, it was just so easy. She gave us a lot of information and everything took place exactly as she said." Adoption applicant

\section{Conflict between what parents wants to hear and what an agency must say}

Public agencies are challenged both to provide information on moving forward with the adoption process and to screen out inappropriate callers. All three agencies in our sample use the initial call for both purposes, though each had a somewhat different approach to doing so. Their approaches varied from focusing on screening out potentially ineligible parents, screening out potential parents who are not ready or willing to adopt the types of children available, or doing a minimal amount of screening and instead focusing on encouraging participation in the adoptive process.

In Miami, the public agency uses the initial contact primarily as a device for screening out ineligible or inappropriate potential adoptive parents. Callers are asked a series of questions from an inquiry form about such topics as income, expenses, and criminal background before being invited to an orientation meeting. If the caller meets these requirements, he or she is mailed a formal invitation to an orientation. In Massachusetts, both the public and private agencies use the initial contact to begin a discussion of matching parents and children, discouraging prospective parents who are seeking newborns, younger children, or other types of children the agency is unlikely to have available for adoption, and inviting others to continue with the process. San Jose asks only basic questions related to criminal background and housing of those who call and invites almost all callers to apply on line and attend an orientation meeting. The agency follows the "Family-to-Family Initiative" in casting a wide net for potential adoptive parents. The recruitment manager said that she would be happy with 200 people at an orientation as it would educate the wider community about adoption.

The focus groups we conducted included potential adoptive parents at several stages of the adoption process, with many having initiated the process more than a year earlier. Over that period of time, each of these agencies has changed its process. San Jose moved much of the screening function from the initial agency contact to the first session of training, reducing the 
time demand on those who respond to initial calls. In Boston, DSS reduced the number of questions it asked initial callers. Again, the responses from those we interviewed provide important information but may not reflect the current practice in these sites.

Workers also mentioned the need for sensitivity in responding to initial calls and handling these two, potentially conflicting challenges. They recognize that for those callers who seek to adopt the youngest, healthiest child possible, there is an inherent tension as they learn the reality that most available children are older, part of sibling groups, and/or have special needs.

"Most of the first calls I get are inquiring about a baby - this is not the program that you want. We're going to lose a lot right then." Private agency worker

"Well I think some of the information is so negative that we give them that I think it turns a lot of people off. Because we have to tell them that most of our children are special needs, they are older, they come from a history of neglect or abuse, or domestic violence, alcoholism, mental health issues, high legal risk." Public agency worker

"I think it is important in terms of how they are told - not just what they are told. In terms of not realizing on the other line where someone is in the infertility stage. But I think that people can hear better if you do tell them in a certain way earlier on [rather] than put them in and just let them wait for a child that does not exist. I think people can hear it better, are far less angrier than hearing it in the beginning. So I think it is important to be honest with them in a kind way." Adoption worker

Reflecting the tension between encouraging parents and informing them, many applicants spoke of the initial insensitivity of agency personnel.

"It was like trick questions, like 'are you interested only in an infant' and I would say that would be my hope, for a child who has had less trauma and then they would snap 'well you will never get an infant.' She didn't say 'would you consider an older child.' I am a human being, I can be flexible." Adoption applicant

"I had discouraging conversations where I ended up feeling not invited, to sum it up. 'You're not appropriate, you are too old, you are single, you're this, you're that, you want an infant, forget it.' It wasn't really any engagement about whether or not there was a match. That put me back a few months each time." Adoption applicant

\section{Confusion about the process}

When potential adoptive families initiate the process, they often do not have an understanding of the number of steps in the process and their sequence. While some of this confusion is due to a lack of information upon entering the process, other issues seem to remain a source of confusion. For example, some applicants were confused about the differences between foster parenting and adopting. Other applicants were unclear about the differences between adoption exchanges and adoption agencies, public and private agencies and orientation versus training processes.

"I actually misunderstand, there is this group called MARE in Massachusetts that is a support organization, as far as I can tell, and they organize a lot of events, but I didn't get good information calling them a few times. Every few months when I would be like 'yes I am going to do something about this' I get some weird conversation with some person 
[at MARE] who doesn't have any function in the actual process of adopting and would tell me that 'you will never get an infant, you shouldn't even bother' instead of 'well what other things would you be open to in terms of what kind of child." Applicant

"It was a very confusing process because the social worker who was involved in adoption for my area didn't really want to talk to me because I didn't have MAPP training but [at the time] I didn't understand what MAPP training was so you kind of got bounced around back and forth because no one would really say 'you don't call us until you get here."' Applicant

"The first thing is to talk to a family that might be interested in adopting and you explain it to them. Many times they have so much misinformation that, even after being in the system, they have no idea of what's going on." Adoption worker

\section{Application and Orientation}

Once prospective adoptive parents connect with the public agency, they are instructed on the next steps in the process. This first of these is often referred to as the orientation process and incorporates completion of an application form or some other sort of initial inquiry form. This is also the stage of the process in which agency officials are likely to provide more information about the types of foster children available for adoption.

The application and orientation process is handled differently in each of the three sites. As mentioned earlier, Miami tends to conduct a more thorough screening over the telephone with each prospective applicant prior to extending an invitation to an orientation session. In San Jose, parents are invited to an orientation after being asked only a few screening-type questions. This was not always the case in San Jose; officials noted they had recently modified their approach and now view the application and orientation process as community education. In Boston, the agency appears most concerned with ensuring that the prospective parents who attend an orientation session understand the types of children available.

There are a number of possible reasons for these differences, including differing demographics of workers or families, available resources, the ratio of available children to interested parents, and the skill level, qualifications and experience of agency staff. In San Jose, the focus of the orientation is the children - who they are and what their needs are, how the system works and parental motivation for adopting. Because this orientation is the first meeting of the training class, those who choose to go forward may move directly into training. Prospective parents complete the application, which is demanding and detailed, during training.

"In the past, we did have certain requirements they had to do before they entered training, but all that's changed in the last year. They can come in and there will be intake workers who will help them during training to complete the application. It's wanting them to have more access, bring more people in than before." San Jose Adoption Worker

"I think families want to not jump over so many hoops until they start actually talking to a live person. Sometimes if the paperwork has to be filled out before they've talked to anyone, it can take a long time to complete all that. So if they get assigned to a licensing worker or a home study worker, someone they can talk to, I think that eases, it's not so indefinite." San Jose Adoption Worker 
"The orientation facilitator tries to be motivational with the applicants and tells them about the kid's needs. The orientation used to provide information about rules and regulations, but now it's not so boring. Applicants often ask questions about whether issues such as income levels, being single, being gay/lesbian, or renting/owning a home will present problems for them during the process." San Jose Recruitment Manager

Consistent with its goal of using orientation to bring in as many potential adoptive parents as possible, San Jose intentionally reaches out to those who call expressing interest but fail to come to orientation.

"There are four intake social workers who are constantly following up with folks who express interest in adopting but do not come to orientation. They mail those people a brochure containing basic information, and then follow-up at three months and six months, later closing out the case. They keep folders on all the callers, and inquiry forms are part of their database." San Jose Recruitment Manager

Prospective adoptive parents in Massachusetts are provided with information on the types of children available when they first contact DSS. Those who are interested in adopting these children are invited to an orientation session where they are given a Registration of Intent form. Subsequently, state workers conduct a criminal background check. Once this registration of intent is completed, a worker schedules a pre-screening visit to the prospective adoptive home. This provides an opportunity for the worker to review the materials in the registration form, gather additional information on the suitability of the family and their living environment, and answer questions about children available for adoption. Prospective parents deemed appropriate are then invited to attend training.

"We usually put up our recruitment board to show who we are recruiting for, because it is very visual. We are trying to get through to them that what we are really talking about are older children. I talk about specific kids if they want. We do a lot of question and answering for them [prospective adoptive applicants]." Boston private agency adoption worker

Workers at both the Massachusetts Department of Social Services and Catholic Charities seek to screen out those who have unresolved infertility issues, are looking to adopt infants, couples with different levels of commitment, or have personal issues such as mental health problems or failed criminal background checks. Through these conversations and the orientation session information, prospective adoptive parents have an opportunity to screen themselves out.

"Approximately half of all the families that apply have some sort of criminal record, but most get waived." Boston private adoption agency manager

"If they have had a miscarriage recently or are still doing IVF treatments, we want them to get counseling before they undertake this process. We would put them on hold for a while to give them time to think about if they are really ready for this. We also do not want to place a child with a family who has history of mental illness or substance abuse." Boston private adoption agency manager

Workers in the Massachusetts Department of Social Services discussed the value of completing an initial home visit before accepting people into training. It provides an opportunity to develop a one-on-one relationship and build trust before the group begins. It also provides an opportunity for potential adoptive parents to be open about their personal concerns, ask 
questions and provide honest information prior to meeting in a group. In such a setting it is easier for parents to accept rejection if the worker believes they should not continue in the training or to voluntarily withdraw if they feel the do not want to go forward.

In Miami, the orientation is designed primarily to screen out inappropriate adoptive parents. In order to preserve resources, applicants are fingerprinted at the beginning of the orientation meeting and the orientation is used to guide applicants through the application form, pointing out any disqualifying circumstances. This enables DCF to screen out prospective parents at the outset for issues such as inadequate housing and income, criminal background or entering the process primarily for personal financial benefit.

"I think that was one of the weak points of the orientation. I was expecting they would walk you through the process and tell you what to expect, what's the next step. Instead, it was just going through the paperwork, which I thought might be at a later time." Miami adoption applicant

"If your question was whether they close the door to some people sitting in the room, I would think not. I felt welcome. With the exception of homosexuality, by law. But on the issue of age, and other issues, I felt there was flexibility there." Miami adoption applicant

\section{Encouraging prospective parents vs. screening out inappropriate individuals}

Applicants in all sites felt that the orientation and application process contained a great deal of negative information about the children. While most applicants (and workers) saw this as a way of presenting a realistic picture of the children, some families felt that the picture presented was too negative, presenting a worst-case scenario, or being used as a way of screening out families.

'It's like 'why do they need all of this [negative information]?' But in the end when you stop and think and you realize the implications..." Adoption applicant

"I thought the orientation presented a worst-case scenario about how kids are, it almost seemed like it served to weed out people." Waiting adoptive applicant

"In regards to new families, the most single important thing we can do is disclose every piece of information about that child because l'd rather scare them straight in the beginning than have an attachment form and then later have to remove the child. So right up front, tell them family background, what the child has been gone through needs to be disclosed. And it shouldn't be sugar-coated at all." Adoption worker

"But the problem with new families is that they don't want to hear it. They just want the baby because he's so cute." Adoption worker

"It goes in one ear and out the other. Even in training, I noticed when we do our orientation, the listening is turned off to certain things. It takes a long time, you want to shake them, and say, 'Listen to me, please.' Because I'm looking for a family for a child, not a child for a family." Adoption worker 


\section{Legal risk adoption - resource fostering}

Almost all prospective adoptive parents who attended orientation meetings with public agency adoption workers reported that they were asked whether they would consider becoming foster parents as opposed to doing a straight adoption. San Jose, like many other communities, is moving in the direction of requiring all adoption seekers to become foster parents before being eligible to adopt. In each site visited, workers noted that the need for foster parents was even greater than the need for adoptive parents. Several parents heard this message and felt pressured to become foster parents. Based on the responses of focus group participants, private agencies appear less likely to introduce the idea of foster parenting. This may be because many private agencies are only contracted to recruit adoptive parents and thus have a financial incentive to keep applicants focused on adoption. Some workers expressed concern about pushing adoption seekers to become foster parents, noting that someone who is a good adoptive parent may not necessarily be a good foster parent.

"I wonder if there is a sense that if you are willing to be a foster parent that you are really useful to them and you might get more help, because that is what they [DSS] want. And someone who wants to "take advantage" of the DSS system to create a family is maybe seen as someone parasitic and non-helpful. .I don't want to be a foster home, I want to create a family. I don't want to be made to feel there is something wrong with that. ... guess it doesn't feel like you are seen as a welcome resource and instead you feel bad about yourself because you don't want to be a foster parent. Instead of feeling great that you can help your community by adopting a child who needs a home." Adoption applicant

"I get the feeling he's [the MAPP trainer] pushing the fost-adopt. He's really pushing that." Adoption trainee

"And if you really want to adopt you can't really come into this [fostering] thinking that [adoption] frame [of mind]. Your job as a foster parent is very different than your job as a pre-adoptive parent." Adoption worker

Even when adoption applicants are not asked to become foster parents, they are often asked whether they will accept a legal risk placement, a child who is very likely to be made available for adoption but whose parental rights have yet to be terminated. In San Jose, the child welfare agency is moving in the direction of requiring all adoption applicants to accept legal risk children, thus technically making them all foster parents before they adopt. Miami has a separate designation, resource fostering, for adoption applicants who were willing to take legal risk children. Applicants who are seeking younger children are encouraged to do resource fostering. In Boston, applicants have the option to accept only children that are legally free for adoption and many, even those seeking younger children, choose this option.

In all three sites, applicants were confused and concerned about agreeing to take children who may be returned home. Based on our focus groups, it appears that workers had difficulty communicating the level and nature of the "risk" in a legal risk placement. Many applicants said that they simply could not take a child into their home to whom they would become attached, only to see that child reunified with his or her parent(s). In some instances, it appeared that applicants overestimated the true level of such risk. Workers may need to explain that all adoptions (foster and private) involve a 
certain level of risk in that applicants may become attached to a child they are not able to adopt. This can occur because of decisions or actions by the child, the birth parent, a court, or the applicants themselves.

\section{Training Prospective Adoptive Parents}

The training process is similar across each of the three sites with each utilizing a prescribed adoption training curriculum. Both Miami and Boston agencies use MAPP ${ }^{15}$ (the Model Approach to Partnership in Parenting), while San Jose uses PRIDE ${ }^{16}$ (Parent Resources for Information, Development, and Education). Both curricula emphasize the group process and contain materials for approximately 10 weekly sessions of 3 hours each. While there are several smaller differences between the two curricula, the primary difference noted by respondents is that the MAPP program was developed for use with adoptive parents while PRIDE was developed as a foster parent training resource. The vast majority of states train adoption and foster parent applicants together using the same curricula (30 of 37 states responding).

While neither adoption applicants nor workers would suggest that the training is easy, participants generally had positive feelings toward the training, especially those who had completed the training and had had time to reflect on their experience. The most common complaints about the training were that it was focused too much on the difficulties of the children needing homes and that information about the services and supports available to address these difficulties came too late in the training sessions.

Another frequent complaint among participants was that the training did not focus enough on the adoption process, informing participants of the steps in the process, timing, and how decision are made by adoption workers. Some adoption applicants also noted a lack of discussion about dealing with birth parents post-adoption.

Many participants were concerned, as they went through the training, about how the workers would be using participant comments to assess whether they would make good adoptive parents. Participants described the training as "being in a fishbowl" with workers looking on to see how they would react when they heard incredibly difficult things.

"I thought it [the training] was good. You kind of come into this with a little bit of a superman cape, you know. 'I'm going to adopt kids and give them the best home.' You kind of get ahead of yourself, but the training gives you a real sense of reality and you take off the superman cape. And it is not about you, it is about them [children] and that really hits home. Takes a few weeks sometimes, you take it in and you see the situations that go on and it really gives a sense of reality. It is a humbling experience and I enjoyed it. It changed my perspective big time." Waiting adoptive applicant

"At the end of this class I find it difficult to imagine adopting a child without the training, honestly. Because I would have thought it was me, I would think that I was screwing up as a parent in some way as these things start to happen. So it

\footnotetext{
${ }^{15}$ Developed by the Child Welfare Institute.

${ }^{16}$ Developed by the Child Welfare League of America.
} 
was good to hear about the things that you can expect could happen, right." Adoptive trainee

"I felt that the whole tone of the class was negative. The topics were important but I think that somebody needs to take a look at how to get those messages across. Because I just felt like it was constant negative and two weeks ago we just had the worst weekend because it was just like - 'I can't take this anymore."' Adoptive trainee

"They made all of these kids sound like future child molesters, jewelry thieves, who don't want to be adopted anyway." Adoptive trainee

"When we went to take the classes, it was great and they got into a lot of stuff but it still didn't answer a lot of our questions about the whole process. Okay, you ask about how long do you think it will take. And they can't answer that. They won't even give you any kind of an idea. And asking them about what are the possibilities of the kid being taken away, what are the statistics. And they can't give you anything." Waiting adoptive applicant

Given differences in the extent of screening before training, it is not surprising that the local sites visited vary in the extent to which adoption applicants tend to drop out during the training. In San Jose, a site that does very little screening prior to training, many people drop out during the training, often after the first week of training. The first week of their training is similar to the orientation meeting that the other sites hold prior to training. Respondents in Boston and Miami report that fewer persons who begin the training process fail to complete it. In most cases, people who are dropping out choose to do so because they come to the realization that they are not emotionally equipped to care for a foster child. In Miami, workers noted that a few people are asked to drop out following a positive response on a criminal background check.

The three sites also varied considerably in the flexibility of their required training. In Boston, applicants are informed at the beginning that if they miss more than one training class they will need to retake the training from the beginning. In Miami and San Jose, adoption applicants may make up missed classes at trainings offered at different locations. On occasion, Miami will even arrange for in-home training of applicants who cannot attend group trainings.

One of the difficulties in developing and implementing adoption training is accommodating the different learning styles that participants may have as well as different perspectives. While some people want lots of detailed information early on as to what to expect, others want to ease into the training by focusing on more general topics related to foster care and adoption. Some people viewed the interaction with other prospective adoptive parents as a real benefit of the training, while others simply wanted written information they could review alone. A number of people discussed the difficulty of sharing such personal information with other participants they barely knew. The differences in people's learning styles were evident in their assessment of specific training exercises. Most people valued the role-playing and visualization exercises designed to get training participants to empathize with foster children waiting to be adopted, yet several people disliked this learning approach.

"But some of it I thought was interesting and useful and certainly the topics and then there was other times - like [when they said to] 'lean back and close your eyes and visualize yourself...' I am sitting in a room with people I don't really know that well, and it is hot and there is this awful incandescent lighting and to 
close your eyes and visualize. . you can't. It seemed a little forced to me." Adoptive trainee

"Everyone in our class- I don't think they expected to learn so much from the role play but they did and at the end of the class, they thought role playing was really great. Puts you in the role of a child being moved from home to home. Makes you understand." Waiting adoptive applicant

Almost all people found the guest speakers (e.g., foster parents, adoptive parents, service providers) that attended the training to be very helpful.

Workers and training participants also noted several group dynamic challenges. Both expressed the impact that people dropping out have on the rest of the group. Participants wanted to know why other people had left, including whether they were asked to leave. Workers wanted to protect the privacy of people who decided not to continue and to let trainees know that it is all right to decide that foster care adoption was not for them, but also to offer reassurance to those that remained that they could complete the process. Another group dynamic challenge was the differences in the backgrounds of participants. For example, many participants already had children and did not feel they needed to learn a lot about issues such as child development. However, workers noted that foster children were different than anyone's own biological children, and that good trainers can use these people to help "teach" the class by relaying their personal experiences. In addition, some participants felt like they were in competition with their fellow trainees, since they all wanted to adopt similar children.

"I found the class to be way too long. I guess they have to go to the least common denominator of people, maybe, but anyone who's parented before or who has a reasonable education, that class could have been wrapped up in 8 hours." Trainee

"It is such a process. Even for the rest of group, when one person leaves, it is kind of scary for the rest of the group especially if they are not explaining why they are leaving." Adoption worker

In all three sites, prospective adoptive parents and foster parents were trained together. ${ }^{17}$ Workers and administrators stressed the benefits of this approach, yet participants were often confused about the relevance of information for themselves, and some noted that the trainings focused too much on foster care issues and not enough on adoption. The main benefit of training foster and adoptive parents together, according to workers and administrators, is that participants get a better understanding of the entire system and where the different types of parents fit in. Yet prospective adoptive parents often felt like the trainings did not focus enough on adoption. In San Jose, adoptive parents were so dissatisfied with the training curricula that the child welfare agency added a class for them that focused solely on adoption issues.

"So they are actually starting to think about how their roles kind of work together and figure out what each of their roles are in this process, whether they are foster or pre-adoptive. . . the majority of the kids that are in placement that need permanent homes are in foster care - so it is important for them to see and work with foster parents, and be in partnership and work towards a transition for that child to move into their home." Adoption worker

\footnotetext{
${ }^{17}$ Except for those training held in Boston by Catholic Charities.
} 
"The one thing that was confusing about the PRIDE class is that classes are put together for foster, adoption is secondary. A lot of focus was on foster issue. I realize that it is a two-step process, you are a foster parent first and then you are an adoptive parent. But for people like us who are really looking at the adoption side, it did seem to focus more on the other process." Adoptive trainee

"Applicants in home study interviews would have gone through the whole training (PRIDE), but would tell us that they didn't understand the process or adoption wasn't really addressed." Adoption worker

\section{Homestudy Process}

In each of the sites, the home study process differs in its timing and intensity. The timing of the home studies varies, depending on the workload of those doing the home study and the length of time it takes prospective families to complete the application.

In Miami, the home study consists of two visits, each made by a separate individual. The first visit is structured to verify the information provided in the application and check the safety of the home; the second is a more detailed interview with the family. Because San Jose is moving toward requiring all potential adoptive families to first be licensed as foster parents, home studies are conducted by two individuals: foster parent licensing staff who do the "safety" home checks and home study workers who make the remaining visits. In San Jose, the number of visits made by the home study worker varies with the specific situation of the family. In Boston workers visit the families on separate occasions to interview each potential parent and again to interview both together. As in San Jose, the number of home visits in Boston varies with the specific circumstances of the family.

The completed homestudy documents look very similar in all three sites. They include approximately 20 pages of detail about the family. Issues covered included the home environment (some actually detailed the layout of the home, the ambience of the home); the neighborhood (single family, nicely kept, nearby schools, etc.); parental employment (where, for how long, salary); each prospective parent's family history, including discipline techniques and relationship with parents, siblings, and extended family; medical backgrounds; spousal relationship and past relationships; information about biological and other children in the home; type of child(ren) interested in adopting; and the homestudy worker's recommendation.

The relationship between the home study worker and the family is complex. Most workers felt there were several purposes for the homestudy, including gaining an understanding of the family in order to make a determination about its suitability as an adoptive family, learning enough about the family to be a successful advocate for it if the application is approved, educating the family about the types of children available, and probing the feasibility of expanding the range of types of children the family feels capable of taking. San Jose workers noted that it is the home study worker who develops the most personal relationship with the family and it is this worker with whom families feel the most connection.

"Well, it is almost like a little couple's therapy that we do, it is 'this is what I am hearing from you and this is what I am hearing from you ...." Adoption worker

It is this close, and sometimes long-term, relationship that complicates the role of the home study worker: 
"I think it's because in general we have two competing roles. We are social workers so I think for a lot of us our clinical training is to really help families and people work through issues, but our role as adoption recruiters is 'you need to have done that work before you get to me.' And I think for me, I have a really hard time with that - and when I am doing homestudies, and even as I am going through MAPP with families I have a really hard time not kind of going into that a little bit. Because I am asking these families to form a relationship with me, I am asking them to give me some trust, I am asking them to let go of some of their control and just let it go and see what happens - let's see where this takes us." Private adoption agency worker

Families also perceive inherent conflicts in this relationship. On the one hand, they know that the home study worker will be their most important advocate in finding a child and it is to their advantage to have this individual know a great deal about them. On the other hand, given the ambiguity of the decision-making process, families express concern about how honest they should be.

"No matter how comfy and clean you might make it (your home), an observer they can see something. And that is your biggest fear, it's like 'what are they looking at that I can't see?" Adoption applicant

"I think people have a misconception about what they think they can say that will make them not be approved or approved. I think they are afraid to tell us they have been in therapy in the past. When actually that might be a positive thing that you have reached out for resources and that you've gotten help when you needed it." Adoption worker

In general, families gave the home study high ratings. They tended to find the social workers professional and the questions relevant. Those few who described their experiences as disappointing attributed this to their dissatisfaction with the worker. In some cases they just didn't "connect" or felt the workers were not listening to what they were saying and were not attentive to their preferences. Their concern is that these workers would not be effective advocates for them. In other cases, they found the questions too intrusive.

"I did have a home study and I found it easy. They had read my life story on the way there and there were issues in there that I was open with. And they definitely had questions as far as infertility and all that, but they were fine with it. They asked the question and I said 'yeah I was in therapy and I resolved it and I am fine with it.' And they asked me if writing the life story was difficult and I said 'no I am past it all so it was easy enough for me to do.' And they did accept it all and move on to the next question." Adoption trainee

The hardest part for me was thinking back to my own childhood years. You remember your teenage years but it was really difficult to think about specific things way back. Like how I was disciplined." Adoption trainee

"She asked the same questions she had asked at our very first meeting, so I didn't understand the point of that. We didn't feel she was listening to anything we said. She wasn't taking notes or recording the interviews. That came into play later when she did our match. She didn't match us for what we asked for. We wanted two boys and she matched us with a boy and a girl. We said we didn't want a boy and a girl. She never really heard what we were telling her. When she came into our home, she was very 
fascinated that my husband was a tax accountant and talked for a half hour about that, but never really about us. It was very, very odd. I still don't feel comfortable with her representing us in a matching meeting because I don't think she knows our needs."

Adoption trainee

Agencies vary on whether they only complete home studies for families likely to be approved and have a child placed, families likely to be approved even if they are seeking a type of child the agency is unlikely to have, or all families, including those unlikely to be approved. Boston, for example, approves more homestudies than do other sites for families who seek the type of children the agency does not have. Miami and San Jose were less likely to approve a homestudy in which the agency does not actively try to place a child.

The primary reasons for not approving home studies included identification of mental health or marital problems, realization that couples had not yet resolved issues around infertility or miscarriages, or disagreement between couples on interest in adopting. In addition, individuals who appear to lack parenting skills or who rely on physical punishment were unlikely to be approved. Finally, families whose perceived underlying motives for adopting were suspect were unlikely to be approved.

"Some reasons a couple might not have their home study approved after training are: they have not resolved their infertility issues; divorce or split families; substandard housing; mental health issues; the kids in the family have expressed that they do not want another child. Everybody in the family has to be involved and on board." Private agency adoption manager

In some cases, however, workers report "getting a feeling" that the family has potentially serious issues and may not be an effective adoptive family, but they cannot delineate specifics. These families may be approved but may not have a child placed with them. Because we do not have specific information on the individuals in our focus groups, we have no way of knowing how much of the dissatisfaction expressed by applicants reflects an intentional slowing down of the process on the part of social workers concerned a family's fitness to adopt and how much reflects dissatisfaction with the process by families with whom social workers feel comfortable placing a child.

"If we can't deny them, because it (reason for denial) is not black and white, it is not so concrete sometimes, it's just that I have a feeling. If we can't deny them then what we do is, our home studies become creative. Read between the lines because there isn't enough to deny them." Adoption worker

Potential parents were unclear about the approval process. When asked about the purpose of the home study, applicants gave a variety of responses, including wanting to see if they were qualified, wanting to figure out what type of child they really wanted and could handle, and educating them about the children available. However, some applicants did not know that a home study might not be approved.

\section{Matching and Placement}

After an applicant completes the training and homestudy processes and the agency approves their homestudy, they are eligible to be matched with an available child. Perhaps more than any other phase of the adoption process, the matching and placement phase involves the most 
uncertainty and misunderstanding. While the preceding processes are somewhat concrete and prescribed (e.g., the training has 10 sessions and the applicant is expected to attend all of them), the matching process can vary considerably in length and the level of activity occurring. Up until this point, the assessment of the applicant was based on whether the prospective adoptive parent was appropriate to become an adoptive parent to a foster child, any child in the system. But from this point on, each applicant's strengths are assessed in relation to individual children available. The matching process becomes more personal-the applicant must now be "right" for a particular child in need of a home.

\section{$\underline{\text { Public adoption agencies are designed to find "families for kids" and not "kids for families" }}$}

In all the sites, adoption workers made it clear that the agency adoption process is designed to meet the needs of the children, not the adoptive applicants who want to adopt a child.

Applicants appeared to understand this as well and while many noted that of course, the process should be designed around the needs of the children, they would have liked to have a little bit more attention to their needs.

"We tell them that they're [applicants] here to meet our needs. Not to meet their needs. What we have is what you get. We're not a true agency for adoption, you can't come in and pick your kid. We have kids whose parents have abused and abandoned them. I used to tell them about having a Gerber baby, this is not what you're gonna get. We tell them they're there to make a difference in a child's life and to make a commitment. We have kids who are cocaine exposed, have issues, and bring baggage with them. So we need to know if they can help us." Adoption worker

"Here at DSS I am scratching at the doors, 'hey, I'm willing to take siblings, I want siblings!' So here I am and I'm not asking you to break the rules, I'm just asking you to lighten up a little bit and you jump instead of me. A little bit, not a lot." Adoption applicant

"We heard that they work for the child and not for the family so they [agency] are going to try and find a home for the child and not find a child for the home." Adoption applicant

"And we finally called the worker and she said, no, the parents chose someone else. And it was like, very cold. No sorry I didn't get back to you. First of all, I wanted to say you're treating us like we didn't get the color chair we wanted. Why didn't you call us? And then what really threw us off was when she said the 'parents' didn't choose us. We didn't know that they'd have input." Adoption applicant

\section{Agencies use different methods for allowing applicants to learn about adoptable children}

There were differences among the three public agencies with regard to how they expected applicants to "find" children they wish to adopt. In Boston, it was made clear by both applicants and adoption workers that applicants must be self advocates as they try to find a child they wish to adopt. Applicants are told to "market" themselves, be proactive by attending adoption parties, registering with the statewide adoption exchange, and watching the Sunday's child adoption recruitment program. The adoption administrators, however, made it clear that if staff had the time, applicants would not need to be so active in the search. Some applicants in Boston said they wanted the worker to be more of an advocate for them and that having the professional knowledge of the process as well as the knowledge of their family after weeks of interaction at training, the worker should be capable of representing the applicant very well. In Miami, some applicants had been successful in the past by getting to know foster parents of infants through 
informal support groups. With the staffing of a homefinder position, the applicants we spoke to in Miami made it clear that they felt their best chance for success was maintaining a good relationship with the homefinder.

"They [adoptive applicants] need to be advocating for themselves, if you sit back and wait for me to call you, you're probably never getting a kid. We're looking for families for kids, not kids for families." Adoption manager

"I consider myself an advocate and I consider a lot of families friends. I've found that I've become really close with the families and I will go to bat for them. I find you do bond with the families. You are the one in the agency they can come to, and they will because they're in a needy position." Homefinder adoption worker

"It was, before they had someone in that position, the homefinder's position, that after you finished training you were on your own." Successful adoptive applicant

"You get mixed messages. Because they told us that we needed to advocate because of the fact that there were less employees but yet when we did do that this social worker that we're working with said, 'No, don't call anybody, don't do anything.' Well what are you saying? First of all you told me that if I was interested to contact this particular agency." Adoption applicant

"So I think matching really depends on the family. And you have families who they could care less that we are recruiting for them because they're at every single adoption party and they are calling up social workers themselves and we were basically the vehicle to get the homestudy written. And then there are some families who are much more dependent on us to kind of go out and recruit for them." Adoption worker

"And it really is much more empowering if these families meet these workers, go out there and kind of advocate. We advocate for them too." Adoption worker

In San Jose, the process appears more agency-driven. Applicants were unable to view photos of the child until after the agency had provided them with background information about the child. Agency workers explained that they feared that if applicants fell in love with a child's photo, they would not be as open to hearing about the child's potential problems. While Miami did provide applicants with an opportunity to look at photos of available children, they did not approve of holding adoption parties though they had done so in the past.

"No, you never meet any children like that [at functions]. We thought we'd go in and look at a book of children but that's not the way it works here." Applicant.

"It's interesting because in our experience that's a piece of it that they don't tell you much about. . . it's like we fell off a cliff when we got to that point. We eventually learned that when they have a child up for adoption they want to place, they pass the child's information around internally and the matching workers will take a look at that and if they feel that they have a foster/adoptive parent who could be matched, they'll get together and have a meeting and present the options." Applicant.

"Our administration does not look highly on adoption parties where you have all the available children there and then people approved who want to adopt come and mingle 
with the kids. We've done it in the past and apparently some children have left feeling very hurt." Adoption worker

\section{Applicants are often frustrated by what they perceive as the secrecy of the matching process}

Applicants in all three of the sites visited were frustrated by the lack of information they received about the matching process. They viewed the matching process as vague. Some applicants noted that they became frustrated not by the process, but by their individual worker's disorganization or lack of sharing information. Other applicants expressed a close relationship with their worker but felt they were still unsure about how the matching process actually occurred.

Agency respondents readily acknowledged that it is difficult for applicants to fully understand or appreciate the complexities of the matching process. In fact, workers in one agency noted that there is a need for some evasiveness about the matching process because as a worker they did not want to disappoint their families by telling them each time they attempted a match and were not successful. In San Jose, workers noted that although they provide applicants with a lot of information about the matching process they knew that applicants remain confused.

“The matching process is a huge mystery. You don't know if you're being matched, or when, or if you were matched first or third until after it's happened." Applicant

“. . . it doesn't feel like there is a concrete process. . .there is some soft fuzzy area about matching and timing stuff that you have no control over and it feels a little scary, a little up in the air." Applicant

"I pictured it being a very dry process. How many bedrooms do they have? Is there a husband and a wife? Does someone stay at home? What are their finances? Almost something you would throw into a computer and it would rank you. But I get the sense from the way he [worker] described it that while that stuff is important there is also something the workers get from the interviews, a feeling about the families, beyond just what are their finances." Applicant

". . . they [waiting families] don't know what is going on behind the scenes. Workers do not know what to tell families. They don't want to lead them on, get their hopes up about a match they are working on. But at the same time, they [workers] don't want the families to believe that nothing is happening." Adoption manager

Adoption applicants and agency respondents both noted that the matching process was very subjective

The process by which agencies match children with adoptive applicants is by all accounts subjective. Different criteria have more or less importance depending upon the agency and individual workers involved. Some of the criteria mentioned during focus groups include single versus two-parent families, whether families had biological children or had previously adopted, whether the mother worked outside the home, and whether same sex couples were welcomed in the agency. In addition, whether agencies frequently placed children transracially, made interstate or interjurisdictional placements, and whether open adoptions were encouraged all affect the matching process. 
Agency respondents and applicants discussed how family structure affected the matching process. In each of the three agencies, single applicants could apply to become an adoptive parent. In two of the three agencies, same-sex couples could apply for adoption. In Boston, workers noted that single applicants and same-sex couples often get the children who are the most difficult to place.

"We tend to give single people and gays and lesbians - the non-traditional families - the most needy children. The ones with the greatest special needs, which we are setting them all up for failure when we do that." Adoption worker

"So it's kind of like, because traditional two parent families turn the special needs kids down so they [non-traditional families] are getting them." Adoption worker

However, in San Jose it appeared that two-parent families in which one parent was at home during the day were often thought to be the best for needy children.

"I'm a stay-at-home mom and that makes a big difference. Everyone wants a stay-athome mom. Yes, social workers who are women who work themselves, yes, they said they want the ideal world." Successful adoptive applicant

"If a child would have trouble attaching, they'd want them with a stay-at-home mom, stuff like that, where sometimes that would come into play. They didn't want the kid in daycare, wanted them home with the family." Successful adoption applicant

In addition, a topic discussed in each of the three sites was whether or not childless applicants were given priority. Workers disagreed about whether applicants who had already adopted should be able to adopt again before others waiting to adopt their first child. There was also some mention that race was a determining factor.

"From talking with our social worker and the classes, they wanted to give people without children first shot. And I completely understand that." Successful adoption applicant

"I hear some people say they want another child after adopting one. I get complaints from families who were given the run-around and told other families need one child before they can have two." Adoption worker

"To go back to these families who already have a child when there are other families waiting, I'm going to lose all the ones who just came in the door. My families are desperate." Adoption worker

"If we're referring to African American children, that's different. We recycle families because we have some who've had three adopted children. We ask if they can take another. That's different and not a problem. If they want another one, they're going to get another one." Adoption worker

Applicants in each of the three sites discussed the potential impact of not accepting the first child the agency matches with you. Applicants wondered if this would be held against them in subsequent matching. 
"Yes, you worry, if I say no [to a presented child], am I on the out? Do I lose my chance?" Successful adoption applicant

"Our social worker was really great about that. He would tell us, it's okay to say no if it doesn't work out. So that was really nice. But I figured because we were older and had three other kids we would 'get the rejects'. That was my guess." Successful adoption applicant

It was also apparent that adoption workers often make assumptions about the type of child a family would be willing or able to parent based on their past experiences or preconceived notions of parenting. One example of this was a family who had requested a pre-teen girl and a worker, upon hearing that the "matched" girl was acting out sexually, made the decision that the "old-school" father would not be able to handle this girl. While this may well have been the outcome, according to this worker the information was never presented to the family. In another example a worker noted a six-year old child with a disability and noted that families are not going to be willing "to take that on." There may well be many cases in which information about a particular foster child is not presented to a potential adoptive family because of a worker's assumptions.

"It [matching] is very subjective, is what we're saying. Depends on what office you are in, who the social worker is, who the supervisor is, it is all very subjective." Adoption worker

"I think it depends on each worker. Each worker carries their own biases. There are some who aren't as open to certain families as others. It's unfortunate because it doesn't necessarily have to do with the best interest of the child. It has to do with personal issues of the worker." Adoption worker

While agency respondents in all three sites professed a willingness to place children transracially and transculturally, applicants often did not feel the agency was neutral on the subject. In both Miami and San Jose, transcultural placements appear to be happening on a frequent basis. In fact, adoptive applicants appear quite willing to adopt a child of a different ethnic background from their own. However, the same did not hold true for transracial placements. Many applicants (either because of their own prejudices or because of information gained through the educational component of the adoption process) did not have a positive view of transracial placements. Applicants in San Jose discussed the impact of the training on their views of transracial adoptions. Most expressed the belief that after viewing a film during the training, they became more hesitant to "take on" transracial parenting.

"The way I look at it, they're already going to come with problems, and now you're adding an extra one." Adoption applicant

"Cause if I adopted a black child I'd like to see them continue their culture and I don't know anything. Of course I could do the homework and all that stuff, I guess. But I don't think it'd be comfortable for either one of us." Adoption applicant

"I think I could adopt a Hispanic child because I was raised with that. And I just don't think l'd have a problem with that. But there aren't a lot of white children in the system here. But I couldn't adopt a black child. I think that'd be a big problem." Adoption applicant 
"Going from adopting a Chinese baby and then seeing what's here, I just envisioned us taking home an African American little boy. After watching the movie, I just thought no. Out of the whole session, that is the one thing that didn't leave a good taste in my mouth. They did a film and it was very powerful to me. I came away with the thought that maybe not (adopt a child of another race)." Adoption applicant

“They're supposed to be colorblind but they're [agency] not." Adoption applicant

"We encourage transracial adoption and we do have some, but it's few and far between." Adoption worker

"I work with the Hispanic families and I know they want to adopt 0-2 years old, white or Hispanic. Maybe they'll go bi-racial but there are grandmothers in these Hispanic families who are very family-oriented and they [applicants] say, "what is my mom going to say if I bring a child of this race into my home.' It's a lot of that." Adoption worker

Workers expressed some "territorialism" with regard to their children and families. Adoption managers noted that developing trust in other adoption agencies' practices and developing relationships with individual workers in other agencies was key to making interjurisdictional or interstate placements. One barrier to such placements is requirements for birth parent visitation during foster care-adoption placements. When efforts are still being made to reunify the child with the birth parent, policies dictate how far the child can be placed from the birth parent.

According to adoption workers in one site, the trend toward allowing some sort of contact between the birth parent and the child, i.e., open adoption, has not been wholeheartedly supported by some applicants. It was noted that contact with the birth parents can be legally mandated; however, contact with siblings is encouraged but not mandated. Workers expressed concern about applicants who, early in the process, profess a desire to have their child visit his or her siblings, but change their minds after the adoption is finalized.

"Sometimes you just feel like they [adoptive applicants] are just 'yessing' me, but they are going to go on with their lives and not maintain the sibling relationship. So you don't always feel good about it for the long term." Adoption worker

"At the very beginning, no problem. Most of the time at the very beginning everyone wants to maintain contact with the birth mother, everything open. As time goes by and they lose some of the protection of the agency, the social worker's no longer there, they tend to be a little more leery." Adoption worker

“. . . They [applicants] have this real willingness up front to cooperate, comply with the agency in terms of allowing some birth parent contact. They think that not complying will be a barrier to having a child placed in their home. But as time goes by they just get more bold or they understand better more of the process and how they can manipulate things." Adoption worker

Applicants who expressed less frustration often had a close working relationship with their homestudy worker. Applicants who felt that their worker really knew who they were and what type of child they wanted to adopt were least likely to feel frustrated by the process. They felt their worker would represent them well in the matching process.

Applicants often change their minds about the type of child/ren they want to adopt 
An important aspect of the homestudy process is the adoptive applicant determining the type of child or children they wish to adopt and the type of child or children the agency worker feels is appropriate to place with the family. However, as the adoption process proceeds, many applicants make modifications. For the most part, applicants broadened the criteria for the types of child/ren they were willing to adopt. Some of this broadening appears to be the result of applicants feeling empowered through the training to take on a sibling group or more challenging child (i.e., older or with disabilities). However, an even larger portion appears to be due to workers intentionally persuading applicants to widen their criteria in order to better their adoptive placement odds.

"In the end it is flexibility and commitment that differentiate those [applicants] who are successful and those who are unsuccessful." Adoption manager

"It's much better than it was when I started years ago. We do a lot better job educating, training; there's a lot more community college training, support groups [for adoptive parents]. It's just a whole different system than it was 20 years ago. Twenty years ago it was "get the child adopted at any cost", "stretch the family as far as you could stretch them." Those things just don't work and we found that out. I've gone completely the other way and if it feels uncomfortable at all with a family, let's move on, try another child. Let's not even pursue placing this child. I've been here long enough to see children whose biological parents were mentally ill develop schizophrenia or bi-polar disorder themselves and these were cute little toddlers when I placed them and now they have major issues. The parents love those kids, but it's a lifelong ordeal for them, so I'm going to say if a family feels uncomfortable about adopting a child. I respect that." Adoption worker

Applicants may also end up accepting a sibling group if one member of the group matches their criteria. For example, a family in search of an infant may accept a sibling group if one member is an infant. Workers had differing views on whether they wanted applicant families to modify the type of child/ren they were willing to adopt. For some workers, family flexibility was important and determined which applicants were successful. Other workers worried that applicants who modify the criteria may be trying to get a placement sooner and not be prepared to care for a sibling group or child older than they had originally wanted. Workers in Boston noted that often times these were the adoptive families that disrupted - where the children were later removed from the family and returned to state care. In addition, workers in Boston noted that they felt applicants often get rushed to make a decision during the matching process and rushed decisions often led to disruptions as well.

"There is a sibling group and they [applicants] fall in love with the five-year old so they take the nine-year old too. . and you have an uneasy feeling that maybe we have closed the case, but that family is going to break up somehow." Adoption worker

"Well we were considering one child but now may accept siblings, if we can get one child the age that I want. I want from infant to two or three years old but I'm willing to take a sibling, an older sibling so I can have the younger one too." Adoption applicant 


\section{Section 4}

\section{Adoption Applicant Placement Patterns and Timing in the Three Sites}

In order to gain a better understanding of the placement process, we analyzed data from 132 case records of adoption applicants who had completed a home study. Of the 132 case records examined, 69 adoption applicants (52 percent) had had a child placed with them at the time of our review. Our conceptual framework for the analysis hypothesizes that several factors influence the success of applicants seeking to adopt children from foster care (Figure 1). These factors include applicants' resources, their past experiences with the foster care system, their suitability to be adoptive parents (as judged by the adoption agency), their willingness to adopt certain types of children, and their persistence. In addition, site specific variables may influence applicants' success.

\section{Figure 1}

\section{Conceptual Framework of Factors Influencing Success of Adoption Applicants ${ }^{18}$}

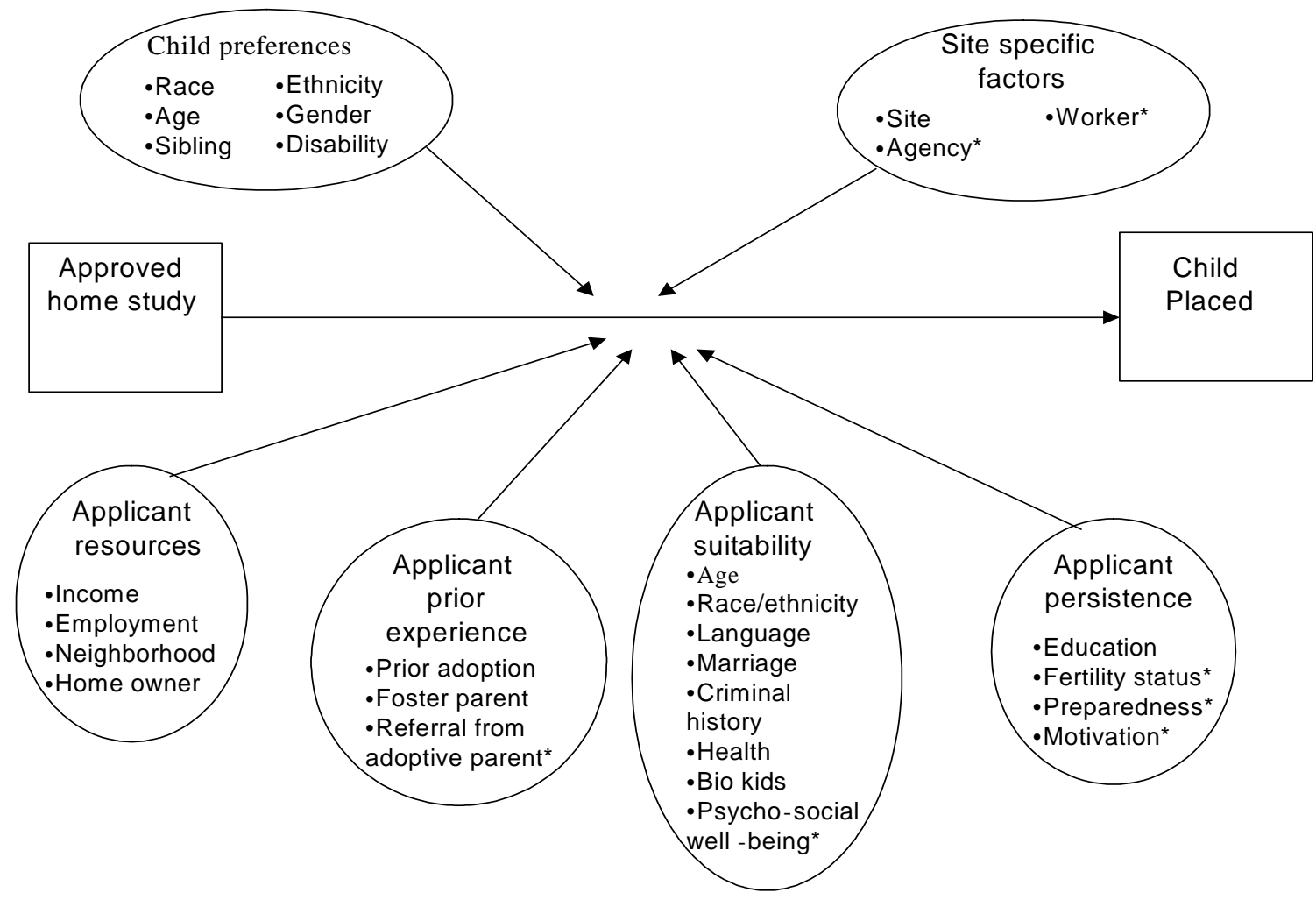

The characteristics of adoptive applicants who had a child placed with them differed from those who did not (Table 4). On average, applicants in Boston and San Jose were far more likely than

\footnotetext{
${ }^{18}$ Note: Asterisks identify variables for which data are not readily available in agency case records.
} 
those in Miami to have had a child placed with them. Applicants of Hispanic origin and those who spoke Spanish were less likely to have had a child placed. ${ }^{19}$

Table 4

Sample Characteristics

\begin{tabular}{|c|c|c|c|c|}
\hline Characteristics & $\begin{array}{c}\text { All } \\
\mathrm{N}=132\end{array}$ & $\begin{array}{l}\text { Child Placed } \\
\qquad N=69\end{array}$ & $\begin{array}{c}\text { Child Not } \\
\text { Placed } \\
\mathrm{N}=63\end{array}$ & $\begin{array}{l}\text { Total } \\
\mathrm{N}=132\end{array}$ \\
\hline \multicolumn{5}{|l|}{ County } \\
\hline Miami & 17 & 9 & 91 & $100 \%$ \\
\hline Boston & 39 & 60 & 40 & $100 \%$ \\
\hline San Jose & $\frac{44}{100 \%}$ & 62 & 38 & $100 \%$ \\
\hline \multicolumn{5}{|l|}{ Race } \\
\hline Black & 7 & 50 & 50 & $100 \%$ \\
\hline White & $\frac{93}{100} \%$ & 52 & 48 & $100 \%$ \\
\hline Hispanic ethnicity & $26 \%$ & 35 & 65 & $100 \%$ \\
\hline Speaks Spanish & $12 \%$ & 31 & 69 & $100 \%$ \\
\hline Married & $77 \%$ & 5 & 42 & $100 \%$ \\
\hline \multicolumn{5}{|l|}{ Years married } \\
\hline $0-5$ & 32 & 64 & 36 & $100 \%$ \\
\hline $6-10$ & 29 & 50 & 50 & $100 \%$ \\
\hline $11+$ & $\frac{38}{99} \%$ & 52 & 48 & $100 \%$ \\
\hline Has criminal history & $15 \%$ & 35 & 65 & $100 \%$ \\
\hline Has biological children & $40 \%$ & 51 & 49 & $100 \%$ \\
\hline Has medical condition & $21 \%$ & 46 & 54 & $100 \%$ \\
\hline Has college education & $89 \%$ & 54 & 46 & $100 \%$ \\
\hline Has adopted children & $5 \%$ & 29 & 71 & $100 \%$ \\
\hline Ever been a foster parent & $10 \%$ & 31 & 69 & $100 \%$ \\
\hline \multicolumn{5}{|l|}{ Age children willing to consider } \\
\hline $0-3$ & $84 \%$ & 56 & 44 & $100 \%$ \\
\hline $4-7$ & $64 \%$ & 49 & 51 & $100 \%$ \\
\hline $8+$ & $26 \%$ & 48 & 51 & $\begin{array}{l}100 \% \\
100 \%\end{array}$ \\
\hline Any gender preference & $37 \%$ & 52 & 48 & $100 \%$ \\
\hline Willing to adopt black child & $44 \%$ & 55 & 45 & $100 \%$ \\
\hline Willing to adopt Hispanic child & $84 \%$ & 55 & 45 & $100 \%$ \\
\hline Willing to adopt sibling group & $54 \%$ & 56 & 44 & $100 \%$ \\
\hline Willing to adopt large sibling group & $6 \%$ & 0 & 100 & $100 \%$ \\
\hline Mean time from application to & & & & \\
\hline homestudy & 7.1 months & 7.7 months & 6.6 months & \\
\hline Mean age of oldest applicant & 42.7 years & 42.7 years & 42.8 years & \\
\hline Median Annual income & $\$ 82,000$ & $\$ 91,000$ & $\$ 75,000$ & \\
\hline $\begin{array}{l}\text { Percent of homes in zip code under } \\
200 \text { percent of FPL }\end{array}$ & $20 \%$ & $17 \%$ & $23 \%$ & \\
\hline
\end{tabular}

${ }^{19}$ This may be the result of Miami's disproportionately low placement rate 
Recently married applicants were more likely to have had a child placed with them than those married for longer periods of time; however, it is unclear from the data whether these are initial or subsequent marriages. Applicants who had a child placed had higher median incomes and came from less-poor neighborhoods.

Surprisingly, there was not much difference in the number of applicants who had a child placed when taking into account whether applicants had biological children, a college education, or were willing to take children typically considered harder to place. Also surprising, while there were a relatively small number of them, applicants who had adopted a child in the past and those who had previously cared for foster children were less likely to have a child placed. As expected, applicants with a criminal history or a medical problem were less likely to have a child placed with them.

In our multivariate analyses we use Cox proportional hazard models to predict having a child placed among our study sample after the completion of a home study. Table 5 shows the hazard-ratio coefficients of our model and whether they are statistically significant. A hazard ratio greater than 1 indicates a higher "risk" or likelihood of placement, while a ratio less than 1 implies a lower "risk" or likelihood. For a categorical variable, the ratio corresponds to the multiplicative change in the hazard of placement associated with a particular value of the variable relative to the comparison category for that variable. For a continuous variable, the hazard ratio shows the multiplicative change in the hazard of placement related to a 1-unit increase in the value of that variable.

We selected variables for the multivariate analyses based on our conceptual model of factors that may influence whether adoption applicants will have a child placed with them, as well as variables that appeared to be significant in the bivariate analysis. We assessed multicollinearity of the variables before putting them into the multivariate model and excluded collinear variables. For 21 of 132 cases included in the analysis, we knew that an adoption applicant had had a child placed with them, but we did not know the exact date. Models run without these cases and models with these cases with the date of data abstraction used as the placement date produced the same results. In addition, some of the case records did not contain data for all the variables used in the multivariate analyses. We handled missing data in two different ways, depending on the variable. For variables related to whether the applicant had a criminal history or medical problem, or was willing to adopt different types of children, we assumed that if such fields were left blank, the applicant did not have a problem or was not willing to adopt certain children. For all other variables we imputed missing data by including the mean of that variable in the remaining sample. Models were run with and without dummy variables for imputed variables and the results did not change.

Our results show that there are a few variables that predicted placement among our sample. The locality in which an applicant sought adoption was significant and had a large impact on whether the applicant had a child placed. In addition, married applicants were more than 4 times as likely as non-married applicants and applicants with a college education were 2.7 times more likely than those without a college degree to have had a child placed with them. Applicants who expressed a willingness to adopt a sibling group were more than twice as likely to have a child placed with them. Somewhat surprisingly, applicants who expressed a willingness to adopt an older child (8 and over) were less than half as likely to have had a child placed with them. 
Table 5 Cox Hazard-Rate Model of Adoption Placement

\begin{tabular}{lc}
\hline Characteristic & Hazard Ratio \\
\hline County & 1.000 \\
$\quad$ Miami & $7.468^{\star *}$ \\
$\quad$ Boston & $12.421^{\star \star *}$ \\
$\quad$ San Jose & .889 \\
Income & $4.311^{\star *}$ \\
Married & $.952^{\star}$ \\
Years married & .978 \\
Age of oldest applicant & .774 \\
Has criminal history & 1.620 \\
Has biological children & .853 \\
Has medical condition & $2.700^{\star}$ \\
College-educated & \\
Oldest age child willing to adopt & 1.000 \\
$\quad 0-3$ & .627 \\
$4-7$ & $.441^{\star}$ \\
8+ & 1.624 \\
Willing to adopt black child & 1.395 \\
Willing to adopt Hispanic child & $2.237^{\star \star}$ \\
Willing to Adopt sibling group & \\
\hline
\end{tabular}

a If more than one applicant, this variable measures whether at least one had a college education. ${ }^{*} \mathrm{p}<.10 \quad{ }^{* *} \mathrm{p}<.05 \quad{ }^{* * *} \mathrm{p}<.01$ 


\section{Section 5}

\section{Making the System Work}

Finding permanent homes for waiting foster children is a priority for child welfare agencies. Despite recent gains, the number of children in foster care eligible for adoption far exceeds those who are successfully adopted each year. In addition, much of the recent gain in foster care adoption is a result of increased foster parent and relative adoptions. While many foster children find permanency with their foster parents or relatives, others must rely on people they do not know who wish to become adoptive parents.

It would be foolish to believe that states can rely on foster parents and relatives to adopt at a rate that would enable all waiting children to find permanent homes. First, there are not enough foster and relative homes to provide adoptive families for all waiting children. If child welfare agencies are going to be successful in significantly reducing the number of children who are waiting to be adopted, they will need to increase the number of general applicants who adopt. Second, despite the challenge of clearly distinguishing between foster and general applicant adopters given problems with available data, it is clear that general applicants do not shy away from adopting those children for whom placement is most difficult. Our research found that although general applicants are less likely than foster or relative parents to adopt a child defined as having special needs, the children they adopt are very similar to those adopted by foster parents.

Policymakers seeking to increase general applicant adoptions must determine why there are not currently more general applicant adoptions. Are there simply not enough people interested in adopting foster children? Is the problem a lack of effective recruitment? Or, do adoption seekers face barriers in the adoption process that agencies can attempt to remove or limit?

There is significant evidence to suggest that a large number of persons at least claim to be interested in adopting a child. It is less certain how many persons are interested in adopting foster children. Our national survey of adoption managers suggests that there are approximately 240,000 calls each year from persons seeking to adopt children in foster care. However, we cannot determine what percentage of inquirers would both be willing to adopt children available and be approved as adoptive parents. As discussed earlier, in 33 of 38 responding states, adoption officials believe that there are enough persons interested in adoption, but not enough interested in adopting foster children. These officials argue that upon learning more about the children and the process, many of these individuals decide adopting a foster child is not for them.

The prevailing wisdom appears to be that additional adoption recruitment efforts are needed to do a better job of attracting persons who will complete the process. The federal government's Adopt US Kids Campaign is currently working with the Ad Council to implement such a recruitment strategy. Based on its own research, the Ad Council has determined that the main thing keeping potential adoption seekers away from child welfare agencies is fear, primarily fear of not being able to successfully parent the children waiting to be adopted. To implement a campaign to address such fears, child welfare agencies must walk a fine and difficult line. On the one hand, child welfare agencies want to reassure adoption seekers that they can in fact effectively parent children who have been abused and neglected. On the other hand, agencies do not want to minimize the challenges that foster children available for adoption present. Doing so may set both the adoption seekers and the children up for failure. This is not simply 
an issue for recruitment. Agencies must continue this balancing act through orientation and training.

Another challenge facing adoption recruitment campaigns is the consistent finding that most applicants are influenced to seek adoption as a result of a personal connection to the foster care system, including "word of mouth" advertising from someone they know who has successfully adopted. This does not mean that general recruitment campaigns are unlikely to have any impact. The decision to adopt is a complex, emotional, and personal decision that is likely to be made over an extended period of time. The likely, though currently unmeasured, impact of general recruitment campaigns is the additive impact they have on convincing adoption seekers to come forward.

Given the increase in the number of foster parents adopting, many states have been moving to require all adoption seekers to be licensed as foster parents and accept legal-risk children. Depending on who one asks, experts in the field will argue that this movement towards "fostadopt" adoption placements holds either great promise or significant pitfalls. The AFCARS data analyzed above demonstrate that foster parents are adopting some of the most difficult children in the system. Some will see this as a surprise, assuming that foster parents would only decide to adopt the youngest, easiest children for whom they care. However, it appears that familiarity with a child, getting to know the child's strengths and weaknesses and how to handle the challenges, leads to the love and commitment necessary to adopt. Thus, emphasizing foster parenting as a precursor to adoption may increase the number of potential adoptive parents for harder-to-place children. For adoptive applicants who do not want to foster a child, agencies may want to bolster opportunities to volunteer with foster children so applicants can better assess whether they are able to care for a foster child on a permanent basis.

However, requiring adoption seekers to become foster parents may also alienate many potential applicants. Many argue that there are people who would make exceptional adoptive parents but simply cannot live with the uncertainty associated with fost-adopt placements. In addition, some minority adoption leaders argue that the movement to force people interested in adopting to first become foster parents is a detriment to attracting minorities. Many minorities want to save a child from foster care - not be part of the system they feel is unjust. In addition, minority leaders have argued that the focus on foster care adoptions is at least partially to blame for the large numbers of transracial adoptions. While our analysis of AFCARS data above suggests that this fear is unfounded, additional research is needed to determine how such an emphasis affects the types of persons seeking to adopt. Moreover, future research should examine whether adoption disruption and dissolution rates are lower for foster parent adoptions.

Many adoption experts argue that the reason more children are not adopted from foster care has less to do with recruitment than it does with retention. A key purpose of this study was to better understand the attrition of adoption applicants. It appears that much of the attrition of adoption applicants is good attrition. That is, some people fail to complete the process who are not ready or appropriate to adopt foster children. Nevertheless, this study identified front-line adoption practices that may contribute to some appropriate adoption seekers failing to follow through with the process.

It appears that the vast majority of persons who contact child welfare agencies about adoption drop out early in the process, many without even attending an orientation meeting to learn more about the process. Most of the people who opt out this early in the process are probably unlikely to adopt foster children regardless of how the agency approaches them. However, given the frustration about initial contact expressed by many people who nevertheless decided 
to pursue adoption, it may be that the important variable "screened in" during the initial contact is tolerance for frustration. The findings from this study support earlier work that suggests that many adoption seekers have difficulty accessing people and/or information to help them through the process. Our case studies in three cities found that applicants often face difficulty making contact with the public child welfare agency. While agency staff try to respond quickly to initial inquiries, many callers do not reach a staff person directly and must leave a message and wait for a return call. Many applicants said this was a frustrating experience. It is difficult to ascertain how many prospective parents may drop out due to inadequacies at the front end. Our focus groups consisted of applicants who were still active in the process. Many applicants and workers we spoke to noted that individuals unable to deal with these small frustrations would never be capable of adoptive parenting. Other participants, however, noted that these frustrations make prospective parents feel unwelcome and unneeded. Many expressed dismay that after hearing about the overwhelming need for adoptive parents, their calls to the agency went unanswered. Additional research is needed to examine whether better client relations at the front-end of the system would increase the number of families that complete the process and adopt a child.

Those who make it through the front door may still be turned off by the process and decide not to pursue adoption through the foster care system. One of the most common complaints among those people who otherwise expressed satisfaction with their experience is that the agency focuses too much on the challenges they will face parenting children who have been abused or neglected and not enough on the supports available to them and examples of successful adoptions. A second common complaint is that the agency hides information from them. As discussed above, agency workers are reluctant to provide applicants with estimates of how long it may take for them to adopt a child, how often legal-risk placements disrupt, the likelihood that a child will have a significant and long-term problem attaching, etc. It is unclear whether agency workers do not want to mislead adoption applicants or inflate their hopes or whether, based on their experiences, they genuinely cannot estimate the time it will take. Whatever the reason, the result is that many adoption seekers believe the agency is being non-responsive. It is noteworthy that many focus group participants who were generally satisfied with their experience still felt that the agency did not provide them with accurate information about this part of the process.

In all sites, the relationship the applicant had with the home study worker was very important. A good relationship with an adoption worker could mean a satisfied customer, regardless of whether a child was placed with the prospective parent. Other applicants were uncertain of their relationship with their worker and felt unable to be open and voice their fears or shortcomings. On the other hand, workers noted that they wanted to hear prospective parents' problems or fears as it provided an opportunity to discuss how the family might cope with the challenges of parenting. Many applicants noted that they felt they were constantly being judged and were uncomfortable with the imbalance of power. Workers were quick to note, however, that the home study process should be one of self-exploration for the applicant. Clearly, the desire to adopt a child must be very strong to overcome the insecurities and uncertainties inherent in the process.

The process by which agencies match children with adoptive applicants is by all accounts the most subjective part of the adoption process. Different criteria have more or less importance depending upon the agency and individual workers involved. Some of the criteria mentioned during focus groups include single versus two-parent families, whether families had biological children or had previously adopted, whether the mother worked outside the home, and whether same sex couples were welcomed in the agency. Results of our multivariate analyses of 
adoptive applicant data confirm what workers who participated in focus groups suspected, that married couples are more likely to experience a placement than single parents. In addition, those applicants willing to adopt a sibling group are also more likely to experience a placement.

Largely because of its subjective nature, the matching process was a period of uneasiness and confusion for many adoptive applicants. Workers vary in whether they are open with applicants about being presented for a match. Some workers openly discuss these presentations with their families while others do not want to disappoint their families by letting them know about matches that do not occur. Agencies also vary in the degree to which they will conduct home studies and train applicants seeking children unlikely to be found in the foster care system (i.e., healthy, young infants). For other applicants, it is less clear why they wait. Workers noted in focus groups that there are some families they approve but feel uncomfortable about and are reluctant to place children with. Thus, it is not surprising that many adoption applicants participating in focus groups believed agency workers did not advocate for them and that the agency was not actively trying to place a child with them. The difficulty is that because we did not have agency information on the waiting parents, we were unable to determine if those prospective parents concerned that the agency was not sufficiently diligent in trying to place a child with them were correctly, or incorrectly, perceiving a situation in which the agency was deliberately slowing down the process.

There are obviously a number of factors that we were not able to measure in our case record abstraction of persons who completed home studies. A key factor was the extent to which prospective parents' personality traits influence the likelihood that they will complete an adoption. Results from our focus groups indicate that both prospective parents and workers feel that proactive individuals were more successful in getting a child placed with them.

Yet, according to our focus groups and other adoption research we have conducted, it appears that the factor that may most influence whether a foster child is adopted is the attitude and perspective of the child's foster care worker. Foster care workers do not actively seek an adoptive placement for many children "free" for adoption. For example, a foster care worker may not believe an older child with behavioral issues is "adoptable." Once a pervasive attitude among workers, many agencies have attempted to change the mindset of foster care workers to believe that there is an adoptive home for every child, regardless of the challenges the child faces. Even if a worker believes that someone may want to adopt a child, the worker may not believe that a child is ready to be adopted. Workers may want to address some of the problems children face before attempting to find them an adoptive home in hopes that this will reduce the likelihood that the placement will later disrupt. Similarly, workers may also not pursue adoption when children express a lack of interest in being adopted. Foster care workers may also not believe that adoption is necessary. When a child is in a stable and loving foster home and the foster parents have decided against adoption, workers may feel that this placement serves the child's best interest more than a potential adoption by a stranger. Finally, foster care workers, who are typically overwhelmed by the demands of their caseload, may simply focus on the dayto-day crises that arise and not put forth the effort to help find an adoptive home for a child on their caseload that is in a stable placement.

\section{Recommendations}

Despite the impressive strides made in the wake of the Adoption and Safe Families Act of 1997, there are 80,000 waiting children in foster care who will not be adopted this year. For these children, the 240,000 Americans who will consider adopting from foster care this year are far too valuable a resource to waste through unnecessary barriers. We make the following 
recommendations with the belief that they will increase the retention rate of prospective parents in public child welfare agencies and make a considerable difference in increasing the number of families who adopt from foster care:

\section{Screening vs. Recruitment}

Throughout the adoption process, public child welfare agencies must strike a balance between recruitment of new adoptive parents and screening prospective parents who may be inappropriate.

- We recommend that in the beginning stages of the adoption process (initial contact, information meetings and orientation) the emphasis be placed on recruitment. Early in the process, the risk of alienating a potentially suitable adoptive parent outweighs the risk of allowing an inappropriate parent to begin the training process. During this time, prospective parents should have clear, written guidelines about the qualifications to adopt and grounds for being screened out.

- Wherever possible, agencies should separate the screening and training functions. There is an inherent conflict for parents in their dealings with adoption workers. On the one hand parents are asked, and generally want, to be open with their feelings as a necessary part of preparation for adopting a child. On the other hand, the adoption worker is their judge and has the power to grant or deny placement of a child. Applicants have stressed the importance of having a strong personal connection with one agency worker. Agencies should look to other means of screening out, including clear written guidelines that allow families to self-screen.

\section{First Contact}

- For most prospective adoptive parents, their first contact with a public child welfare agency to learn about adoption is very emotionally charged, frequently the culmination of losses such as broken relationships, infertility and medical problems. The first contact with an agency must be treated in this context. The first person to speak with prospective parents should be professional staff with a background in counseling and specialized training in adoption.

- Many prospective parents expressed frustration with the difficulty in reaching the right person with their first phone call. Agencies should have a specialized adoption hotline where a well-trained and friendly individual assures callers of a direct and immediate response.

- In addition to the inherent uncertainties, the adoption process is very confusing to many prospective parents. Parents expressed confusion about the roles played by different workers and the order of different steps in the adoption process. Agencies should provide families with a clear, written, road map of the adoption process ay the outset.

\section{Matching}

In terms of parental involvement, the process of matching children and families is handled very differently in the sites we studied. While there are good reasons to make matching a primarily 
worker-driven process, there are also reasons to involve parents in the process. Some parents expressed concern that their worker did not know them well enough to make a decision about a best placement or were not sufficiently aware of the parent's ability to expand beyond the initial profile of a child they would find an acceptable match. We recommend that all applicants receive clear information about the matching process and expectations of prospective parents.

\section{Training}

While recognizing the need to present prospective parents with a realistic view of the challenges they will face, applicants expressed a strong need for a more balanced perspective in the training sessions. Bringing adoptive parents into the training curriculum earlier would accomplish this goal, as would talking about support services available for adoptive parents.

\section{Buddy System}

Adopting a child from foster care is an inherently difficult process. For the prospective adoptive parent, adoption may be the most emotionally intense experience of their lives. But for an overworked and beleaguered child welfare agency, whose focus is the child, not the parent, the resources may not be available to provide the "hand-holding" that parents require. As one prospective parent put it, "this a very impersonal process for a very personal thing."

Ideally, the adoption process should be far more personal and intimate. Given the financial strains under which public child welfare agencies now operate, it is unrealistic to expect agencies to provide smaller classes and more personal service to prospective parents. One way to bridge this gap may be to make more use of families that have previously adopted. Many applicants found the input of adoptive parents to be of enormous help during training. By pairing new adoptive parents with established ones, many of the issues they raise can be addressed. Using parents who have previously adopted can make the process more personal, give families the realistic view of adoptive families they seek in training, and take some of the burden off overburdened agency staff.

\section{Further Study}

This study was designed to better understand how many people express interest in adopting children with whom they have no prior relationship and to begin to assess how and why many who begin the adoption process do not complete it. This study was largely exploratory in nature, raising more questions than it answers. There are important limitations to each data collection component that readers should be aware of while interpreting the findings.

- The main limitation of the AFCARS data analysis is that the data provided by the state child welfare agencies are of uncertain quality. In particular, it is not clear how often a child is adopted by a parent we would label as "general applicant" that may in fact be a relative or a former foster parent. Similarly, states may label persons as foster parents who may in fact be general applicants. This labeling of adoptive applicants is made even more problematic by the fact that in some states, adoption seekers are encouraged to become foster parents to increase their chances of adopting, or become foster parents between the time of placement and finalization in order to receive subsidy payments. 
- Our national survey of adoption managers provided useful information on the number of adoption inquirers and the number who continue through the process. However, these data are, by states' own admission, of questionable accuracy. Moreover, estimates of the percent of persons who drop out between points in the process were sometimes based on the individual adoption managers' impressions rather than hard data.

- The case studies of adoption practices provide rich qualitative information that provides an excellent context within which to understand the data collected from other methods. However, the persons interviewed and the focus group participants were by no means selected to be representative of adoption workers or person who have inquired about adoption.

- The case record abstractions were limited by the accuracy and completeness of the data available in the case records. Moreover, while the records were selected randomly, they were not selected randomly from the pool of all available case records of persons who completed a home study.

- Finally, a major limitation is that we only studied people who had at least attended an orientation meeting; we were unable to study the vast majority of individuals who call for information but do not take the next step. We have documented both a steep drop-off between initial call and attendance at an orientation meeting and frequent difficulties callers have during their initial contact. The question of the number of people who are lost as potential adoption parents because of a bad experience during their initial contact is worth further study.

\section{Conclusion}

The above limitations not withstanding, our findings support the contention that any effort to increase the number of waiting children who are adopted must focus not only on improving recruitment efforts but also on improving elements of the adoption process. Results of this study provide detailed information about a number of different aspects of the adoption process from a variety of data sources. Overall, most of the prospective adoptive parents we spoke with in our focus groups had a positive experience with their public agency. Frustrations occurred most often at the beginning and end of the process--when applicants were first trying to contact the agency for information and after completing the home study and waiting for a match. To some extent, agency resources play a role here. Licensed social workers are needed to conduct the trainings and home studies. Answering the many calls received may seem like a task that less trained or skilled professionals can handle. However, as we learned during our focus groups, miscommunication or mishandling these calls at the outset certainly affects how applicants view the agency. Since word-of-mouth is such a large recruitment tool, customer relations are extremely important. Indeed, greater emphasis on maintaining good communication with parent applicants throughout the process appears likely to increase the number of successful adoptions of foster children. 


\section{References}

Adoption and Foster Care Analysis and Reporting System, 2003.

Barth, R.P., Brooks, D., and lyer, S. (1995) "Adoptions in California: current demographic profiles and projections through the end of the century," Executive Summary. Berkeley, California: Child Welfare Research Center.

Chandra, Anjani, Abma, Joyce, Maza, Penelope, and Bachrach, Christine. (1999) "Adoption, Adoption Seeking, and Relinquishment for Adoption in the United States," National Center for Health Statistics, Advance Data 306: 9.

Day, D. (1979) "The adoption of Black children," Lexington, MA: D.C. Health.

Family Impact Seminar (1997). Finding Families for Waiting Kids: The Challenge of Special Needs Adoption in the 90's and Beyond. Washington, DC: Family Impact Seminar

Festinger, Trudy and Pratt, Rachel. (2003) "Retaining Interest: A Look at New York City's Recruitment of Adoptive Parents for Waiting Children."

Festinger, T. (1972) "Why some choose not to adopt through agencies," New York: Metropolitan Applied Research Center.

Gilles, T. and Kroll, J. (1991) "Barriers to same race placement," St. Paul, MN: North American Council on Adoptable Children.

Hamm 1997 Hamm, Wilfred. (1997). "Guide for effectively recruiting African-American adoptive families," Journal of Multicultural Social Work, 5(3/4): 139-149.

Harvard University Kennedy School of Government. (1988). Finding Black Parents: One Church, One Child, Boston, Massachusetts: The President and Fellows of Harvard College.

Herzog, E., Sudia, C., Harwood, J., \& Newcomb, C. (1971). "Families for black children," Washington, DC: U.S. Government Printing Office.

Hollingsworth, Leslie Doty. (1998) "Promoting Same-Race Adoption for Children of Color," Social Work, 43(2): 104-115.

Hollingsworth, Leslie D. (2002), "A content analysis of reasons given by African American adoption-seekers regarding their decision not to adopt," African American Research

Perspectives, 7(1): 226-236

Lakin, D. and Whitfield, L. (1997) "Adoption recruitment: Meeting the needs of waiting children." In R. Avery (1997). Adoption and special needs children (pp. 107-126). Connecticut: Auburn House.

Princeton Survey Research Associates (for The Evan B. Donaldson Adoption Institute). (1998) Benchmark Survey on Adoption: Report on the Findings. Washington, D.C.: Princeton Survey Research Associates, October 1997

Rodriguez, Pereta; and Meyer, Alan S. (1990) "Minority Adoptions and Agency Practices," Social Work, 35(6): 528-531.

Rosenthal, James; Groze Victor; and Curiel, Herman. (1990) "Race, Social Class, and Special Needs Adoption," Social Work, 35(6): 532-539

United States State Department (2004) Immigrant Visas Issued to Orphans Coming to the U.S.http://travel.state.gov/orphan_numbers.html (accessed January 9, 2004). 


\section{Appendix A}

National Survey of State Adoption Agencies: Understanding the Attrition of Adoption Applicants 


\section{National Survey of State Adoption Agencies: Understanding the Attrition of Adoption Applicants}

The Urban Institute and the Kennedy School of Government at Harvard University are conducting a study to better understand the experiences of adoption applicants. While we are particularly interested in adoption only applicants (persons who express an interest in adopting a child out of the public foster care system with whom they do not have a prior relationship), the questions address all adoption applicants. This study, funded by the David and Lucile Packard Foundation, is the first ever that seeks to obtain national data on adoption applicants, including the number of completed applications, the number of applicants who complete a home study, the number of children adopted and the average waiting time for prospective adoptive parents. Nationally, the level of interest and attention paid to adoption issues has increased significantly since the passage of the Adoption and Safe Families Act. However, policy makers lack concrete information to understand the challenges faced by adoption agencies and to make decisions about future policy directions.

We recognize that you receive many surveys asking you to take time away from your primary responsibility of helping children find loving, permanent homes. We have coordinated with a number of organizations including the National Association of Adoption Mangers to ensure that no other organization has, or plans to collect, these data. In addition, based on conversations with adoption managers in several states, we realize that most states do not collect these data on a regular basis. However, adoption managers we spoke to thought that any information that documented the attrition of adoption applicants would be useful. Thus, we ask that you provide whatever information you can.

Based on pilot testing with other states, we estimate that this survey will take no more than 30 minutes to complete. We hope you agree with us that the benefits from completing this survey outweigh the burden we are placing on you. If you have any questions about this survey please do not hesitate to contact Rob Geen at (202) 261-5822 or rgeen@ui.urban.org.

Please mail or fax completed surveys to Rob Geen by May 17, 2002

The Urban Institute

2100 M Street, NW

Washington, DC 20037

Fax: (202) $452-1840$

If you would prefer an electronic copy of the

survey that you can complete and return via e-mail, please e-mail Rob Geen (rgeen@ui.urban.org). 


\section{Instructions}

Please answer all questions: Partial data are better than no data, so please try to answer as many questions as you can. If you cannot provide an estimate, please write N/A (not available).

Please provide copies of adoption applications and policies: Instead of asking you additional questions about the adoption process in your state, we would like to review copies of your application forms and policies. We would like to receive any written materials you have that describe the adoption process in your state including eligibility guidelines, information provided to prospective adoptive parents, home study forms, and agency policy and procedures manuals.

Definitions: We recognize that states' adoption practices vary greatly and that states use different terminology for their activities. We have defined the terminology we use in the questions that follow. If you are unable to provide answers that meet these definitions, please provide whatever data you can and note how your answers reflect different definitions.

\section{State Adoption Data}

The following questions ask for data on adoption applicants. We are also asking that you attempt to differentiate between foster parent and relative adoptions and adoptions in which the applicant did not have a prior relationship to the foster child. Two persons seeking to adopt a child together should be counted as a single applicant.

1. How many children are currently (or as of _______ _insert date\}) free for adoption (children whose birth parents have relinquished (or had terminated) their parental rights)?

Children

1a. Are youth with a permanency goal of independent living/emancipation included in this number?
a Yes
a No
口 Don't know

2. Please provide an estimate (monthly or yearly, specify below) of how many potential adoption applicants request information (include calls to your state adoption exchange, regional exchanges, calls to private agencies with which you contract, and calls directly to your agency) about adopting a child from your state's foster care system.

$$
\text { (estimated \# of applicants requesting information) }
$$

Time period upon which this estimate is based
$\checkmark$ One year
口 One month
口 Other (specify) 
3. In your opinion, approximately what percent of individuals requesting information go forward with the adoption process, either attending an orientation session or completing an application? In your estimate, please include persons who decide to become foster parents so that they can improve their opportunity to adopt.

- Less than 25 percent

a Between a 25 and 50 percent

a More than 50 percent but less 75 percent

a More than 75 percent

Of these individuals who go forward, approximately what percent become foster parents so that they can improve their opportunity to adopt?

a Less than 25 percent

a Between a 25 and 50 percent

a More than 50 percent but less 75 percent

- More than 75 percent

4. Please provide your best estimate of how many adoption homestudies your agency (and private agencies under contract with your agency) completed during the past year (or month, please specify below) (estimated \# of adoption homestudies completed)

Time period upon which this estimate is based

a One year

a One month

○ Other (specify)

Of all the individuals who complete an initial adoption application, approximately what percent complete the home study process?

ㄴ Less than 25 percent

- Between a 25 and 50 percent

- More than 50 percent but less 75 percent

- More than 75 percent

5. In your opinion, approximately what percent of individuals being homestudied never complete the process?

Less than 25 percent

- Between a 25 and 50 percent

- More than 50 percent but less 75 percent

a More than 75 percent

In your opinion, what is (are) the primary reasons why individuals never complete the homestudy process? 
6. Please provide your best estimate of the number of children placed (in a year or month, please specify) in pre-adoptive homes by your agency (and/or private agencies with which you contract).

(estimated \# of children placed in pre-adoptive homes)

(estimated \% of these which are "adoption only," that is, they were not related to or the foster parent of the child placed)

Time period upon which this estimate is based

- One year

a One month

- Other (specify)

7. Please provide the number of children for whom adoptions were finalized (specify the time period below) by your agency (and/or by private agencies with which you contract). (estimated \# of finalized adoptions)

(estimated \% of these which are "adoption only," that is, they were not related to or the foster parent of the child adopted)

Time period upon which this estimate is based

口 One year

a One month

○ Other (specify)

8. Please describe any efforts or strategies you have used to track the number of persons who express interest in adopting a child out of the foster care system and whether they complete the adoption process. 


\section{Information About the Adoption Process}

1. Which if any of the following components of the adoption process are conducted by private agencies under contract with the state; please indicate whether none, some, most, or all of these components are contracted out:

\begin{tabular}{llccc}
\hline Type of Activity & \multicolumn{4}{l}{ Contract out to private agency (or agencies) } \\
\hline Recruitment (e.g., media campaigns) & $\square$ None & व Some & व Most & $\square$ All \\
Orientation meetings & $\square$ None & $\square$ Some & $\square$ Most & $\square$ All \\
Application process & $\square$ None & $\square$ Some & $\square$ Most & $\square$ All \\
Home study & $\square$ None & $\square$ Some & $\square$ Most & $\square$ All \\
Training & $\square$ None & $\square$ Some & $\square$ Most & $\square$ All \\
Matching (e.g., adoption exchanges) & $\square$ None & $\square$ Some & $\square$ Most & $\square$ All \\
Placement & $\square$ None & $\square$ Some & $\square$ Most & $\square$ All \\
Post-adoptive services & $\square$ None & $\square$ Some & $\square$ Most & $\square$ All \\
Other & $\square$ None & $\square$ Some & $\square$ Most & $\square$ All \\
\hline
\end{tabular}

2. How many public agency staff (Full Time Equivalents (FTEs)) work on adoptions?

FTES

3. Approximately how many FTE at private agencies under contract with your agency (working on adoption)?

FTES

4.

4. What types of recruitment activities does your state currently conduct (or have private, contracted agencies conduct)? Please mark all that apply.

- State adoption exchange

- Regional adoption exchange participation

- National Adoption Exchange participation

- Media campaigns (e.g., Wednesday's Child programs)

口 Church presentations (e.g., One Church One Child programs)

व Presentation booths (at malls or fairs)

- Adoption parties

other (specify)

5. In your opinion, which type of recruitment activity has proved most effective in your state? 
6. Are adoptive parent applicants and foster parent applicants trained together? Do they receive the same training?

- They receive the same training and are trained together

- They receive the same training but are trained separately

- They receive different training, usually as part of a group

- They receive different training, usually on an individual basis

7. What fees may adoption applicants be asked to pay during the adoption process, (e.g., if they adopted a foster child through a private agency under contract to the child welfare agency)? Approximately what percentage of applicants pay these fees?

\begin{tabular}{lcc}
\hline & Approximate Fee & $\begin{array}{c}\text { Percentage of adoptive } \\
\text { parents paying these fees }\end{array}$ \\
\hline Application & $\$$ & $\%$ \\
Training & $\$$ & $\%$ \\
Home study & $\$$ & $\%$ \\
Finalization & $\$$ & $\%$ \\
Other & $\$$ & $\%$ \\
\hline
\end{tabular}

8. Considering the types of foster children that are available for adoption in your state, which statement best describes adoptions of foster children in your state:

a There are enough persons interested and have applied to become adoptive parents

a There are enough persons interested, but not enough of them have applied

- There are enough persons interested in adoption, but not enough who are interested in adopting the types of children available through foster care

- There are not enough persons interested in adoption

\title{
Respondent Information:
}

\author{
Name: \\ Title: \\ Telephone: \\ Fax: \\ Email:
}

Thank you again for taking the time to complete this survey. Please do not forget to enclose your state's written adoption policies (i.e., eligibility guidelines), application forms, information provided to prospective adoptive parents, home study forms, and other agency materials related to adoption-only applicants.

\section{Please provide additional comments or clarifications.}




\section{Appendix B}

\section{RESULTS}

National Survey of State Adoption Agencies: Understanding the Attrition of Adoption Applicants 


\section{State Adoption Data}

The following questions ask for data on adoption applicants. Two persons seeking to adopt a child together should be counted as a single applicant.

1. How many children are currently (or as of ___ I__ _insert date\}) free for adoption (children whose birth parents have relinquished (or had terminated) their parental rights)?

1a. Are youth with a permanency goal of independent living/emancipation included in this number?
- Yes
a No
口 Don't know

\begin{tabular}{|c|c|c|c|c|c|}
\hline FREE & $\begin{array}{l}\text { Children } \\
\text { FOR ADOPTION }\end{array}$ & $\begin{array}{c}\text { Youth } \\
\text { Included }\end{array}$ & & ION & $\begin{array}{c}\text { Youth } \\
\text { Included }\end{array}$ \\
\hline AK & 350 & Yes & MS & 335 & Yes \\
\hline$A L$ & 707 & Yes & MT & NA & NA \\
\hline AR & 512 & No & NC & 1364 & No \\
\hline$A Z$ & 1088 & No & $\mathrm{NH}$ & 119 & No \\
\hline CA & 5409 & no & NJ & 2538 & No \\
\hline $\mathrm{CO}$ & 549 & Yes & NM & 389 & No \\
\hline CT & 125 & No & OK & 1046 & No \\
\hline DC & 210 & Don't Know & OR & 891 & No \\
\hline DE & 188 & Yes & PA & 4079 & No \\
\hline $\mathrm{FL}$ & 4216 & No & $\mathrm{RI}$ & 190 & Don't Know \\
\hline GA & 1888 & Yes & SC & 607 & No \\
\hline $\mathrm{HI}$ & 395 & No & SD & 105 & No \\
\hline IN & 1141 & Yes & $\mathrm{TX}$ & 3475 & No \\
\hline KS & 1620 & Yes & UT & 180 & No \\
\hline KY & 1035 & No & VA & 912 & No \\
\hline MD & 1192 & No & VT & 272 & Yes \\
\hline ME & 889 & Yes & WA & 1746 & No \\
\hline MI & 5920 & yes & WI & 395 & No \\
\hline MO & 846 & No & & & \\
\hline
\end{tabular}


2. Please provide an estimate (monthly or yearly, specify below) of how many potential adoption applicants request information (include calls to your state adoption exchange, regional exchanges, calls to private agencies with which you contract, and calls directly to your agency) about adopting a child from your state's foster care system.

\begin{tabular}{|c|c|c|}
\hline \multirow{2}{*}{\multicolumn{3}{|c|}{$\begin{array}{l}\text { Potential Adoption Applicants Requesting } \\
\text { Information } \\
\text { Annual Estimates }\end{array}$}} \\
\hline & & \\
\hline AK & & 75 \\
\hline DC & & 538 \\
\hline GA & & 8280 \\
\hline IN & & 18359 \\
\hline KS & & 3600 \\
\hline MD & & 750 \\
\hline MS & & 3750 \\
\hline $\mathrm{NH}$ & & 400 \\
\hline NJ & & 624 \\
\hline OR & & 75 \\
\hline PA & & 12760 \\
\hline RI & & 600 \\
\hline TX & & 21476 \\
\hline WI & & 775 \\
\hline \multicolumn{3}{|c|}{ Extrapolated Annual from Monthly } \\
\hline$A L$ & 400 & 4800 \\
\hline AR & 250 & 3000 \\
\hline CT & 65 & 780 \\
\hline DE & $12-15$ & 162 \\
\hline ME & 100 & 1200 \\
\hline NC & 300 & 3600 \\
\hline NM & 120 & 1440 \\
\hline UT & 600 & 7200 \\
\hline VA & 250 & 3000 \\
\hline \multicolumn{3}{|c|}{ Extrapolated Annual from "other" } \\
\hline$A Z$ & 325 (36 days) & \\
\hline $\mathrm{HI}$ & 300-400 (3 mos.) & 1400 \\
\hline KY & 2572 (8 mos.) & 3858 \\
\hline OK & 445 (6 mos.) & 890 \\
\hline \multicolumn{3}{|l|}{ NA } \\
\hline CA & & NA \\
\hline $\mathrm{CO}$ & & NA \\
\hline $\mathrm{FL}$ & & NA \\
\hline MI & & NA \\
\hline MO & & NA \\
\hline MT & & NA \\
\hline SC & & NA \\
\hline SD & & NA \\
\hline VT & & NA \\
\hline WA & & NA \\
\hline
\end{tabular}


3. In your opinion, approximately what percent of individuals requesting information go forward with the adoption process, either attending an orientation session or completing an application? In your estimate, please include persons who decide to become foster parents so that they can improve their opportunity to adopt.

\begin{tabular}{|c|c|c|}
\hline \multicolumn{3}{|c|}{$\begin{array}{c}\text { Percentage of Individuals Requesting Information Who GO FORWARD, Either Attending } \\
\text { Orientation Session or Completing Application }\end{array}$} \\
\hline Frequency & \# of States & States \\
\hline Less than $25 \%$ & - & $\mathrm{DE}, \mathrm{GA}, \mathrm{MD}, \mathrm{MO}, \mathrm{NC}, \mathrm{NM}, \mathrm{OK}, \mathrm{VA}$ \\
\hline Between $25-50 \%$ & 21 & $\begin{array}{l}\mathrm{AK}, \mathrm{AL}, \mathrm{AR}, \mathrm{AZ}, \mathrm{CO}, \mathrm{CT}, \mathrm{DC}, \mathrm{FL}, \mathrm{HI}, \mathrm{IN}, \mathrm{KS}, \mathrm{KY}, \mathrm{ME} \text {, } \\
\mathrm{MS}, \mathrm{NH}, \mathrm{NJ}, \mathrm{OR}, \mathrm{PA}, \mathrm{RI}, \mathrm{TX}, \mathrm{UT}\end{array}$ \\
\hline $\begin{array}{l}\text { More than } 50 \text { but } \\
\text { less than } 75 \%\end{array}$ & 1 & WI \\
\hline More than $75 \%$ & 1 & MT \\
\hline NA & 6 & $\mathrm{CA}, \mathrm{MI}, \mathrm{SC}, \mathrm{SD}, \mathrm{VT}, \mathrm{WA}$ \\
\hline
\end{tabular}

Of these individuals who go forward, approximately what percent become foster parents so that they can improve their opportunity to adopt?

\begin{tabular}{|l|r|l|}
\hline \multicolumn{2}{|c|}{ Of Individuals Who GO FORWARD, Percent Who Become Foster Parents to Improve Their } \\
Opportunity to Adopt
\end{tabular}


4. Please provide your best estimate of how many adoption homestudies your agency (and private agencies under contract with your agency) completed during the past year (or month, please specify below) (estimated \# of adoption homestudies completed)

\begin{tabular}{|c|c|c|}
\hline \multirow{2}{*}{\multicolumn{3}{|c|}{ Adoption Homestudies Completed }} \\
\hline & & \\
\hline \multicolumn{3}{|c|}{ Annual Estimates } \\
\hline AK & & 119 \\
\hline$A L$ & & 120 \\
\hline AR & & 250 \\
\hline CA & & 10138 \\
\hline CT & & 175 \\
\hline DC & & 152 \\
\hline $\mathrm{DE}$ & & $50-60$ \\
\hline GA & & 884 \\
\hline IN & & 150 \\
\hline MD & & 360 \\
\hline ME & & 240 \\
\hline MI & & 1822 \\
\hline MO & & 79 \\
\hline MS & & 364 \\
\hline $\mathrm{NH}$ & & 153 \\
\hline NJ & & 202 \\
\hline OR & & 700 \\
\hline PA & & 602 \\
\hline RI & & $60-70$ \\
\hline TX & & 488 \\
\hline VA & & 241 \\
\hline WI & & 620 \\
\hline \multicolumn{3}{|c|}{ Extrapolated Annual from Monthly } \\
\hline$A Z$ & 18 & 216 \\
\hline $\mathrm{HI}$ & $15-20$ & 210 \\
\hline KS & 45 & 540 \\
\hline UT & 30 & 360 \\
\hline \multicolumn{3}{|c|}{ Extrapolated Annual from "other" } \\
\hline KY & 162 (8 mos.) & 243 \\
\hline NM & 168 (8 mos.) & 252 \\
\hline OK & 100 (6mos.) & 200 \\
\hline WA & 296 (6 mos.) & 592 \\
\hline \multicolumn{3}{|c|}{ No Data Available for Extrapolation } \\
\hline $\mathrm{CO}$ & & NA \\
\hline FL & & NA \\
\hline MT & & NA \\
\hline NC & & NA \\
\hline SC & & NA \\
\hline SD & & NA \\
\hline VT & & NA \\
\hline
\end{tabular}


Of all the individuals who complete an initial adoption application, approximately what percent complete the home study process?

\begin{tabular}{|l|r|l|}
\hline \multicolumn{2}{|c|}{ Of Individuals Who COMPLETE APPLICATION, Percent Who Complete Homestudy Process } \\
\hline Frequency & \# of States & States \\
\hline Less than $25 \%$ & 4 & DE, KY, MS, TX \\
\hline Between $25-50 \%$ & 12 & AL, CO, CT, DC, FL, MD, NH, NM, OK, VA, KS, UT \\
\hline $\begin{array}{l}\text { More than } 50 \text { but } \\
\text { less than } 75 \%\end{array}$ & 10 & AR, GA, HI, IN, MT, NC, NJ, PA, RI, OR \\
\hline More than 75\% & 5 & AZ, ME, MO, WA, WI \\
\hline NA & 6 & AK, CA, MI, SC, SD, VT \\
\hline
\end{tabular}

5. In your opinion, approximately what percent of individuals being homestudied never complete the process?

\begin{tabular}{|l|r|l|}
\hline \multicolumn{3}{|c|}{ Of Individuals Being HOMESTUDIED } \\
\hline Frequency & \# of States & States \\
\hline Less than $25 \%$ & 21 & $\begin{array}{l}\text { AL, AR, AZ, CO, CT, FL, IN, KS, ME, MI, MO, MS, MT, } \\
\text { NC, NM, OK, OR, PA, VA, VT, WI }\end{array}$ \\
\hline Between 25-50\% & 7 & DC, GA, HI, KY, NJ, RI, UT \\
\hline $\begin{array}{l}\text { More than } 50 \text { but } \\
\text { less than 75\% }\end{array}$ & 5 & AK, DE, MD, NH, TX \\
\hline More than 75\% & 0 & \\
\hline NA & 4 & CA, SC, SD, WA \\
\hline
\end{tabular}


In your opinion, what is (are) the primary reasons why individuals never complete the homestudy process?

\begin{tabular}{|c|c|}
\hline state & Primary Reasons Applicants NEVER Complete Homestudy Process \\
\hline AK & $\begin{array}{l}\text { Many families contact our agency asking about adoption generally, not just the adoption of children } \\
\text { through foster care. We find many families would prefer to adopt either privately/internationally so opt } \\
\text { not to pursue adoption through DFYS }\end{array}$ \\
\hline $\mathrm{AL}$ & Suitability issues \\
\hline AR & $\begin{array}{l}\text { A change in their personal circumstance } \\
\text { Information they learn about parenting children with special needs }\end{array}$ \\
\hline$A Z$ & Family problems, divorce, death, etc; Fingerprint requirements \\
\hline CA & na \\
\hline $\mathrm{CO}$ & $\begin{array}{l}\mathrm{CO} \text { is a concurrent planning state and families not wanting to do legal risk. } \\
\text { Additionally, children older with emotional and behavioral problems } \\
\text { Want younger children }\end{array}$ \\
\hline & $\begin{array}{l}\text { Changes in their personal situations, no longer interested or capable of adoption. } \\
\text { Not interested in special needs children }\end{array}$ \\
\hline CT & $\begin{array}{l}\text { Not interested in legal risk placements } \\
\text { Decided after training that they were not ready. Or they became pregnant. } \\
\text { Maryland and Virginia requirement too rigid. }\end{array}$ \\
\hline DC & Respective homes not free of lead paint, a few with criminal records. \\
\hline & $\begin{array}{l}\text { Too long - training hours/time commitment. } \\
\text { Cost to the family }\end{array}$ \\
\hline $\mathrm{DE}$ & Child they were interested in is no longer available. \\
\hline FL & $\begin{array}{l}\text { Disqualification due to criminal record; } \\
\text { Not really interested in the type of children who are waiting. }\end{array}$ \\
\hline & $\begin{array}{l}\text { Rule themselves out as they learn more about the children who are available for adoption through the } \\
\text { department. } \\
\text { Do not follow through on required verification. }\end{array}$ \\
\hline GA & Screened out by department due to criminal history, history of abuse or neglect. \\
\hline $\mathrm{HI}$ & $\begin{array}{l}\text { Change in the family's situation - eg. Employment changes, pregnancy, military deployment or transfer, } \\
\text { etc. }\end{array}$ \\
\hline & Not interested in a special needs adoption \\
\hline IN & $\begin{array}{l}\text { Not able or willing to commit training and homestudy. } \\
\text { Find another way to bring a child into their life. }\end{array}$ \\
\hline & $\begin{array}{l}\text { Frustration with the volume of paperwork and length of time the home evaluation process takes are } \\
\text { typical reasons for not completing the process. }\end{array}$ \\
\hline KY & We are currently actively reviewing our process to address both issues. \\
\hline MD & $\begin{array}{l}\text { Have a criminal record/previous child protective service case. } \\
\text { Do not pass health/fire inspection. } \\
\text { Do not complete medicals. } \\
\text { Type of children available are not what they wish to adopt. } \\
\text { Change their minds about adoption. }\end{array}$ \\
\hline ME & Most often they do not meet the core standards identified in ME DHS policy \\
\hline MI & $\begin{array}{l}\text { Orientation sessions may sort out some applicants who self-select themselves out as they determine } \\
\text { special needs adoption may not be for them. }\end{array}$ \\
\hline MO & $\begin{array}{l}\text { Family doesn't want type of children we have for adoption } \\
\text { Personal reasons (ie, illness, marital problems) }\end{array}$ \\
\hline
\end{tabular}


State Primary Reasons Applicants NEVER Complete Homestudy Process

The application process is lengthy.

Conflicting schedules of applicants (both not available at the same time.)

Transportation problem.

Loss of interest in adoption.

MS Agency rules, regulations, policy and procedures.

Circumstances change within their family structure. Decide it would be too difficult and/or stressful on

MT their family.

Verbal reports indicate individuals do not complete process because

They are not interested in children with special needs,

Not willing to meet requirements regarding background check, discipline policy and hours of training;

NC Have life change that prohibits adoption; and 4. Have a biological child.

During the process the family determines that adoption of a child with special needs is not the best

$\mathrm{NH}$ option.

Both couples are "not on the same page" regarding adoption.

Personal health and unresolved fertility issues.

Individuals hidden agendas surface.

Disqualifying information about potential adoptive parents become known to agency.

NJ Marital and family problems which may or may not be related to adoption

NM The process is invasive. Too much homework, and culturally insensitive.

Only one spouse wants to adopt (out of married couple);

OK Couple changes their mind due to needs or desires of biological children.

PA They decide a special needs adoption is not for them.

One of the primary reasons is a recognition that adoption - at least adoption of a child from the foster care system - is not what they want.

Second would be changes in their personal situations, e.g. an older parent moves in with them, a job transfer

RI out of state, etc.

SC na

SD $\mathrm{Na}$

Families self select out of the program because the type of child available for adoption does not match

TX the type of child they are willing to adopt.

Frustration with process.

Do not qualify because of criminal records, etc.

Dissatisfaction with agency personnel and practices.

VA Interested in specific child only.

Marital difficulties/differences which come out in home study process.

VT Family is counseled out as they may have issues not suitable to raising a child.

WA Issues come up that could disqualify

Wanted healthy infants; change in family circumstances (eg. Divorce, financial, health); changing needs of child;

Doesn't meet licensing standards;

Change mind; change of family plans;

WI Move out of state. 
6. Please provide your best estimate of the number of children placed (in a year or month, please specify) in pre-adoptive homes by your agency (and/or private agencies with which you contract).

(estimated \# of children placed in pre-adoptive homes)

(estimated \% of these which are "adoption only," that is, they were not related to or the foster parent of the child placed)

\begin{tabular}{|c|c|c|}
\hline NuI & Placed & $\begin{array}{l}\% \\
\text { adoption } \\
\text { only }\end{array}$ \\
\hline Ann & & \\
\hline$A L$ & 253 & 80 \\
\hline AR & 350 & 55 \\
\hline $\mathrm{CA}$ & 8267 & 15 \\
\hline $\mathrm{CO}$ & na & $25-35$ \\
\hline CT & 151 & 19 \\
\hline DC & 60 & 10 \\
\hline GA & 996 & 18 \\
\hline IN & 826 & 25 \\
\hline KS & 450 & 25 \\
\hline KY & 390 & 20 \\
\hline MD & 832 & na \\
\hline ME & 300 & 25 \\
\hline MI & 2927 & 10 \\
\hline $\mathrm{MO}$ & 1000 & 70 \\
\hline MS & 295 & $<24$ \\
\hline $\mathrm{NH}$ & 125 & 20 \\
\hline $\mathrm{NJ}$ & 1189 & 19 \\
\hline OK & 1003 & 24 \\
\hline OR & 1000 & 30 \\
\hline PA & 921 & na \\
\hline SC & $450-500$ & 40 \\
\hline SD & 140 & 24 \\
\hline TX & 2331 & 50 \\
\hline UT & 403 & 37 \\
\hline WI & 800 & 16 \\
\hline
\end{tabular}

\begin{tabular}{|l|r|r|r|}
\hline \multicolumn{4}{|c|}{ Extrapolated Annual from Monthly } \\
\hline AZ & 21 & 252 & 60 \\
\hline DE & 10 & 120 & 55 \\
\hline FL & 166 & 1992 & 49 \\
\hline HI & 22 & 264 & 5 \\
\hline VA & 37 & 444 & 25 \\
\hline
\end{tabular}

Extrapolated Annual from "other"

NM $\quad$ Pt in time $\quad 121 \quad \mathrm{Na}$

\begin{tabular}{|l|r|r|}
\hline \multicolumn{3}{|c|}{ No time frame provided } \\
\hline AK & $\mathrm{Na}$ & $\mathrm{Na}$ \\
\hline MT & $\mathrm{Na}$ & $\mathrm{Na}$ \\
\hline NC & 23 & 17 \\
\hline RI & $\mathrm{Na}$ & $\mathrm{Na}$ \\
\hline VT & 120 & $\mathrm{Na}$ \\
\hline WA & 516 & $\mathrm{Na}$ \\
\hline
\end{tabular}


7. Please provide the number of children for whom adoptions were finalized (specify the time period below) by your agency (and/or by private agencies with which you contract).

(estimated \# of finalized adoptions)

(estimated \% of these which are "adoption only," that is, they were not related to or the foster parent of the child adopted)

\begin{tabular}{|c|c|c|c|c|c|c|}
\hline \multirow{2}{*}{\multicolumn{2}{|c|}{$\begin{array}{l}\text { Number of Adoptions } \\
\text { Finalized } \\
\text { Annual Estimates }\end{array}$}} & \multirow{3}{*}{$\begin{array}{l}\text { \% Adoption } \\
\text { only } \\
\\
\end{array}$} & \multirow{2}{*}{\multicolumn{4}{|c|}{$\begin{array}{l}\text { Number of Adoptions Finalized } \\
\text { Extrapolated Annual from Monthly Data }\end{array}$}} \\
\hline & & & & & & \\
\hline AL & 234 & & DE & 10 & 120 & 55 \\
\hline AK & 278 & na & $\mathrm{FL}$ & 150 & 1800 & na \\
\hline AR & 311 & 55 & $\mathrm{RI}$ & \multirow[t]{2}{*}{35} & 420 & \multirow[t]{2}{*}{25} \\
\hline CA & 6728 & 15 & & & & \\
\hline $\mathrm{CO}$ & 757 & $25-35$ & \multicolumn{4}{|c|}{ Extrapolated Annual from "other" } \\
\hline CT & 429 & 20 & $A Z$ & 467 (6 mos.) & 934 & \\
\hline DC & 251 & na & VA & 236 (6 mos.) & \multirow[t]{2}{*}{472} & \\
\hline GA & 905 & 17 & & & & \\
\hline $\mathrm{HI}$ & \multirow{2}{*}{$\begin{array}{r}265 \\
1076\end{array}$} & $3-5$ & \multicolumn{4}{|c|}{ No time frame provided } \\
\hline IN & & 25 & MI & $\mathrm{Na}$ & -- & -- \\
\hline KS & 460 & 25 & SD & 92 & -- & 24 \\
\hline KY & 512 & 20 & & & & \\
\hline MD & 858 & na & & & & \\
\hline ME & 350 & 20 & & & & \\
\hline MO & 1229 & 70 & & & & \\
\hline MS & 271 & 24 & & & & \\
\hline MT & 250 & na & & & & \\
\hline NC & 1338 & 25 & & & & \\
\hline $\mathrm{NH}$ & 94 & 20 & & & & \\
\hline $\mathrm{NJ}$ & 1035 & 20 & & & & \\
\hline NM & 350 & na & & & & \\
\hline OK & 885 & 24 & & & & \\
\hline OR & 1071 & 32 & & & & \\
\hline PA & 1690 & na & & & & \\
\hline SC & $450-500$ & na & & & & \\
\hline$T X$ & 2261 & 50 & & & & \\
\hline UT & 338 & 37 & & & & \\
\hline VT & 120 & 1 & & & & \\
\hline WA & 1183 & na & & & & \\
\hline WI & 729 & 16 & & & & \\
\hline
\end{tabular}


8. Please estimate the number of adoption applicants who have approved home studies who are waiting to be matched with a child in foster care? (estimated \# of applicants waiting to be matched)

\begin{tabular}{|l|r|r|r|}
\hline \multicolumn{4}{|c|}{$\begin{array}{r}\text { Number of } \\
\text { WAITING TO BE MATCHED }\end{array}$} \\
\hline AL & 200 & SC & 300 \\
\hline AR & 150 & WI & 130 \\
\hline CA & na & HI & 60 \\
\hline CO & na & NM & 124 \\
\hline CT & 150 & AK & 12 \\
\hline DC & 46 & MT & na \\
\hline GA & 460 & NC & 1070 \\
\hline IN & $175-200$ & VT & na \\
\hline KS & 165 & WA & na \\
\hline KY & 280 & DE & na \\
\hline MD & 50 & FL & na \\
\hline ME & 35 & RI & 80 \\
\hline MO & na & AZ & 398 \\
\hline MS & 182 & VA & 167 \\
\hline NH & 20 & TX & na \\
\hline NJ & 612 & UT & na \\
\hline OR & 100 & MI & na \\
\hline OK & 264 & SD & na \\
\hline PA & 2600 & & \\
\hline & & & \\
\hline
\end{tabular}


9. Please describe any efforts or strategies you have used to track the number of persons who express interest in adopting a child out of the foster care system and whether they complete the adoption process.

\begin{tabular}{|c|c|}
\hline \multicolumn{2}{|r|}{ Efforts and Strategies to Track Interest in Adopting Child out of Foster Care System } \\
\hline AK & Alaska adoption exchange and the Northwest Adoption Exchange. \\
\hline AL & $\begin{array}{l}\text { Contractor tracks from initial intake call to whether application packet was returned to whether invitation } \\
\text { to group preparation class was accepted; their tracking whether applicants attended initial session, } \\
\text { selected out prior to completing sessions or completed process. }\end{array}$ \\
\hline AR & Each adoption specialist prepares a monthly report which includes this information. \\
\hline$A Z$ & $\begin{array}{l}\text { One contact agency has a data base tracking system and another agency uses a paper face sheet that } \\
\text { is filled in a case record at some point }\end{array}$ \\
\hline CA & na \\
\hline $\mathrm{CO}$ & Individual counties are tracking but not everyone is. \\
\hline CT & $\begin{array}{l}\text { When a person telephones the office or comes to a recruitment booth, we take their name and create an } \\
\text { inquiry document which a recruiter can use as a tool to follow up and encourage the person to attend a } \\
\text { public open house for more information. The recruiter stays with this person until they attend the open } \\
\text { house or withdraws their interest. If the family attends the open house, the case is transferred to a pre- } \\
\text { licensing social worker who tracks the family thru pre licensing training and licensing process. } \\
\text { Supervisors track their workers cases, applications, and inquiries. Our computer system holds the name } \\
\text { of each inquiry and outcome. }\end{array}$ \\
\hline DC & $\begin{array}{l}\text { Information documented on a spreadsheet. Information recorded in monthly statistics. Information kept } \\
\text { in computer. Information documented on intake form. }\end{array}$ \\
\hline DE & $\begin{array}{l}\text { This is a weak area and I would like information as to how other states track these families. Manual, but } \\
\text { no access to data. }\end{array}$ \\
\hline $\mathrm{FL}$ & $\begin{array}{l}\text { Each district has a recruitment/retention counselor charged with the responsibility of making sure } \\
\text { interested parties make it through the system. The headquarters office also employs a } \\
\text { recruitment/retention specialist to provide guidance in this area. }\end{array}$ \\
\hline GA & $\begin{array}{l}\text { The office of adoptions contracts with an agency who produces our photolisting book and photolisting } \\
\text { website. They provide us with a monthly report of the number of people who contact their agency and } \\
\text { web site information. They provide us with referrals on families in our state interested in becoming an } \\
\text { adoptive parent. In addition, our regional adoption coordinators provide a report of the number of } \\
\text { families contacting them for information (at the local level. Beginning in FY } 2002 \text { our agency contracted } \\
\text { with an agency to serve as the central point of intake for all callers - do not have a full year of data on } \\
\text { this yet. }\end{array}$ \\
\hline $\mathrm{HI}$ & We are able to track this from the electronic data system. \\
\hline IN & $\begin{array}{l}\text { Kansas Children's Service League is informed of a child's change in permanency goal to adoption, prior } \\
\text { to referral to the adoption contract. Potential resource families are engaged and assessed when they } \\
\text { become known. }\end{array}$ \\
\hline KY & $\begin{array}{l}\text { At present we are reviewing our tracking process and this is an area needing further improvement. We } \\
\text { currently use several databases to track this information and are in the continuing process of new } \\
\text { adoption technology development. Currently, we use a training tracking datatbase (TRIS) and a paradox } \\
\text { system which houses information on children and families. }\end{array}$ \\
\hline MD & na \\
\hline ME & $\begin{array}{l}\text { We are presently in the process of developing a tracking system that measures this outcome. Expect to } \\
\text { have a system in place by } 09 / 02\end{array}$ \\
\hline MI & na \\
\hline MO & by county as there is no consistent method. \\
\hline
\end{tabular}


Efforts and Strategies to Track Interest in Adopting Child out of Foster Care System

\begin{tabular}{|c|c|}
\hline MS & $\begin{array}{l}\text { Recruiters for three districts. Website; word of mouth by foster parents; word of mouth by adoptive } \\
\text { parents; contacts made from media exposure of children. }\end{array}$ \\
\hline MT & This activity is done at the local level. Info not available here. \\
\hline NC & $\begin{array}{l}\text { NC kids send an information packet to review. This packet includes information about the county } \\
\text { departments and private agencies. They then contact each new family on a regular } 2 \text { week schedule } \\
\text { after initial contact, then } 60 \text { days. NC kids capture the date in which an agency was identified, the date } \\
\text { required training was completed, the date study was approved, and the date when service is no longer } \\
\text { needed. They also capture the reason the family is no longer in need of service (i.e., adopt, bio child, no } \\
\text { longer interested). Again, } 100 \text { local departments and } 4 \text { private agencies also track their numbers of } \\
\text { which are not reported to the state. }\end{array}$ \\
\hline $\mathrm{NH}$ & none \\
\hline NJ & $\begin{array}{l}\text { Inquiries and applications for families interested in a child from the child welfare system (non-foster care } \\
\text { adoptions) are received by the foster and adoptive family services. Statistics are forwarded monthly to } \\
\text { the office of adoption operations. Completed applications are sent to one of four adoption resource } \\
\text { centers (ARCs). They are assigned for follow-up and studied and tracked using access data base } \\
\text { systems. Monthly statistics are submitted to the central office of adoption operations. }\end{array}$ \\
\hline NM & $\begin{array}{l}\text { Inquiries are entered into FACTS and a note is made in the inquiries narrative then assigned to the } \\
\text { adoption social worker }\end{array}$ \\
\hline OK & $\begin{array}{l}\text { SACWIS system: a pre-resource is entered into kids at the time of inquiry. The pre-resource will track } \\
\text { the prospective applicant from initial inquiry through the results of the adoptive home assessment. A } \\
\text { field management report is produced each month which summarizes and details \# of inquiries, \# of } \\
\text { pending applications, \# of completed assessments, and \# of withdrawals from the process. }\end{array}$ \\
\hline OR & $\begin{array}{l}\text { We have some processes in place to be able to do this, but we have not yet done it. Eg., all calls to our } \\
1-800 \text { \# are input into a database that is compatible with a separate database that records approved } \\
\text { homestudies and adoptive placements and finalizations by family. Also, we hope to complete our } \\
\text { SACWIS provider module by mid 2003. In addition, we have a recruitment project underway with Casey } \\
\text { sponsorship. }\end{array}$ \\
\hline PA & $\begin{array}{l}\text { None, but: family profiles (homestudies) that are paid for by the SWAN prime contract are registered } \\
\text { with our states adoption exchange. When a family has been asked to be placed on a "hold" status } \\
\text { because of an adoption, or for any other reason, the PA adoption exchange makes those changes and } \\
\text { further matching is put on a "hold" status unless or until the family requests active status. }\end{array}$ \\
\hline RI & $\begin{array}{l}\text { Adoption Rhode Island tracks the calls, inquiries, etc. They contract with us to do recruitment and } \\
\text { matching and they keep their own statistics. Our tracking here at DCYF is minimal and chiefly based on } \\
\text { our guestimates (calls regarding foster care go to a separate office) }\end{array}$ \\
\hline SC & na \\
\hline SD & na \\
\hline TX & $\begin{array}{l}\text { Each region in the state has a system to track the number of people who inquire about adoption. This } \\
\text { information is kept in the database. There is also an automated system to track the number of people } \\
\text { who inquire through the internet, Texas Adoption Resource Exchange (TARE), the web site, and the } \\
\text { statewide } 800 \text { number. }\end{array}$ \\
\hline UT & We have no method of tracking numbers who express interest. \\
\hline VA & $\begin{array}{l}\text { Most inquiries are coming in through our 1-800-DO-ADOPT telephone line and e-mail. We do not follow } \\
\text { up on inquiries. Inquiries are forwarded by our local department of social services. }\end{array}$ \\
\hline VT & $\begin{array}{l}\text { We rely primarily upon foster parent adoption. For about } 20-30 \text { children we use a private agency to } \\
\text { recruit families. We have a federal adoption opportunity grant (start 10/00) to begin process of recruiting, } \\
\text { matching, placing, and finalize adoption of older children when foster parents do not adopt. We have } \\
\text { completed about } 30 \text { homestudies and have placed } 10 \text { children, } 8 \text { of which are now final. }\end{array}$ \\
\hline WA & na \\
\hline WI & WI SACWIS; stand alone database; special needs adoption network; manual records \\
\hline
\end{tabular}




\section{Information About the Adoption Process}

10. Which if any of the following components of the adoption process are conducted by private agencies under contract with the state; please indicate whether none, some, most, or all of these components are contracted out:

\begin{tabular}{llccc}
\hline Type of Activity & \multicolumn{4}{l}{ Contract out to private agency (or agencies) } \\
\hline Recruitment (e.g., media campaigns) & $\square$ None & $\square$ Some & $\square$ Most & $\square$ All \\
Orientation meetings & $\square$ None & $\square$ Some & $\square$ Most & $\square$ All \\
Application process & $\square$ None & $\square$ Some & $\square$ Most & $\square$ All \\
Home study & $\square$ None & $\square$ Some & $\square$ Most & $\square$ All \\
Training & $\square$ None & $\square$ Some & $\square$ Most & $\square$ All \\
Matching (e.g., adoption exchanges) & $\square$ None & $\square$ Some & $\square$ Most & $\square$ All \\
Placement & $\square$ None & $\square$ Some & $\square$ Most & $\square$ All \\
Post-adoptive services & $\square$ None & $\square$ Some & $\square$ Most & $\square$ All \\
Other & $\square$ None & $\square$ Some & $\square$ Most & $\square$ All \\
\hline
\end{tabular}

\begin{tabular}{|l|r|l|}
\hline \multicolumn{3}{|c|}{ Recruitment (contract out to private agency) } \\
\hline Frequency & \# of States & States \\
\hline None & 5 & AR, MS, NH, NM, OK, \\
\hline Some & 20 & CO, CT, DE, DC, FL, GA, KY, OR, PA, MD, MI, MO, MT, NJ, SC, \\
& & SD, TX, WA, WI, VA \\
\hline Most & 3 & AL, AK, IN \\
\hline All & 6 & AZ, HI, KS, ME, RI, UT \\
\hline na & 3 & CA, NC, VT \\
\hline
\end{tabular}

\begin{tabular}{|l|r|l|}
\hline \multicolumn{3}{|c|}{ Orientation Meetings (contract out to private agency) } \\
\hline Frequency & \# of States & States \\
\hline None & 6 & AR, DC, MS, NH, NM, OK \\
\hline Some & 16 & $\begin{array}{l}\text { AK, CT, FL, GA, KY, ME, MD, MI, MO, MT, OR, SC, SD, TX, VA, } \\
\text { WA }\end{array}$ \\
\hline Most & 5 & AL, DE, IN, NJ, PA \\
\hline All & 6 & AZ, KS, HI, RI, UT, WI \\
\hline na & 4 & CA, CO, NC, VT \\
\hline
\end{tabular}

\begin{tabular}{|l|r|l|}
\hline \multicolumn{3}{|c|}{ Application Process (contract out to private agency) } \\
\hline Frequency & \# of States & States \\
\hline None & 10 & AR, DC, ME, MS, MT, NH, OK, RI, WA, UT \\
\hline Some & 15 & AK, CT, FL, GA, KY, MD, MI, MO, NM, OR, SC, SD, TX, VA, WI \\
\hline Most & 8 & AL, CO, DE, HI, IN, NJ, PA, VT \\
\hline All & 2 & AZ, KS \\
\hline na & 2 & CA, NC \\
\hline
\end{tabular}




\begin{tabular}{|l|r|l|}
\hline \multicolumn{2}{|c|}{ Home Study (contract out to private agency) } \\
\hline Frequency & \# of States & States \\
\hline None & 1 & WA \\
\hline Some & 19 & $\begin{array}{l}\text { CT, DC, FL, GA, KY, MD, MI, MO, MS, MT, NJ, NH, OR, RI, SC, } \\
\text { SD, TX, UT, VA }\end{array}$ \\
\hline Most & 11 & AL, AR, CO, DE, HI, IN, ME, NM, PA, VT, WI \\
\hline All & 4 & AK, AZ, KS, OK \\
\hline na & 2 & CA, NC \\
\hline
\end{tabular}

\begin{tabular}{|l|r|l|}
\hline \multicolumn{3}{|c|}{ Training (contract out to private agency) } \\
\hline Frequency & \# of States & States \\
\hline \multicolumn{1}{|c|}{ None } & 4 & DC, MT, NH, VT \\
\hline Some & 20 & $\begin{array}{l}\text { AK, CO, CT, FL, GA, KY, MD, MI, MO, MS, NJ, NM, OR, RI, SC, } \\
\text { SD, TX, VA, AS, WI }\end{array}$ \\
\hline Most & 5 & AL, AR, DE, IN, PA \\
\hline All & 6 & AZ, KS, HI, ME, OK, UT \\
\hline na & 2 & CA, NC \\
\hline
\end{tabular}

\begin{tabular}{|l|r|l|}
\hline \multicolumn{3}{|c|}{ Matching (contract out to private agency) } \\
\hline Frequency & \# of States & States \\
\hline \multicolumn{1}{|c|}{ None } & 13 & Al, AZ, AR, DE, GA, HI, KY, MD, MO, NH, NJ, SC, VT \\
\hline Some & 17 & $\begin{array}{l}\text { CO, CT, DC, FL, IN, ME, MI, MS, MT, NM, PA, OK, OR, SD, TX, } \\
\text { VA, WA }\end{array}$ \\
\hline Most & 4 & AK, RI , UT, WI \\
\hline All & 1 & KS \\
\hline na & 2 & CA, NC \\
\hline
\end{tabular}

\begin{tabular}{|l|r|l|}
\hline \multicolumn{2}{|c|}{ Placement (contract out to private agency) } \\
\hline Frequency & \# of States & States \\
\hline None & 14 & AK, AL, AZ, AK, HI, KY, MD, MO, NH, NJ, OK, RI, VT, UT \\
\hline Some & 18 & $\begin{array}{l}\text { CO, CT, DE, DC, FL, GA, IN, ME, MI, MS, MT, NM, OR, SC, SD, } \\
\text { TX, WA }\end{array}$ \\
\hline Most & 2 & PA, WI \\
\hline All & 1 & KS \\
\hline na & 2 & CA, NC \\
\hline
\end{tabular}

\begin{tabular}{|l|r|l|}
\hline \multicolumn{3}{|c|}{ Post-Adoptive Services (contract out to private agency) } \\
\hline Frequency & \# of States & States \\
\hline \multicolumn{1}{|c|}{ None } & 5 & AZ, AR, MI, NH, OK \\
\hline Some & 15 & AK, CO, CT, DE, FL, KY, MD, MS, MO, MT, OR, PA, SC, UT, VA \\
\hline Most & 7 & GA, HI, IN, ME, NJ, NM, WI \\
\hline All & 7 & AL, KS, RI, SD, TX, VT, WA \\
\hline na & 3 & CA, DC, NC \\
\hline
\end{tabular}


11. How many public agency staff (Full Time Equivalents (FTEs)) work on adoptions?

\begin{tabular}{|l|r|l|r|}
\hline Public Agency Staff (FTE) & \multicolumn{2}{|c|}{ Public Agency Staff (FTE) } \\
\hline AK & 7 & MO & 300 \\
\hline AL & 5 & MS & 33 \\
\hline AR & 41 & MT & 12 \\
\hline AZ & 65 & NC & na \\
\hline CA & 563.8 & NH & 8 \\
\hline CO & na & NJ & 400 \\
\hline CT & 50 & NM & 68 \\
\hline DC & 61 & OK & 42 \\
\hline DE & 18 & OR & 150 \\
\hline FL & 118 & PA & na \\
\hline GA & na & RI & $10-15$ \\
\hline HI & 30 & SC & 75 \\
\hline IN & 30 & SD & na \\
\hline KS & na & TX & na \\
\hline KY & 75 & UT & na \\
\hline MD & 800 & VA & 68 \\
\hline ME & 53 & VT & 15 \\
\hline MI & 92 & WA & na \\
\hline & & WI & 25.5 \\
\hline
\end{tabular}

12. Approximately how many FTE at private agencies under contract with your agency (working on adoption)?

\begin{tabular}{|l|r|l|r|}
\hline \multicolumn{2}{|c|}{ Private Agency Staff (FTE) } & \multicolumn{2}{|c|}{ Private Agency Staff (FTE) } \\
\hline AK & 2.5 & MO & 30 \\
\hline AL & 0 & MS & 35 \\
\hline AR & 12 & MT & 3 \\
\hline AZ & 56 & NC & na \\
CA & na & NH & 0 \\
\hline CO & na & NJ & 195 \\
\hline CT & 28 & NM & 16 \\
\hline DC & 22 & OK & 3 \\
\hline DE & 6 & OR & 60 \\
\hline FL & 129 & PA & na \\
\hline GA & na & RI & $30-40$ \\
\hline HI & na & SC & na \\
\hline IN & 15 & SD & na \\
\hline KS & 120 & TX & na \\
\hline KY & 8 & UT & 4 \\
\hline MD & 10 & VA & 13 \\
\hline ME & 15 & VT & 2 \\
\hline MI & na & WA & na \\
\hline & & WI & 71 \\
\hline
\end{tabular}


13. What types of recruitment activities does your state currently conduct (or have private, contracted agencies conduct)? Please mark all that apply.

- State adoption exchange

- Regional adoption exchange participation

- National Adoption Exchange participation

- Media campaigns (e.g., Wednesday's Child programs)

- Church presentations (e.g., One Church One Child programs)

- Presentation booths (at malls or fairs)

a Adoption parties

- Other (specify)

\begin{tabular}{|l|r|}
\hline \multicolumn{2}{|c|}{ Types of Recruitment Activities Currently Conducting } \\
\# of states with:
\end{tabular}

\begin{tabular}{|l|l|}
\hline state & \multicolumn{1}{|c|}{ By state } \\
\hline AK & Statewide campaign, media etc. currently underway \\
\hline AR & direct mailings, referrals from foster and adoptive families \\
\hline AZ & Special event advertising \\
\hline CT & booths at sporting events \\
\hline DC & Child specific recruitment activities \\
\hline DE & Nov. Culture day activities statewide, baseball games, in yearbook. \\
\hline GA & Videoconferences, state photolisting book and state sponsored web site \\
\hline HI & group orientations monthly \\
\hline KS & Targeted Recruitment \\
\hline KY & targeted child specific recruitment by the special needs adoption program staff \\
\hline MD & Bus Ads \\
\hline MS & picnics \\
\hline NC & recently one private agency, another choice for black children, had a unique recruitment \\
& effort, an adoption train. \\
\hline NH & attached is a copy of our recruitment protocol. \\
\hline NM & Run for adoption, Heart Gallery \\
\hline PA & Matching Desserts, Annual Conference, Minor League and Pro Sporting Events \\
\hline RI & yearly adoption conference \\
\hline VA & video conferences, match retreats, networking with staff from other agencies. \\
\hline WI & General Media campaign \\
\hline & \\
\hline
\end{tabular}


14. In your opinion, which type of recruitment activity has proved most effective in your state?

\begin{tabular}{|c|c|}
\hline \multicolumn{2}{|r|}{ Opinions about Effective Recruitment Activities } \\
\hline AK & $\begin{array}{l}\text { Currently we have bus signs on buses in our largest city Anchorage. This has produced } \\
\text { an influx of calls to our 800\#. Also word of mouth still seems to be our best recruitment. } \\
\text { In villages, it is their local TV station and paper. }\end{array}$ \\
\hline $\mathrm{AL}$ & $\begin{array}{l}\text { National Adoption Exchange (FACES of adoption) and activities during National } \\
\text { adoption month (adoption fairs) }\end{array}$ \\
\hline AR & referrals from foster and adoptive families, exchanges \\
\hline$A Z$ & $\begin{array}{l}\text { History of agency and word of mouth by foster parents and adoptive parents and other } \\
\text { workers. Helps families see kids, continued public awareness }\end{array}$ \\
\hline $\mathrm{CA}$ & na \\
\hline $\mathrm{CO}$ & Counties say Wednesday's child, also the internet \\
\hline CT & $\begin{array}{l}\text { National adoption exchange registration of children, Wednesday's Child, Media } \\
\text { Marketing Campaign. }\end{array}$ \\
\hline $\mathrm{DC}$ & $\begin{array}{l}\text { Wednesday's Child. Radio announcements. Special matching activities. Adoptive } \\
\text { parents. Annual celebrations (National Adoption month celebration). Support or } \\
\text { endorsement from special people (ie, mayor and other celebrities or influential people) }\end{array}$ \\
\hline $\mathrm{DE}$ & $\begin{array}{l}\text { Displays at fairs/malls. Newspaper/TV ads, webside - NAC ... increased the number of } \\
\text { children placed out of state for adoption. }\end{array}$ \\
\hline FL & Child specific activities such as Wednesday's child program \\
\hline GA & $\begin{array}{l}\text { Wednesday's child and videoconferencing. The activities that allow a family to interact } \\
\text { or see children in action seem to speak to folks the most. }\end{array}$ \\
\hline $\mathrm{HI}$ & Word of mouth, targeted presentations to churches, special interest organizations. \\
\hline IN & $\begin{array}{l}\text { Our website with our picture book on it in color. Also we feature children weekly on a } \\
\text { television news program and in the newspaper. Adoptive families who have had a good } \\
\text { experience are also very effective recruiters. The kids tend to recruit for themselves } \\
\text { among the people they know and admire. }\end{array}$ \\
\hline KS & Child specific targeted recruitment, media profiles \\
\hline KY & $\begin{array}{l}\text { Advertisement on the internet currently appears to be the most effective. The other } \\
\text { efforts have not resulted in dramatic results. }\end{array}$ \\
\hline MD & 1. Matching parties. 2. Presentation Booths. 3. Media Campaigns. 4. Bus Ads. \\
\hline ME & $\begin{array}{l}\text { We believe they all provide some help in recruitment - I still think that "word of mouth" } \\
\text { is still the most effective (by experienced foster and adoptive parents). }\end{array}$ \\
\hline $\mathrm{Ml}$ & probably word of mouth network of foster and adoptive parents \\
\hline $\mathrm{MO}$ & Participation in all the exchanges and the adoption parties \\
\hline MS & $\begin{array}{l}\text { media campaigns are most effective for this state. More children have been featured } \\
\text { and adopted through this process. It has also proved to be an excellent awareness } \\
\text { program }\end{array}$ \\
\hline MT & Word of mouth \\
\hline
\end{tabular}




\begin{tabular}{|l|l|}
\hline \multicolumn{2}{|c|}{ Opinions about Effective Recruitment Activities } \\
\hline NC & $\begin{array}{l}\text { Wednesday's Child, 2. Website for N.C handled by NC Kids. 3. Community based } \\
\text { activities. 4. Successful foster family adoptions. And 5. Immediate feedback from } \\
\text { private and local agencies. }\end{array}$ \\
\hline NH & $\begin{array}{l}\text { Recruitment among experienced adoptive families (families which previously adopted a } \\
\text { child with special needs). 2. Recruitment that features picture, profiles and videos of } \\
\text { specific children. }\end{array}$ \\
\hline NJ & $\begin{array}{l}\text { Letters to the editor; community adds and displays; forums and speaking } \\
\text { engagements; website and word of mouth from satisfied parents }\end{array}$ \\
\hline NM & Presentation booths, yellow page listings, and adoption columns in local newspapers. \\
\hline OK & Adoption parties; church presentations, media campaigns. \\
\hline OR & $\begin{array}{l}\text { 1. Wednesday's Child. 2. Family Matters Newsletter. 3. Billboards. 4. Phone book ads. } \\
\text { 5. Website postings. 6. Child specific recruitment. \#2-4 not necessarily in order. }\end{array}$ \\
\hline PA & Media Campaign and Web site \\
\hline RI & $\begin{array}{l}\text { Television media in RI (Tuesday's child) over 45\% of families who have adopted in past } \\
\text { two years say they first heard of program via "Tuesday's Child." Next is the web. }\end{array}$ \\
\hline SC & All the exchanges and the Media campaigns \\
\hline SD & na \\
\hline TX & $\begin{array}{l}\text { Presentations that are co-presented with foster /adoptive parent who can speak about } \\
\text { their experience. }\end{array}$ \\
\hline UT & $\begin{array}{l}\text { 1. Internet site. 2. TV Spotlight. 3. Targeted Recruitment. 4.Through the adoption } \\
\text { exchange. }\end{array}$ \\
\hline VA & Continuum of all of the above. \\
\hline VT & We are just getting started. We are in the development phase of adoption recruitment. \\
\hline WA & $\begin{array}{l}\text { They are all equally important and provide an opportunity to educate and increase } \\
\text { awareness }\end{array}$ \\
\hline WI & Internet, word of mouth, local community events \\
\hline
\end{tabular}

15. Are adoptive parent applicants and foster parent applicants trained together? Do they receive the same training?

\begin{tabular}{|l|l|l|}
\hline \multicolumn{3}{|c|}{ Adoptive Applicants and Foster Parent Applicants Training } \\
\hline & $\begin{array}{c}\text { \# of states } \\
\text { with: }\end{array}$ & \multicolumn{1}{|c|}{ States } \\
\hline $\begin{array}{l}\text { They receive same training and are } \\
\text { trained together }\end{array}$ & 29 & $\begin{array}{l}\text { AK, AL, AR, AZ, CT, DC, FL, GA, HI, IN, } \\
\text { KS, KY, MD, ME, MI, MO, MT, NC, NJ, } \\
\text { NM, OK, OR, RI, SD, TX, UT, VT, WA, WI }\end{array}$ \\
\hline $\begin{array}{l}\text { They receive same training but are } \\
\text { trained separately }\end{array}$ & 1 & MS \\
\hline $\begin{array}{l}\text { They receive different training, usually } \\
\text { as part of a group }\end{array}$ & 4 & DE, NH, PA, SC \\
\hline $\begin{array}{l}\text { They receive different training, usually } \\
\text { on an individual basis }\end{array}$ & -- & \\
\hline $\mathrm{Na}$ & 3 & $\mathrm{CA}, \mathrm{CO}, \mathrm{VA}$ \\
\hline
\end{tabular}


16. What fees may adoption applicants be asked to pay during the adoption process, (e.g., if they adopted a foster child through a private agency under contract to the child welfare agency)? Approximately what percentage of applicants pay these fees?

\begin{tabular}{|c|c|c|c|}
\hline \multicolumn{4}{|c|}{ Fees that Adoption Applicants Must Pay } \\
\hline State & Activity & Approximate Fee & \% of Adoptive Parents Paying \\
\hline$\overline{A L}$ & $\begin{array}{l}\text { Other: Fingerprinting for } \\
\mathrm{ABI} / \mathrm{FBI} \text { and Criminal History } \\
\text { Check }\end{array}$ & $\$ 49.00$ & NA \\
\hline \multirow[t]{3}{*}{$\mathrm{AZ}$} & Application & $\$ 18.00-45.00$ & $\begin{array}{l}90 \% \text { - however, these fees are usually } \\
\text { reimbursed through nonrecurring } \\
\text { Adoption expenses }\end{array}$ \\
\hline & Home Study & 800.00 & $<10 \%$ - usually waived \\
\hline & Finalization & $\$ 2000.00$ & $\begin{array}{l}60 \% \text { - however, these fees are usually } \\
\text { reimbursed through nonrecurring } \\
\text { Adoption expenses }\end{array}$ \\
\hline CA & Home Study & $\$ 500.00$ & $\% 16.2$ \\
\hline $\mathrm{CO}$ & Home Study & $\begin{array}{l}\$ 800.00 \text { Initial Study and } \\
\$ 500.00 \text { update }\end{array}$ & NA - usually fee is waived \\
\hline $\mathrm{DE}$ & $\begin{array}{l}\text { Application, Training, and } \\
\text { Home study }\end{array}$ & \multicolumn{2}{|c|}{$\begin{array}{l}\text { The fee is sliding scale per agency and most of the money is } \\
\text { reimbursed when family adopts the foster child. }\end{array}$} \\
\hline \multirow[t]{2}{*}{ GA } & Finalization & $\$ 500.00$ & $\begin{array}{l}100 \% \text { - but reimbursable following } \\
\text { finalization }\end{array}$ \\
\hline & Cost of Medicals & NA & NA \\
\hline KY & Finalization & $\$ 1000.00$ & $\begin{array}{l}100 \% \text { - however the finalization and home } \\
\text { study costs are reimbursed at the rate of } \\
\$ 1000.00 \text { per child upon finalization }\end{array}$ \\
\hline $\mathrm{ME}$ & Home Study & $\$ 2000.00$ & $\begin{array}{l}5 \% \text { - however, these fees can be } \\
\text { reimbursed through the nonrecurring } \\
\text { Adoption expenses program }\end{array}$ \\
\hline MT & Home Study & $\$ 1500.00$ & NA \\
\hline \multirow[t]{2}{*}{$\overline{O R}$} & Application & $\$ 150.00$ & $5 \%$ \\
\hline & Home Study & $\$ 3000.00$ & $5 \%$ \\
\hline TX & Finalization & Varies & $\begin{array}{l}\text { Adoptive Families are responsible for } \\
\text { paying for finalization but could be eligible } \\
\text { for reimbursement through non-recurring } \\
\text { adoption subsidy. }\end{array}$ \\
\hline UT & Finalization & $\$ 400.00-600.00$ & $\begin{array}{l}100 \% \text { - however, there is reimbursement } \\
\text { by tax credits or adoption subsidy }\end{array}$ \\
\hline
\end{tabular}


17. Considering the types of foster children that are available for adoption in your state, which statement best describes adoptions of foster children in your state:

\begin{tabular}{|l|r|}
\hline \multicolumn{2}{|c|}{ State Best Describes Adoptions of Foster Children in Your State } \\
(\# of States)
\end{tabular}




\begin{tabular}{|c|c|}
\hline \multicolumn{2}{|r|}{ Additional Comments } \\
\hline AK & $\begin{array}{l}\text { While they receive the same training and are trained together, an additional day is added for specific } \\
\text { adoption issues/questions/concerns. }\end{array}$ \\
\hline$A Z$ & $\begin{array}{l}\text { For question } 6 \text { in state section: pre-adoptive placement definition used is a legally free child placed in } \\
\text { a certified adoptive home or approved adoptive relative home for the purpose of adoption }\end{array}$ \\
\hline CA & $\begin{array}{l}\text { We were unable to provide detailed information about the matriculation of adoptive applicants through } \\
\text { the adoption homestudy process. CA has a state supervised, county administered child welfare } \\
\text { system. Such details about the homestudy process are followed at the local county level and handled } \\
\text { differently in each our } 58 \text { counties }\end{array}$ \\
\hline $\mathrm{CO}$ & $\begin{array}{l}\text { For question one (state information) of the } 549 \text { children - } 301 \text { were under five. These are children who } \\
\text { will be adopted by caretaker but haven't switched to adoption. In CO free for adoption doesn't mean } \\
\text { available for adoption as we have many children in permanent homes who will not be adopted ( } 886 \\
\text { children are free for adoption). CO is state supervised and county administered. Counties also do } \\
\text { many of the recruiting activities mentioned in question } 7 \text { in the adoption process section. For the } \\
\text { training question (6) it varies from county to county. Most large counties train together as many of our } \\
\text { families do legal risk/post adoption. Cindy's note* Many of the na's in this survey are because CO } \\
\text { provided some of the answers as estimates at the county level and not at the state level. }\end{array}$ \\
\hline CT & $\begin{array}{l}\text { For question two in the adoption process section: approximately } 50 \text { staff at } 10 \text { locations } \\
\text { geographically, all pre-licensing workers work with foster and adoptive families simultaneously. They } \\
\text { do not have specialties so it is difficult to state what } \% \text { of their time is totally adoption work. }\end{array}$ \\
\hline $\mathrm{DE}$ & $\begin{array}{l}\text { Most fees are sliding scale per agency and most of the money is reimbursed when family adopts the } \\
\text { foster child. Currently, all foster parent adoptions are contracted out for the training, home study, etc. } \\
\text { After 09/02, the Division of Family Services will be doing the training, home study etc, for children in } \\
\text { DFS foster homes where the foster parents want to adopt. Policies will be sent in regular mail. About } \\
55 \% \text { of foster parents adopt the child in their home. Tracking from orientation or sending information to } \\
\text { finalization is very difficult.. }\end{array}$ \\
\hline $\mathrm{GA}$ & $\begin{array}{l}\text { For question } 1 \text { in state section: of that number of children, only } 269 \text { are ready for adoption with no } \\
\text { identified adoptive resource. These are the children our agency is actively recruiting for. For question } \\
2 \text { in state section: there is no way to account for duplication in this number. They are collected from } \\
\text { two sources. Some callers may have contacted both sources. }\end{array}$ \\
\hline IN & $\begin{array}{l}\text { The estimation of adoption homestudies is only based on the number completed by contracted } \\
\text { agencies and she does not know how many county homestudies were completed last year. }\end{array}$ \\
\hline $\mathrm{KS}$ & $\begin{array}{l}\text { In regards to question 7, Families are not charged a fee for any of the items listed below. Families are } \\
\text { responsible, however, for the cost of their own legal fees at the time of finalization. As part of the state } \\
\text { subsidy process, families may be eligible for up to } \$ 2000 \text { to support these costs. Kansas Children's } \\
\text { Service League is the primary contractor for adoption services in the state of Kansas. In addition to } \\
\text { providing adoption service itself, KCSL subcontracts with } 4 \text { smaller agencies. }\end{array}$ \\
\hline $\mathrm{KY}$ & $\begin{array}{l}\text { For question } 7 \text { in the adoption process section: the finalization and home study costs are reimbursed } \\
\text { at the rate of } \$ 1000 \text { per child upon finalization. The cabinet for families and children currently using } \\
\text { MAPP/GPS materials as the application process. }\end{array}$ \\
\hline $\mathrm{ME}$ & $\begin{array}{l}\text { However the fees can be reimbursed thru the non-recurring adoption expensed program. We have a } \\
\text { combined/merged foster and adoptive family. Training since } 1991 \text {, study since } 06 / 2000 \text { and } \\
\text { recruitment since } 12 / 2000\end{array}$ \\
\hline $\mathrm{MI}$ & $\begin{array}{l}\text { As noted in number } 9 \text {, we are unable to respond to many questions as there is no data base available. } \\
\text { Our data relates to children. Recruitment, home studies are essentially handled by individual FIA ofcs } \\
\text { and private agencies. While localities do collaborate on these activities there is not central collection of } \\
\text { data. Question } 4 \text { on state section: includes home studies for relatives and foster parents who adopt. } \\
\text { Michigan contracts with } 55 \text { private agencies which do about } 60 \% \text { of all public child welfare adoptions. } \\
\text { They are paid a fee by the state for completed adoption but not individual components listed below. }\end{array}$ \\
\hline
\end{tabular}




\begin{tabular}{|c|c|}
\hline \multicolumn{2}{|r|}{ Additional Comments } \\
\hline $\mathrm{MO}$ & $\begin{array}{l}\text { For question two on the state adoption data: reported } 532 \text { kids based on one metro area statistics, } \\
\text { does not include total state data which was unavailable. We contract with private agencies to provide } \\
\text { training and homestudy assessments on foster/adoptive applicants based on the type of homes we } \\
\text { need (ie, special needs children). We also contract with private agencies to provide case management } \\
\text { services in our two larger metro areas. To clarify question } 7 \text { under the adoption process regarding } \\
\text { amounts an applicant may be asked to pay, any family that obtains our training and adopts a child in } \\
\text { state custody would not pay any amount. If a family goes through a private agency to adopt, they } \\
\text { would be responsible for those fees if the child was not eligible for the MO Adoption Subsidy Program } \\
\text { (ie, not a special needs child) }\end{array}$ \\
\hline $\mathrm{MS}$ & Applicants must pay if child being adopted is not eligible for adoption assistant \\
\hline NC & $\begin{array}{l}\text { It is important to note that NC is county administered and has } 100 \text { county departments of social } \\
\text { services that provide adoption services. The state contracts with } 4 \text { private agencies to provide } \\
\text { services on a statewide basis. All of these entities keep their own data. NC kids is our state's adopitn } \\
\text { exchange and receives information provided by the local departments on children and families, and } \\
\text { information provided by the private agencies on families. In regards to the fees, there are none if } \\
\text { adopting a child from foster care system. Adoptive parents may pay cost of court with attorney, but are } \\
\text { reimbursed from non-recurring expenses up to } \$ 2000 \text { per child if adopted from foster care system. }\end{array}$ \\
\hline OK & Adoption policy is online at www.okdhs.org. \\
\hline OR & $\begin{array}{l}\text { in State adoption data section: q2 - Does not include "conversion" families - those who move from } \\
\text { foster care to adoption. Also number is estimated from a statewide } 800 \text { number only. We have no way } \\
\text { of correctly counting the number of calls that go directly to our local offices. The number of estimated } \\
\text { homestudies is based on the number of adoption petitions filed. Adoption process section: q } 8 \text { - we } \\
\text { place a large number of children in adoptive homes out of state. In fy } 2001,6.82 \text { percent of finalized } \\
\text { adoption were with out of state private agencies, and } 9.24 \text { percent were with out of state public } \\
\text { agencies. }\end{array}$ \\
\hline PA & $\begin{array}{l}\text { For questions } 2 \text { and } 3 \text { in the adoption process section: The PA Statewide Adoption Network works } \\
\text { with both public and private agencies to find permanency for children in the PA foster care system. PA } \\
\text { is a state supervised, county administered commonwealth. PA has } 67 \text { county child welfare agencies } \\
\text { and approximately } 200 \text { private adoption agencies. We have no way of knowing how many people are } \\
\text { employed in those agencies as adoption workers, or how many family profiles (homestudies) are done } \\
\text { by county agencies for foster-adopt cases. }\end{array}$ \\
\hline RI & $\begin{array}{l}\text { Foster parent recruitment and licensing is separate and apart from adoption recruitment and training. } \\
\text { At the present time it is not possible to state with any accuracy the number of people who come } \\
\text { through the foster care door wanting to adopt since no one asks that question. Of those people who } \\
\text { come through the foster care door, apply to become foster parents and come into training classes I } \\
\text { would guesstimate about } 80 \text { percent or more lose the desire to adopt. Folks who are interested in } \\
\text { adoption come in another door with another application. It is easier for us to track these folks through } \\
\text { the process as it is not so split. }\end{array}$ \\
\hline SC & Fees are only for children with no special needs. \\
\hline TX & $\begin{array}{l}\text { Adoptive families are responsible for paying for finalization but could be eligible for re-imbursement } \\
\text { through non-recurring adoption study. More data is available at our web site, TDPRS.state.tx.us }\end{array}$ \\
\hline VA & $\begin{array}{l}\text { All } 121 \text { local departments of social services use their own approach to training adoptive parent } \\
\text { applicants and foster parent applicants, so all of the above are used. Virginia is a state supervised, } \\
\text { locally administered system. There are } 121 \text { local departments of social services. }\end{array}$ \\
\hline WA & $\begin{array}{l}\text { We do not keep or track a lot of this information. The answer to question } 4 \text { under state data is not } \\
\text { accurate - information is not input correctly. For question } 7 \text { under adoption process: all private agency } \\
\text { charge fees that vary from agency to agency. The fee charged by an private agency is not related to } \\
\text { the contract the private agency has with state agency. WA does not contract for homestudies. We } \\
\text { have contracts that provide for placements of state children into private agency homes The private } \\
\text { agencies are generally paid a monthly fee for service. WA also does have a purchase of service } \\
\text { contract that provides assistance with in the agencies total fees for service. }\end{array}$ \\
\hline WI & $\begin{array}{l}\text { Wisconsin is in the process of implementing a standardized statewide training program of foster and } \\
\text { adoptive families. }\end{array}$ \\
\hline
\end{tabular}




\section{Appendix C}

AFCARS

Analysis 


\section{Data-Pre-Adoptive Relation by State}

\begin{tabular}{|c|c|c|c|}
\hline \multirow[b]{2}{*}{ State } & \multicolumn{3}{|c|}{ Pre-Adoptive Relationship to the Child } \\
\hline & $\begin{array}{c}\text { Pre-Adoptive } \\
\text { Foster Parent } \\
(\mathrm{N}=25180)\end{array}$ & $\begin{array}{c}\text { Pre-Adoptive } \\
\text { Other Relative } \\
\quad(\mathrm{N}=6290)\end{array}$ & $\begin{array}{c}\text { Pre-Adoptive } \\
\text { Non-Relative } \\
(\mathrm{N}=7877) \\
\end{array}$ \\
\hline Alabama & 0.00 & 3.92 & 96.08 \\
\hline Alaska & 59.56 & 40.44 & 0.00 \\
\hline Arizona & 35.79 & 30.88 & 33.33 \\
\hline Arkansas & 61.64 & 16.04 & 22.33 \\
\hline California & 51.87 & 34.30 & 13.84 \\
\hline Colorado & 67.19 & 23.35 & 9.46 \\
\hline Connecticut & 50.62 & 18.86 & 30.52 \\
\hline Delaware & 60.61 & 12.12 & 27.27 \\
\hline District of Columbia & 89.76 & 2.41 & 7.83 \\
\hline Florida & 49.00 & 16.11 & 34.89 \\
\hline Georgia & 76.50 & 8.51 & 14.99 \\
\hline Hawaii & 51.61 & 46.95 & 1.43 \\
\hline Idaho & 76.53 & 2.04 & 21.43 \\
\hline Illinois & 99.90 & 0.10 & 0.00 \\
\hline Indiana & 32.06 & 10.55 & 57.39 \\
\hline lowa & 82.72 & 0.13 & 17.15 \\
\hline Kansas & 67.85 & 16.87 & 15.28 \\
\hline Kentucky & 0.00 & 6.76 & 93.24 \\
\hline Lousiana & 78.93 & 2.81 & 18.26 \\
\hline Maine & 0.50 & 3.00 & 96.50 \\
\hline Maryland & 65.69 & 25.21 & 9.09 \\
\hline Massachusetts & 99.78 & 0.22 & 0.00 \\
\hline Michigan & 59.28 & 30.70 & 10.02 \\
\hline Minnesota & 26.54 & 28.91 & 44.55 \\
\hline Mississippi & 60.96 & 2.63 & 36.40 \\
\hline Missouri & 66.54 & 23.69 & 9.77 \\
\hline Montana & 81.08 & 17.30 & 1.62 \\
\hline Nebraska & 0.00 & 0.00 & 0.00 \\
\hline Nevada & 65.29 & 4.96 & 29.75 \\
\hline New Hampshire & 80.95 & 11.11 & 7.94 \\
\hline New Jersey & 80.91 & 0.00 & 19.09 \\
\hline New Mexico & 15.89 & 31.40 & 52.71 \\
\hline New York & 0.00 & 0.00 & 0.00 \\
\hline North Carolina & 57.16 & 14.74 & 28.10 \\
\hline North Dakota & 35.25 & 2.88 & 61.87 \\
\hline Ohio & 68.83 & 9.33 & 21.83 \\
\hline Oklahoma & 43.97 & 29.72 & 26.31 \\
\hline Oregon & 23.14 & 32.16 & 44.71 \\
\hline Pennsylvania & 43.73 & 4.06 & 52.20 \\
\hline Rhode Island & 47.90 & 39.16 & 12.94 \\
\hline South Carolina & 50.00 & 5.70 & 44.30 \\
\hline South Dakota & 71.08 & 9.64 & 19.28 \\
\hline Tennessee & 55.79 & 3.95 & 40.26 \\
\hline
\end{tabular}




\section{Data-Pre-Adoptive Relation by State}

\begin{tabular}{|l|r|r|r|}
\hline \multirow{2}{*}{} & \multicolumn{3}{|c|}{ Pre-Adoptive Relationship to the Child } \\
\cline { 2 - 4 } State & \multicolumn{2}{|c|}{$\begin{array}{c}\text { Pre-Adoptive } \\
\text { Foster Parent } \\
(\mathrm{N}=25180)\end{array}$} & $\begin{array}{c}\text { Pre-Adoptive } \\
\text { Other Relative } \\
(\mathrm{N}=6290)\end{array}$ \\
\hline Texas & 53.65 & 19.73 & $\begin{array}{c}\text { Pre-Adoptive } \\
\text { Non-Relative } \\
(\mathrm{N}=7877)\end{array}$ \\
Utah & 51.09 & 5.74 & 26.63 \\
Vermont & 84.89 & 13.67 & 43.17 \\
Virginia & 76.73 & 4.73 & 1.44 \\
Washington & 63.05 & 0.19 & 18.55 \\
West Virginia & 83.01 & 12.18 & 36.76 \\
Wisconsin & 71.81 & 10.90 & 4.81 \\
Wyoming & 68.18 & 11.36 & 17.29 \\
Puerto Rico & 36.88 & 38.75 & 20.45 \\
\hline
\end{tabular}


1999

CHARACTERISTICS OF CHILDREN ADOPTED

By parents' pre-adoptive relationship to child

\begin{tabular}{|c|c|c|c|}
\hline \multirow{2}{*}{$\begin{array}{l}1999 \text { DATA } \\
\text { Variable }\end{array}$} & \multicolumn{3}{|c|}{ Pre-Adoptive Relationship to the Child } \\
\hline & $\begin{array}{l}\text { Pre-Adoptive } \\
\text { Foster Parent } \\
(\mathrm{N}=25180)\end{array}$ & $\begin{array}{c}\text { Pre-Adoptive } \\
\text { Other Relative } \\
(\mathrm{N}=6290)\end{array}$ & $\begin{array}{c}\text { Pre-Adoptive } \\
\text { Non-Relative } \\
(\mathrm{N}=7877)\end{array}$ \\
\hline \multicolumn{4}{|l|}{ Age of child at time of adoption } \\
\hline$<1$ year & $1.45 \%$ & $0.62 \%$ & $3.53 \%$ \\
\hline $1-5$ years & 47.56 & 44.50 & 46.74 \\
\hline $6-10$ years & 34.96 & 37.47 & 35.27 \\
\hline $11-15$ years & 14.21 & 15.64 & 13.13 \\
\hline $16-18$ years & 1.77 & 1.73 & 1.28 \\
\hline $19+$ years & 0.05 & 0.03 & 0.05 \\
\hline Mean & 6.25 & 6.59 & 6.00 \\
\hline Median & 6.00 & 6.00 & 5.00 \\
\hline Missing & 0.00 & 0.00 & 0.00 \\
\hline \multicolumn{4}{|l|}{ Child Sex } \\
\hline Female & $50.20 \%$ & $53.09 \%$ & $48.46 \%$ \\
\hline Male & 49.80 & 46.91 & 51.54 \\
\hline Missing & 0.01 & 0.02 & 0.04 \\
\hline \multicolumn{4}{|l|}{ Child Race/Ethnicity } \\
\hline White, Non-Hispanic & $43.89 \%$ & $47.38 \%$ & $55.01 \%$ \\
\hline Black, Non-Hispanic & 52.86 & 45.10 & 41.53 \\
\hline American Indian/Alaskan Native & 1.54 & 2.60 & 1.48 \\
\hline Asian/Pacific Islander & 1.35 & 3.94 & 0.60 \\
\hline 2 or more races & 0.36 & 0.98 & 1.38 \\
\hline Unable to Determine & 5.11 & 7.38 & 4.77 \\
\hline Missing & 2.34 & 4.36 & 8.06 \\
\hline \multicolumn{4}{|l|}{ Hispanic Origin } \\
\hline Yes & $11.71 \%$ & $21.88 \%$ & $17.15 \%$ \\
\hline No & 88.29 & 78.12 & 82.85 \\
\hline Missing & 0.24 & 0.17 & 0.15 \\
\hline
\end{tabular}




\section{9 \\ CHARACTERISTICS OF CHILDREN ADOPTED \\ By parents' pre-adoptive relationship to child}

\begin{tabular}{|c|c|c|c|}
\hline \multirow{2}{*}{$\begin{array}{l}1999 \text { DATA } \\
\text { Variable }\end{array}$} & \multicolumn{3}{|c|}{ Pre-Adoptive Relationship to the Child } \\
\hline & $\begin{array}{l}\text { Pre-Adoptive } \\
\text { Foster Parent } \\
(\mathrm{N}=25180)\end{array}$ & $\begin{array}{c}\text { Pre-Adoptive } \\
\text { Other Relative } \\
(\mathrm{N}=6290)\end{array}$ & $\begin{array}{c}\text { Pre-Adoptive } \\
\text { Non-Relative } \\
(\mathrm{N}=7877)\end{array}$ \\
\hline $\begin{array}{l}\text { Special Needs } \\
\text { Yes } \\
\text { No } \\
\text { Missing } \\
\end{array}$ & $\begin{array}{l}87.96 \% \\
12.04 \\
1.76 \\
\end{array}$ & $\begin{array}{c}86.76 \% \\
13.24 \\
3.48 \\
\end{array}$ & $\begin{array}{l}66.55 \% \\
33.45 \\
5.41 \\
\end{array}$ \\
\hline $\begin{array}{l}\text { Special Needs Basis } \\
\text { Not Applicable } \\
\text { Racial/original background } \\
\text { Age } \\
\text { Sibling group member } \\
\text { Medical condition or disabilities } \\
\text { Other } \\
\text { Missing }\end{array}$ & $\begin{array}{c}11.13 \% \\
8.79 \\
36.67 \\
13.91 \\
17.73 \\
11.76 \\
1.05 \\
\end{array}$ & $\begin{array}{l}11.97 \% \\
12.36 \\
20.99 \\
24.41 \\
13.67 \\
16.59 \\
0.94 \\
\end{array}$ & $\begin{array}{l}30.49 \% \\
11.43 \\
13.04 \\
13.93 \\
21.55 \\
9.56 \\
1.69 \\
\end{array}$ \\
\hline $\begin{array}{l}\text { Mental Retardation } \\
\text { Yes } \\
\text { No } \\
\text { Missing }\end{array}$ & $\begin{array}{l}2.34 \% \\
97.66 \\
3.11 \\
\end{array}$ & $\begin{array}{c}2.02 \% \\
97.98 \\
2.53\end{array}$ & $\begin{array}{c}3.93 \% \\
96.07 \\
2.21 \\
\end{array}$ \\
\hline $\begin{array}{l}\text { Visual Hearing Impaired } \\
\text { Yes } \\
\text { No } \\
\text { Missing } \\
\end{array}$ & $\begin{array}{c}1.17 \% \\
98.83 \\
5.44 \\
\end{array}$ & $\begin{array}{c}0.88 \% \\
99.12 \\
5.60 \\
\end{array}$ & $\begin{array}{c}1.67 \% \\
98.33 \\
7.52 \\
\end{array}$ \\
\hline $\begin{array}{l}\text { Physically Disabled } \\
\text { Yes } \\
\text { No } \\
\text { Missing } \\
\end{array}$ & $\begin{array}{c}3.12 \% \\
96.88 \\
3.11 \\
\end{array}$ & $\begin{array}{c}1.89 \% \\
98.11 \\
2.51 \\
\end{array}$ & $\begin{array}{c}3.23 \% \\
96.77 \\
2.21 \\
\end{array}$ \\
\hline $\begin{array}{l}\text { Emotionally Disturbed } \\
\text { Yes } \\
\text { No } \\
\text { Missing }\end{array}$ & $\begin{array}{c}9.98 \% \\
90.02 \\
3.11 \\
\end{array}$ & $\begin{array}{c}8.04 \% \\
91.96 \\
2.53 \\
\end{array}$ & $\begin{array}{c}13.06 \% \\
86.94 \\
2.21 \\
\end{array}$ \\
\hline $\begin{array}{l}\text { Other Diagnosed Condition } \\
\text { Yes } \\
\text { No } \\
\text { Missing }\end{array}$ & $\begin{array}{l}12.44 \% \\
87.56 \\
3.12\end{array}$ & $\begin{array}{c}10.63 \% \\
89.37 \\
2.51\end{array}$ & $\begin{array}{l}14.26 \% \\
85.74 \\
2.22\end{array}$ \\
\hline
\end{tabular}


1999

CHARACTERISTICS OF ADOPTIVE PARENTS

By parents' pre-adoptive relationship to child

\begin{tabular}{|c|c|c|c|}
\hline \multirow{2}{*}{$\begin{array}{l}1999 \text { DATA } \\
\text { Variable }\end{array}$} & \multicolumn{3}{|c|}{ Pre-Adoptive Relationship to the Child } \\
\hline & $\begin{array}{l}\text { Pre-Adoptive } \\
\text { Foster Parent } \\
(\mathrm{N}=25180)\end{array}$ & $\begin{array}{c}\text { Pre-Adoptive } \\
\text { Other Relative } \\
(\mathrm{N}=6290)\end{array}$ & $\begin{array}{c}\text { Pre-Adoptive } \\
\text { Non-Relative } \\
(\mathrm{N}=7877)\end{array}$ \\
\hline \multicolumn{4}{|l|}{ Adoptive Family Structure } \\
\hline Married Couple & $64.70 \%$ & $55.46 \%$ & $77.87 \%$ \\
\hline Unmarried Couple & 0.71 & 0.81 & 0.50 \\
\hline Single Female & 32.73 & 40.71 & 19.59 \\
\hline Single male & 1.86 & 3.01 & 2.04 \\
\hline Unable to Determine & 0.00 & 0.00 & 0.00 \\
\hline Missing & 3.51 & 2.34 & 3.50 \\
\hline \multicolumn{4}{|l|}{ Age of Mother at Time of Adoption } \\
\hline Mean & 44.65 & 46.26 & 41.55 \\
\hline Median & 44.00 & 46.00 & 41.00 \\
\hline \multicolumn{4}{|l|}{ Age of Father at Time of Adoption } \\
\hline Mean & 44.72 & 47.55 & 42.56 \\
\hline Median & 43.00 & 46.00 & 41.00 \\
\hline \multicolumn{4}{|l|}{ Race of Adoptive Parents } \\
\hline White, Non-Hispanic & $49.94 \%$ & $42.51 \%$ & $59.82 \%$ \\
\hline Black, Non-Hispanic & 42.82 & 35.85 & 28.74 \\
\hline American Indian/Alaskan Native & 0.38 & 1.72 & 0.74 \\
\hline Asian/Pacific Islander & 1.52 & 6.71 & 3.35 \\
\hline Mixed Racial Background & 5.34 & 13.21 & 7.35 \\
\hline Unable to Determine & 2.56 & 6.90 & 2.75 \\
\hline Missing & 6.20 & 7.34 & 15.70 \\
\hline \multicolumn{4}{|l|}{ Adoptive Parents Hispanic Origin } \\
\hline Yes & $4.69 \%$ & $14.91 \%$ & $3.97 \%$ \\
\hline No & 91.70 & 80.49 & 90.73 \\
\hline Mixed & 3.61 & 4.60 & 5.29 \\
\hline Missing & 0.23 & 0.17 & 0.67 \\
\hline
\end{tabular}




\section{9}

CHARACTERISTICS OF ADOPTION PROCESS

By parents' pre-adoptive relationship to child

\begin{tabular}{|c|c|c|c|}
\hline \multirow{2}{*}{1999 DATA } & \multicolumn{3}{|c|}{ Pre-Adoptive Relationship to the Child } \\
\hline & $\begin{array}{c}\text { Pre-Adoptive } \\
\text { Foster Parent } \\
(\mathrm{N}=25180)\end{array}$ & $\begin{array}{l}\text { Pre-Adoptive } \\
\text { Other Relative } \\
(\mathrm{N}=6290)\end{array}$ & $\begin{array}{c}\text { Pre-Adoptive } \\
\text { Non-Relative } \\
(\mathrm{N}=7877)\end{array}$ \\
\hline \multicolumn{4}{|l|}{ Time Between TPR and Adoption } \\
\hline$<1$ month & $3.54 \%$ & $3.11 \%$ & $3.37 \%$ \\
\hline 1-5 months & 22.39 & 16.33 & 13.73 \\
\hline 6-11 months & 32.81 & 31.08 & 26.58 \\
\hline $12-17$ months & 18.11 & 21.01 & 21.54 \\
\hline $18-23$ months & 9.77 & 11.16 & 13.52 \\
\hline 24-29 months & 4.96 & 7.14 & 8.32 \\
\hline 30-35 months & 2.81 & 3.97 & 4.47 \\
\hline 36-48 months & 3.14 & 3.70 & 4.89 \\
\hline $49+$ months & 2.46 & 2.49 & 3.57 \\
\hline Mean & 13.76 & 15.35 & 17.04 \\
\hline Median & 10.05 & 11.96 & 13.67 \\
\hline Missing & 6.16 & 4.29 & 4.04 \\
\hline \multicolumn{4}{|l|}{ Location of Custodial Agency/Individual } \\
\hline Within State & $99.50 \%$ & $97.90 \%$ & $97.14 \%$ \\
\hline Another State & 0.33 & 1.10 & 1.27 \\
\hline Another Country & 0.17 & 1.00 & 1.59 \\
\hline Missing & 0.16 & 0.02 & 0.25 \\
\hline \multicolumn{4}{|l|}{ Agency/Individual Placing Child } \\
\hline Public Agency & $99.30 \%$ & $97.90 \%$ & $96.28 \%$ \\
\hline Private Agency & 0.64 & 1.18 & 3.22 \\
\hline Tribal Agency & 0.05 & 0.72 & 0.19 \\
\hline Independent Person & 0.01 & 0.02 & 0.08 \\
\hline Birth Parent & 0.01 & 0.19 & 0.23 \\
\hline Missing & 0.03 & 0.00 & 0.30 \\
\hline \multicolumn{4}{|l|}{ Receiving Subsidy } \\
\hline & $89.46 \%$ & $87.71 \%$ & $81.14 \%$ \\
\hline & 10.54 & 12.29 & 18.86 \\
\hline Missing & 0.26 & 0.29 & 0.23 \\
\hline $\begin{array}{l}\text { Percent of Children Receiving Subsidy } \\
\text { with Special Needs }\end{array}$ & $92.35 \%$ & $89.91 \%$ & $87.16 \%$ \\
\hline Amount of Subsidy & & & \\
\hline Mean & $\$ 688.67$ & $\$ 409.73$ & $\$ 741.99$ \\
\hline Median & $\$ 394.00$ & $\$ 376.00$ & $\$ 365.00$ \\
\hline \multicolumn{4}{|l|}{ IV-E Assistance Claimed } \\
\hline Yes & $74.85 \%$ & $73.61 \%$ & $67.46 \%$ \\
\hline & 25.15 & 26.39 & 32.54 \\
\hline Missing & 0.05 & 0.11 & 0.05 \\
\hline
\end{tabular}


1998

CHARACTERISTICS OF CHILDREN ADOPTED

By parents' pre-adoptive relationship to child

\begin{tabular}{|c|c|c|c|}
\hline \multirow{2}{*}{$\begin{array}{l}1998 \text { DATA } \\
\text { Variable }\end{array}$} & \multicolumn{3}{|c|}{ Pre-Adoptive Relationship to the Child } \\
\hline & $\begin{array}{l}\text { Pre-Adoptive } \\
\text { Foster Parent } \\
(\mathrm{N}=19149)\end{array}$ & $\begin{array}{c}\text { Pre-Adoptive } \\
\text { Other Relative } \\
(\mathrm{N}=4539)\end{array}$ & $\begin{array}{c}\text { Pre-Adoptive } \\
\text { Non-Relative } \\
(\mathrm{N}=6259)\end{array}$ \\
\hline \multicolumn{4}{|l|}{ Age of child at time of adoption } \\
\hline$<1$ year & $1.35 \%$ & $0.59 \%$ & $3.91 \%$ \\
\hline 1-5 years & 48.97 & 44.24 & 44.96 \\
\hline $6-10$ years & 35.28 & 38.71 & 36.51 \\
\hline $11-15$ years & 12.73 & 14.81 & 13.24 \\
\hline $16-18$ years & 1.61 & 1.56 & 1.34 \\
\hline $19+$ years & 0.06 & 0.09 & 0.03 \\
\hline Mean & 6.14 & 6.63 & 6.10 \\
\hline Median & 5.00 & 6.00 & 6.00 \\
\hline Missing & 0.02 & 0.00 & 0.00 \\
\hline \multicolumn{4}{|l|}{ Child Sex } \\
\hline Female & $49.52 \%$ & $51.35 \%$ & $47.94 \%$ \\
\hline Male & 50.48 & 48.65 & 52.06 \\
\hline Missing & 0.04 & 0.00 & 0.05 \\
\hline \multicolumn{4}{|l|}{ Child Race/Ethnicity } \\
\hline White, Non-Hispanic & $45.71 \%$ & $44.54 \%$ & $55.06 \%$ \\
\hline Black, Non-Hispanic & 51.04 & 46.35 & 41.89 \\
\hline American Indian/Alaskan Native & 1.61 & 3.23 & 1.57 \\
\hline Asian/Pacific Islander & 1.39 & 5.73 & 1.07 \\
\hline 2 or more races & 0.25 & 0.14 & 0.41 \\
\hline Unable to Determine & 4.84 & 2.14 & 3.85 \\
\hline Missing & 0.23 & 0.04 & 0.51 \\
\hline \multicolumn{4}{|l|}{ Hispanic Origin } \\
\hline Yes & $11.39 \%$ & $19.75 \%$ & $9.96 \%$ \\
\hline No & 88.61 & 80.25 & 90.04 \\
\hline Missing & 0.20 & 0.07 & 0.42 \\
\hline
\end{tabular}




\section{8}

CHARACTERISTICS OF CHILDREN ADOPTED

By parents' pre-adoptive relationship to child

\begin{tabular}{|c|c|c|c|}
\hline \multirow{2}{*}{$\begin{array}{l}1998 \text { DATA } \\
\text { Variable } \\
\end{array}$} & \multicolumn{3}{|c|}{ Pre-Adoptive Relationship to the Child } \\
\hline & $\begin{array}{l}\text { Pre-Adoptive } \\
\text { Foster Parent } \\
(\mathrm{N}=19149)\end{array}$ & $\begin{array}{c}\text { Pre-Adoptive } \\
\text { Other Relative } \\
(\mathrm{N}=4539)\end{array}$ & $\begin{array}{c}\text { Pre-Adoptive } \\
\text { Non-Relative } \\
(\mathrm{N}=6259)\end{array}$ \\
\hline $\begin{array}{l}\text { Special Needs } \\
\text { Yes } \\
\text { No } \\
\text { Missing } \\
\end{array}$ & $\begin{array}{c}87.39 \% \\
12.61 \\
0.50 \\
\end{array}$ & $\begin{array}{c}86.24 \% \\
13.76 \\
1.54 \\
\end{array}$ & $\begin{array}{l}59.18 \% \\
40.82 \\
1.49 \\
\end{array}$ \\
\hline $\begin{array}{l}\text { Special Needs Basis } \\
\text { Not Applicable } \\
\text { Racial/original background } \\
\text { Age } \\
\text { Sibling group member } \\
\text { Medical condition or disabilities } \\
\text { Other } \\
\text { Missing }\end{array}$ & $\begin{array}{l}11.59 \% \\
10.64 \\
33.94 \\
14.41 \\
16.18 \\
13.24 \\
1.12 \\
\end{array}$ & $\begin{array}{l}12.20 \% \\
10.70 \\
23.06 \\
25.81 \\
12.94 \\
15.29 \\
1.59 \\
\end{array}$ & $\begin{array}{l}33.35 \% \\
11.11 \\
13.62 \\
11.12 \\
21.34 \\
9.47 \\
12.24 \\
\end{array}$ \\
\hline $\begin{array}{l}\text { Mental Retardation } \\
\text { Yes } \\
\text { No } \\
\text { Missing }\end{array}$ & $\begin{array}{c}2.31 \% \\
97.69 \\
0.33\end{array}$ & $\begin{array}{c}1.72 \% \\
98.28 \\
0.11\end{array}$ & $\begin{array}{c}3.77 \% \\
96.23 \\
0.78 \\
\end{array}$ \\
\hline $\begin{array}{l}\text { Visual Hearing Impaired } \\
\text { Yes } \\
\text { No } \\
\text { Missing }\end{array}$ & $\begin{array}{c}1.14 \% \\
98.86 \\
4.19 \\
\end{array}$ & $\begin{array}{c}0.84 \% \\
99.16 \\
3.06 \\
\end{array}$ & $\begin{array}{c}1.19 \% \\
98.81 \\
8.52 \\
\end{array}$ \\
\hline $\begin{array}{l}\text { Physically Disabled } \\
\text { Yes } \\
\text { No } \\
\text { Missing }\end{array}$ & $\begin{array}{c}3.19 \% \\
96.81 \\
0.33 \\
\end{array}$ & $\begin{array}{c}2.16 \% \\
97.84 \\
0.11 \\
\end{array}$ & $\begin{array}{c}3.30 \% \\
96.70 \\
0.78 \\
\end{array}$ \\
\hline $\begin{array}{l}\text { Emotionally Disturbed } \\
\text { Yes } \\
\text { No } \\
\text { Missing }\end{array}$ & $\begin{array}{c}9.72 \% \\
90.28 \\
0.33 \\
\end{array}$ & $\begin{array}{c}7.19 \% \\
92.81 \\
0.11 \\
\end{array}$ & $\begin{array}{c}11.61 \% \\
88.39 \\
0.78 \\
\end{array}$ \\
\hline $\begin{array}{l}\text { Other Diagnosed Condition } \\
\text { Yes } \\
\text { No } \\
\text { Missing }\end{array}$ & $\begin{array}{c}11.80 \% \\
88.20 \\
0.33 \\
\end{array}$ & $\begin{array}{c}9.09 \% \\
90.91 \\
0.11 \\
\end{array}$ & $\begin{array}{c}11.51 \% \\
88.49 \\
0.78 \\
\end{array}$ \\
\hline
\end{tabular}


1998

CHARACTERISTICS OF ADOPTIVE PARENTS

By parents' pre-adoptive relationship to child

\begin{tabular}{|c|c|c|c|}
\hline \multirow{2}{*}{$\begin{array}{l}1998 \text { DATA } \\
\text { Variable }\end{array}$} & \multicolumn{3}{|c|}{ Pre-Adoptive Relationship to the Child } \\
\hline & $\begin{array}{c}\text { Pre-Adoptive } \\
\text { Foster Parent } \\
(\mathrm{N}=19149)\end{array}$ & $\begin{array}{c}\text { Pre-Adoptive } \\
\text { Other Relative } \\
(\mathrm{N}=4539)\end{array}$ & $\begin{array}{c}\text { Pre-Adoptive } \\
\text { Non-Relative } \\
(\mathrm{N}=6259)\end{array}$ \\
\hline \multicolumn{4}{|l|}{ Adoptive Family Structure } \\
\hline Married Couple & $66.69 \%$ & $54.12 \%$ & $76.69 \%$ \\
\hline Unmarried Couple & 0.69 & 0.96 & 0.42 \\
\hline Single Female & 30.96 & 43.09 & 21.11 \\
\hline Single male & 1.66 & 1.83 & 1.78 \\
\hline Unable to Determine & 0.00 & 0.00 & 0.00 \\
\hline Missing & 3.70 & 1.32 & 2.14 \\
\hline \multicolumn{4}{|l|}{ Age of Mother at Time of Adoption } \\
\hline Mean & 44.05 & 46.42 & 41.40 \\
\hline Median & 43.00 & 46.00 & 40.00 \\
\hline \multicolumn{4}{|l|}{ Age of Father at Time of Adoption } \\
\hline Mean & 44.58 & 47.61 & 42.45 \\
\hline Median & 43.00 & 47.00 & 41.00 \\
\hline \multicolumn{4}{|l|}{ Race of Adoptive Parents } \\
\hline White, Non-Hispanic & $54.02 \%$ & $46.91 \%$ & $61.88 \%$ \\
\hline Black, Non-Hispanic & 40.75 & 38.60 & 29.50 \\
\hline American Indian/Alaskan Native & 0.42 & 1.83 & 0.64 \\
\hline Asian/Pacific Islander & 0.50 & 4.05 & 0.18 \\
\hline Mixed Racial Background & 4.31 & 8.62 & 7.79 \\
\hline Unable to Determine & 3.73 & 2.73 & 4.60 \\
\hline Missing & 1.94 & 0.86 & 1.66 \\
\hline \multicolumn{4}{|l|}{ Adoptive Parents Hispanic Origin } \\
\hline Yes & $5.48 \%$ & $14.81 \%$ & $3.34 \%$ \\
\hline No & 90.82 & 79.21 & 88.67 \\
\hline Mixed & 3.70 & 5.98 & 7.99 \\
\hline Missing & 0.18 & 0.15 & 0.42 \\
\hline
\end{tabular}


1998

CHARACTERISTICS OF ADOPTION PROCESS

By parents' pre-adoptive relationship to child

\begin{tabular}{|c|c|c|c|}
\hline \multirow[t]{2}{*}{1998 DATA } & \multicolumn{3}{|c|}{ Pre-Adoptive Relationship to the Child } \\
\hline & $\begin{array}{l}\text { Pre-Adoptive } \\
\text { Foster Parent } \\
(\mathrm{N}=19149)\end{array}$ & $\begin{array}{c}\text { Pre-Adoptive } \\
\text { Other Relative } \\
(\mathrm{N}=4539)\end{array}$ & $\begin{array}{c}\text { Pre-Adoptive } \\
\text { Non-Relative } \\
(\mathrm{N}=6259)\end{array}$ \\
\hline \multicolumn{4}{|l|}{ Time Between TPR and Adoption } \\
\hline$<1$ month & $2.54 \%$ & $3.68 \%$ & $4.69 \%$ \\
\hline 1-5 months & 19.43 & 12.36 & 13.16 \\
\hline 6-11 months & 32.67 & 28.54 & 26.23 \\
\hline $12-17$ months & 19.20 & 21.45 & 22.19 \\
\hline $18-23$ months & 10.55 & 13.06 & 12.90 \\
\hline 24-29 months & 6.14 & 7.23 & 7.40 \\
\hline 30-35 months & 3.10 & 4.71 & 4.88 \\
\hline 36-48 months & 3.56 & 5.96 & 4.47 \\
\hline $49+$ months & 2.82 & 3.01 & 4.07 \\
\hline Mean & 14.79 & 16.93 & 17.08 \\
\hline Median & 11.04 & 13.34 & 13.44 \\
\hline Missing & 4.40 & 1.28 & 3.51 \\
\hline \multicolumn{4}{|l|}{ Location of Custodial Agency/Individual } \\
\hline Within State & $99.65 \%$ & $97.68 \%$ & $96.72 \%$ \\
\hline Another State & 0.30 & 1.50 & 1.89 \\
\hline Another Country & 0.04 & 0.82 & 1.39 \\
\hline Missing & 0.14 & 0.26 & 6.92 \\
\hline \multicolumn{4}{|l|}{ Agency/Individual Placing Child } \\
\hline Public Agency & $96.34 \%$ & $91.61 \%$ & $89.79 \%$ \\
\hline Private Agency & 3.52 & 7.16 & 9.53 \\
\hline Tribal Agency & 0.05 & 0.42 & 0.06 \\
\hline Independent Person & 0.01 & 0.02 & 0.15 \\
\hline Birth Parent & 0.08 & 0.79 & 0.47 \\
\hline Missing & 0.00 & 0.00 & 1.60 \\
\hline \multicolumn{4}{|l|}{ Receiving Subsidy } \\
\hline & $87.28 \%$ & $85.22 \%$ & $75.57 \%$ \\
\hline No & 12.72 & 14.78 & 24.43 \\
\hline Missing & 0.30 & 0.26 & 1.36 \\
\hline $\begin{array}{l}\text { Percent of Children Receiving Subsidy } \\
\text { with Special Needs (\%) }\end{array}$ & $90.22 \%$ & $90.96 \%$ & $82.62 \%$ \\
\hline Amount of Subsidy & & & \\
\hline Mean & $\$ 519.66$ & $\$ 409.12$ & $\$ 557.33$ \\
\hline Median & $\$ 369.00$ & $\$ 360.00$ & $\$ 327.00$ \\
\hline \multicolumn{4}{|l|}{ IV-E Assistance Claimed } \\
\hline Yes & $68.67 \%$ & $73.38 \%$ & $62.94 \%$ \\
\hline No & 31.33 & 26.62 & 37.06 \\
\hline Missing & 0.13 & 0.02 & 0.38 \\
\hline
\end{tabular}


1997

CHARACTERISTICS OF CHILDREN ADOPTED

By parents' pre-adoptive relationship to child

\begin{tabular}{|c|c|c|c|}
\hline \multirow{2}{*}{$\begin{array}{l}1997 \text { DATA } \\
\text { Variable }\end{array}$} & \multicolumn{3}{|c|}{ Pre-Adoptive Relationship to the Child } \\
\hline & $\begin{array}{l}\text { Pre-Adoptive } \\
\text { Foster Parent } \\
(\mathrm{N}=8038)\end{array}$ & $\begin{array}{c}\text { Pre-Adoptive } \\
\text { Other Relative } \\
(\mathrm{N}=1807)\end{array}$ & $\begin{array}{c}\text { Pre-Adoptive } \\
\text { Non-Relative } \\
(\mathrm{N}=2676)\end{array}$ \\
\hline \multicolumn{4}{|l|}{ Age of child at time of adoption } \\
\hline$<1$ year & $1.16 \%$ & $0.44 \%$ & $4.04 \%$ \\
\hline 1-5 years & 48.91 & 49.31 & 46.73 \\
\hline $6-10$ years & 35.68 & 35.86 & 36.04 \\
\hline $11-15$ years & 12.80 & 12.78 & 11.74 \\
\hline $16-18$ years & 1.43 & 1.60 & 1.42 \\
\hline $19+$ years & 0.02 & 0.00 & 0.04 \\
\hline Mean & 6.16 & 6.25 & 5.93 \\
\hline Median & 5.00 & 6.00 & 5.00 \\
\hline Missing & 0.00 & 0.00 & 0.04 \\
\hline \multicolumn{4}{|l|}{ Child Sex } \\
\hline Female & $50.04 \%$ & $51.83 \%$ & $48.60 \%$ \\
\hline Male & 49.96 & 48.17 & 51.40 \\
\hline Missing & 0.07 & 0.17 & 0.19 \\
\hline \multicolumn{4}{|l|}{ Child Race/Ethnicity } \\
\hline White, Non-Hispanic & $46.34 \%$ & $53.96 \%$ & $65.23 \%$ \\
\hline Black, Non-Hispanic & 50.16 & 36.62 & 30.36 \\
\hline American Indian/Alaskan Native & 1.77 & 3.69 & 2.90 \\
\hline Asian/Pacific Islander & 1.74 & 5.73 & 1.52 \\
\hline Unable to Determine & 4.84 & 4.70 & 4.15 \\
\hline Missing & 0.44 & 0.94 & 0.82 \\
\hline \multicolumn{4}{|l|}{ Hispanic Origin } \\
\hline Yes & $11.61 \%$ & $25.89 \%$ & $10.22 \%$ \\
\hline No & 88.39 & 74.11 & 89.78 \\
\hline Missing & 1.59 & 0.17 & 4.52 \\
\hline
\end{tabular}




\section{7}

CHARACTERISTICS OF CHILDREN ADOPTED

By parents' pre-adoptive relationship to child

\begin{tabular}{|c|c|c|c|}
\hline \multirow{2}{*}{$\begin{array}{l}1997 \text { DATA } \\
\text { Variable }\end{array}$} & \multicolumn{3}{|c|}{ Pre-Adoptive Relationship to the Child } \\
\hline & $\begin{array}{l}\text { Pre-Adoptive } \\
\text { Foster Parent } \\
(\mathrm{N}=8038)\end{array}$ & $\begin{array}{c}\text { Pre-Adoptive } \\
\text { Other Relative } \\
(\mathrm{N}=1807)\end{array}$ & $\begin{array}{c}\text { Pre-Adoptive } \\
\text { Non-Relative } \\
(\mathrm{N}=2676)\end{array}$ \\
\hline $\begin{array}{l}\text { Special Needs } \\
\text { Yes } \\
\text { No } \\
\text { Missing } \\
\end{array}$ & $\begin{array}{c}88.68 \% \\
11.32 \\
8.02 \\
\end{array}$ & $\begin{array}{l}84.08 \% \\
15.92 \\
19.70 \\
\end{array}$ & $\begin{array}{l}64.04 \% \\
35.96 \\
14.28 \\
\end{array}$ \\
\hline $\begin{array}{l}\text { Special Needs Basis } \\
\text { Not Applicable } \\
\text { Racial/original background } \\
\text { Age } \\
\text { Sibling group member } \\
\text { Medical condition or disabilities } \\
\text { Other } \\
\text { Missing }\end{array}$ & $\begin{array}{l}10.93 \% \\
33.70 \\
13.53 \\
15.08 \\
13.94 \\
12.83 \\
8.34 \\
\end{array}$ & $\begin{array}{l}14.24 \% \\
9.96 \\
14.17 \\
26.02 \\
14.73 \\
20.90 \\
21.08 \\
\end{array}$ & $\begin{array}{c}35.76 \% \\
9.42 \\
11.25 \\
9.99 \\
22.24 \\
11.34 \\
14.31 \\
\end{array}$ \\
\hline $\begin{array}{l}\text { Mental Retardation } \\
\text { Yes } \\
\text { No } \\
\text { Missing }\end{array}$ & $\begin{array}{c}1.61 \% \\
98.39 \\
8.12\end{array}$ & $\begin{array}{l}1.44 \% \\
98.56 \\
19.54\end{array}$ & $\begin{array}{l}4.34 \% \\
95.66 \\
10.35\end{array}$ \\
\hline $\begin{array}{l}\text { Visual Hearing Impaired } \\
\text { Yes } \\
\text { No } \\
\text { Missing } \\
\end{array}$ & $\begin{array}{l}0.63 \% \\
99.37 \\
10.97 \\
\end{array}$ & $\begin{array}{l}1.24 \% \\
98.76 \\
19.70 \\
\end{array}$ & $\begin{array}{l}0.91 \% \\
99.09 \\
18.12 \\
\end{array}$ \\
\hline $\begin{array}{l}\text { Physically Disabled } \\
\text { Yes } \\
\text { No } \\
\text { Missing }\end{array}$ & $\begin{array}{c}2.61 \% \\
97.39 \\
8.12 \\
\end{array}$ & $\begin{array}{l}2.06 \% \\
97.94 \\
19.54\end{array}$ & $\begin{array}{l}3.54 \% \\
96.46 \\
10.35\end{array}$ \\
\hline $\begin{array}{l}\text { Emotionally Disturbed } \\
\text { Yes } \\
\text { No } \\
\text { Missing }\end{array}$ & $\begin{array}{c}8.23 \% \\
91.77 \\
8.12\end{array}$ & $\begin{array}{l}8.47 \% \\
91.53 \\
19.59\end{array}$ & $\begin{array}{l}11.55 \% \\
88.45 \\
10.35\end{array}$ \\
\hline $\begin{array}{l}\text { Other Diagnosed Condition } \\
\text { Yes } \\
\text { No } \\
\text { Missing }\end{array}$ & $\begin{array}{c}12.81 \% \\
87.19 \\
8.12 \\
\end{array}$ & $\begin{array}{l}11.76 \% \\
88.24 \\
19.54 \\
\end{array}$ & $\begin{array}{l}14.55 \% \\
85.45 \\
10.35 \\
\end{array}$ \\
\hline
\end{tabular}


1997

CHARACTERISTICS OF ADOPTIVE PARENTS

By parents' pre-adoptive relationship to child

\begin{tabular}{|c|c|c|c|}
\hline \multirow{2}{*}{$\begin{array}{l}1997 \text { DATA } \\
\text { Variable }\end{array}$} & \multicolumn{3}{|c|}{ Pre-Adoptive Relationship to the Child } \\
\hline & $\begin{array}{l}\text { Pre-Adoptive } \\
\text { Foster Parent } \\
(\mathrm{N}=8038)\end{array}$ & $\begin{array}{c}\text { Pre-Adoptive } \\
\text { Other Relative } \\
(\mathrm{N}=1807)\end{array}$ & $\begin{array}{c}\text { Pre-Adoptive } \\
\text { Non-Relative } \\
(\mathrm{N}=2676)\end{array}$ \\
\hline \multicolumn{4}{|l|}{ Adoptive Family Structure } \\
\hline Married Couple & $72.91 \%$ & $57.26 \%$ & $79.38 \%$ \\
\hline Unmarried Couple & 1.95 & 1.24 & 0.80 \\
\hline Single Female & 23.76 & 39.02 & 17.19 \\
\hline Single male & 1.38 & 2.48 & 2.63 \\
\hline Unable to Determine & 0.00 & 0.00 & 0.00 \\
\hline Missing & 36.80 & 6.25 & 20.44 \\
\hline \multicolumn{4}{|l|}{ Age of Mother at Time of Adoption } \\
\hline Mean & 42.76 & 46.43 & 40.95 \\
\hline Median & 42.00 & 47.00 & 40.00 \\
\hline \multicolumn{4}{|l|}{ Age of Father at Time of Adoption } \\
\hline Mean & 43.57 & 48.21 & 41.81 \\
\hline Median & 43.00 & 47.00 & 41.00 \\
\hline \multicolumn{4}{|l|}{ Race of Adoptive Parents } \\
\hline White, Non-Hispanic & $66.14 \%$ & $57.00 \%$ & $71.27 \%$ \\
\hline Black, Non-Hispanic & 27.52 & 30.97 & 20.04 \\
\hline American Indian/Alaskan Native & 0.43 & 1.37 & 0.59 \\
\hline Asian/Pacific Islander & 0.50 & 3.50 & 0.10 \\
\hline Mixed Racial Background & 5.41 & 7.15 & 8.00 \\
\hline Unable to Determine & 5.56 & 4.54 & 11.14 \\
\hline Missing & 28.25 & 3.32 & 0.56 \\
\hline \multicolumn{4}{|l|}{ Adoptive Parents Hispanic Origin } \\
\hline Yes & $5.34 \%$ & $21.30 \%$ & $4.11 \%$ \\
\hline No & 90.85 & 73.53 & 88.73 \\
\hline Mixed & 3.81 & 5.17 & 7.16 \\
\hline Missing & 0.11 & 0.50 & 5.53 \\
\hline
\end{tabular}


1997

CHARACTERISTICS OF ADOPTION PROCESS

By parents' pre-adoptive relationship to child

\begin{tabular}{|c|c|c|c|}
\hline \multirow{2}{*}{$\begin{array}{l}1997 \text { DATA } \\
\text { Variable }\end{array}$} & \multicolumn{3}{|c|}{ Pre-Adoptive Relationship to the Child } \\
\hline & $\begin{array}{l}\text { Pre-Adoptive } \\
\text { Foster Parent } \\
(\mathrm{N}=8038)\end{array}$ & $\begin{array}{c}\text { Pre-Adoptive } \\
\text { Other Relative } \\
(\mathrm{N}=1807)\end{array}$ & $\begin{array}{c}\text { Pre-Adoptive } \\
\text { Non-Relative } \\
(\mathrm{N}=2676)\end{array}$ \\
\hline \multicolumn{4}{|l|}{ Time Between TPR and Adoption } \\
\hline$<1$ month & $2.52 \%$ & $6.59 \%$ & $2.31 \%$ \\
\hline 1-5 months & 17.28 & 13.23 & 11.36 \\
\hline 6-11 months & 32.81 & 25.61 & 27.38 \\
\hline $12-17$ months & 20.48 & 22.20 & 21.76 \\
\hline 18-23 months & 11.49 & 13.23 & 13.85 \\
\hline 24-29 months & 6.19 & 7.16 & 8.73 \\
\hline 30-35 months & 3.27 & 4.49 & 5.97 \\
\hline $36-48$ months & 3.06 & 3.35 & 4.89 \\
\hline $49+$ months & 2.90 & 4.15 & 3.76 \\
\hline Mean & 15.08 & 16.51 & 18.58 \\
\hline Median & 11.50 & 13.00 & 14.09 \\
\hline Missing & 15.97 & 2.55 & 17.41 \\
\hline \multicolumn{4}{|l|}{ Location of Custodial Agency/Individual } \\
\hline Within State & $99.61 \%$ & $98.40 \%$ & $98.40 \%$ \\
\hline Another State & 0.34 & 1.60 & 1.08 \\
\hline Another Country & 0.05 & 0.00 & 0.52 \\
\hline Missing & 3.83 & 2.99 & 13.49 \\
\hline \multicolumn{4}{|l|}{ Agency/Individual Placing Child } \\
\hline Public Agency & $98.04 \%$ & $93.85 \%$ & $93.13 \%$ \\
\hline Private Agency & 1.63 & 1.55 & 5.82 \\
\hline Tribal Agency & 0.17 & 0.61 & 0.12 \\
\hline Independent Person & 0.00 & 0.28 & 0.23 \\
\hline Birth Parent & 0.15 & 3.71 & 0.70 \\
\hline Missing & 0.10 & 0.06 & 4.30 \\
\hline \multicolumn{4}{|l|}{ Receiving Subsidy } \\
\hline & $81.21 \%$ & $82.71 \%$ & $81.29 \%$ \\
\hline & 18.79 & 17.29 & 18.71 \\
\hline Missing & 0.14 & 0.17 & 1.53 \\
\hline Percent of Children Receiving Subsidy & $82.32 \%$ & $88.58 \%$ & $78.68 \%$ \\
\hline \multicolumn{4}{|l|}{ Amount of Subsidy } \\
\hline Mean & $\$ 546.41$ & $\$ 379.79$ & $\$ 615.30$ \\
\hline Median & $\$ 341.00$ & $\$ 345.00$ & $\$ 300.00$ \\
\hline \multicolumn{4}{|l|}{ IV-E Assistance Claimed } \\
\hline Yes & $57.61 \%$ & $72.97 \%$ & $59.03 \%$ \\
\hline No & 42.39 & 27.03 & 40.97 \\
\hline Missing & 5.88 & 16.27 & 10.16 \\
\hline
\end{tabular}


